\title{
7. Die Entstehung des donatistischen Schismas: Historische Argumente zur causa Caeciliani
}

In den Auseinandersetzungen über die traditio und die persecutio lassen sich Ursachen und Hintergründe des Schismas erschließen. Im Streit um die causa Caeciliani zeigen sich Anlass, Umstände und die frühen Entwicklungen, die zur Spaltung der Kirche und zur Verfestigung der gegensätzlichen Auffassungen führten. Die unterschiedlichen historischen Argumente, die von Donatisten und Augustins zur causa Caeciliani zusammengetragen und verwendet wurden, sollen im Folgenden dargestellt werden. Wie im vorangehenden Kapitel sollen dabei sowohl die historischen Zusammenhänge als auch die Argumentationsstrukturen verdeutlicht werden. Der Verlauf dieses Kapitels folgt der Chronologie der Ereignisse: Ausgangspunkt der causa Caeciliani ist das Konzil von Karthago, an dem Caecilianus abgesetzt und mit Maiorinus ein erster „donatistischer" Gegenbischof ernannt wurde. Anschließend wird die Abfolge der Anklagen und Verfahren gegen Caecilianus betrachtet: die Verhandlungen des Falles vor den Bischofsgerichten in Rom und Arles, und schließlich das Urteil des Kaisers Konstantin. Im jeweiligen Zusammenhang wird beleuchtet, wie die Ereignisse durch die beiden Parteien zur Zeit Augustins dargestellt und interpretiert wurden.

\section{Das Konzil von Karthago und die Absetzung Caecilians}

\subsection{Die Akten des Konzils von Karthago}

Die heute nicht mehr erhaltenen Akten des Konzils von Karthago waren zur Zeit Augustins die wichtigsten historischen Dokumente in den Händen der Donatisten. ${ }^{1}$ In ihren Augen erbrachten diese Akten den entscheidenden Beweis für die Schuld Caecilians und damit für die Rechtmäßigkeit ihrer eigenen Kirche. Unter Berufung auf die Konzilsakten argumentierten Cresconius, ${ }^{2}$ die

1 Zu den Quellenfragmenten siehe von Soden, Nr. 6; Maier I, Nr. 10, 128-135; Monceaux IV, 18-20, 326-332; V, 8 f. - Seeck (ZKG 10, 1889, 535-542) hielt die Akten zunächst für eine Fälschung, revidierte diese Meinung jedoch später (ZKG 30, 1909,182).

2 Unter Heranziehung der Sentenz des Silvanus, Cresc. III 16, 31, 34; IV 66-67; vgl. o. Kap. 3.4.1. 
Gesprächspartner Augustins in Thubursicum Numidarum ${ }^{3}$ sowie die donatistischen Bischöfe auf der Konferenz im Jahr 411. ${ }^{4}$ Die zahlreichen Anspielungen Augustins auf dieses Konzil und seine Versuche, die Rechtmäßigkeit des Urteils gegen Caecilianus in Frage zu stellen, bezeugen zudem, welchen Stellenwert diese Dokumente für die Donatisten und die gesamte Auseinandersetzung besaßen. ${ }^{5}$

Die Akten enthielten die Verhandlungsprotokolle mit den Anklagen gegen Caecilianus und seiner Ordinatoren sowie die Sentenzen aller anwesenden Bischöfe. Zudem wurde zum Abschluss des Konzils ein Synodalschreiben verfasst, in dem das Ergebnis allen Kirchengemeinden in Afrika mitgeteilt wurde. ${ }^{6}$ Dieser Brief war mit Sicherheit ebenfalls im Aktenmaterial erhalten und gehörte zu den Dokumenten, die Optatus seinem Werk beifügte. ${ }^{7}$ Möglicherweise geht auf diesen Brief der in den Capitula der Konferenzakten von 411 verwendete Begriff decretum de Caeciliani damnatione zurück. ${ }^{8}$ Vom Wortlaut des gesamten Aktenmaterials sind heute lediglich zwei kleine Fragmente in der pseudoaugustinischen Schrift contra Fulgentium überliefert, darunter die Sentenz eines Bischofs namens Marcianus. ${ }^{9}$ Für die näheren Umstände und den Ablauf des Konzils steht nur die Darstellung bei Optatus zur Verfügung, ${ }^{10}$ ergänzt um wenige weiterführende Hinweise bei Augustinus. Viele Einzelheiten des Verhandlungsverlaufs und der Motivation der Bischöfe sowie der genaue Zeitpunkt der Synode bleiben jedoch im Dunkeln.

Vielleicht um die Jahre 309/10 ${ }^{11}$ versammelten sich etwa siebzig mehrheitlich numidische Bischöfe unter der Leitung des numidischen Primas Secundus

3 Ep. 43.3; vgl. o. Kap. 4.2.1.

4 Cap. conl. Carth. III 343-346, 367-369; breuic. III 26, 29; c. Don. 38; vgl. o. Kap. 5.1.3 u. 5.3.1.

5 Vgl. Ps. c. Don. 73-84; c. ep. Parm. I 5; cath. fr. 46, 73 (Synodalbrief); en. Ps. 36, 2, 19; s. 46. 39; Cresc. II 45, III 44, 67; IV 9, 66; un. bapt. 28; epp. 43.3, 14, 18; 88.3; breuic. III 26, 28-32; c. Don. 3, 38; ep. 141.6.

6 Cath. fr. 73; Opt. I 20.

7 Vgl. Opt. I 20.

8 So Monceaux IV, 331; vgl. Cap. Conl. Carth. III 346.

9 C. Fulg. 5, 24 (ed. Lambot, RevBen 58, 148, 117-221); vgl. Maier I, 134 f.

10 Vgl. auch zum Folgenden Opt. I 18-20.

11 Die Datierung des Konzils von Karthago ist wie die gesamte Chronologie der Entstehungsphase des Schismas sehr schwierig und bis heute umstritten. Bereits die auf der Konferenz im Jahre 411 vorgelegten Akten enthielten kein Datum, lediglich eine Tagesangabe (Cap. conl. Carth III 350; breuic. III 26, 30; c. Don. 19). In der Forschung werden zwei gegensätzliche Positionen vertreten: Für eine Frühdatierung um 307 plädierte bereits Seeck (ZKG 30, 1909, 224 f.; Geschichte III, 323, 509), mit anderen Argumenten später u. a. Barnes (JThS 26, 1975, 18-20) und Lancel (REAug 25, 1979, 226 229). Eine Datierung in die Jahre 311/12 vertraten dagegen Duchesne (Dossier, $597 \mathrm{f}$, 626) und Monceaux (IV, 18 f., 327). Ihnen folgten u.a. Frend (Donatist Church, 19 f.; JThS 28, 1977, 104-109), Congar (BA 28, 713 f.), de Veer (REAug 22, 1976, 353-355) 
von Tigisi in einem Privathaus in Karthago. ${ }^{12}$ Ziel der Bischöfe war es, den neu gewählten und ordinierten Bischof der Stadt Caecilianus seines Amtes zu entheben. Caecilianus wurde zur Anhörung vorgeladen, doch weigerte er sich zu kommen und ließ übermitteln, dass seine Ankläger Beweise gegen ihn vorlegen sollten. Ohne einen weiteren Versuch der Vorladung verhandelten die Bischöfe den Fall in Abwesenheit Caecilians. Ob tatsächlich eine aufgewühlte Stimmung herrschte und die Bischöfe durch eine anwesende Volksmenge gegen Caecilianus aufgehetzt und beeinflusst wurden, wie Augustinus später behauptet (ep. 43.14), ist sehr fraglich. Fest steht jedoch, dass persönliche Anschuldigungen gegen Caecilianus vorgebracht wurden, darunter der Vorwurf, er habe während der Verfolgung die Besuche und Versorgung von Christen in den Gefängnissen gewaltsam verhindert, möglicherweise auch die Anschuldigung, er habe bei der traditio mit den Behörden kollaboriert. ${ }^{13}$ Bei diesen Anklagen spielten Caecilians Gegner in der karthagischen Gemeinde eine entscheidende Rolle. Optatus spricht von drei Parteien, die gegen Caecilianus agitiert hätten:

und Maier (I, 129-134). Mit der Datierung des Konzils in die Jahre 309/10 folge ich der Darstellung Kriegbaums (Kirche der Traditoren, 135-149). Wenngleich Kriegbaums chronologische Rekonstruktion aufgrund der Quellenlage nicht zwingend ist, so ist sie dennoch die bessere Alternative im Vergleich zu den übrigen Erklärungsansätzen: Entscheidend für die Chronologie ist die bei Optatus (I 17) überlieferte sog. „Affäre Felix“. Der Diakon Felix hatte ein Pamphlet gegen einen „tyrannus imperator“ geschrieben, wurde daraufhin verfolgt und erhielt Asyl bei Mensurius, dem Bischof von Karthago. Mensurius musste sich deswegen am Hofe verantworten, verließ Karthago und kehrte nicht wieder zurück. Die weiteren Umstände und Hintergründe liegen völlig im Dunkeln. Es scheint aber am wahrscheinlichsten, dass mit jenem „Tyrannen“ Kaiser Maximian gemeint war (so auch Barnes und Lancel). Ausgehend von der politischen Situation folgert Kriegbaum, dass die Vorladung des Mensurius in die Zeit des Machtkampfes zwischen Maxentius und seinem Vater gefallen sei, d.h. in das Jahr 308. Nachdem sich Maxentius durchgesetzt hatte, sei die Anklage gegen Mensurius hinfällig geworden, der aber aufgrund der Revolte des Domitius Alexander nicht nach Afrika hätte zurückkehren können und bald darauf gestorben sei. In der gleichen Zeit sei auch das Toleranzedikt des Maxentius gegenüber den Christen promulgiert worden. Die Wahl und Weihe Caecilians als Nachfolger des Mensurius sowie seine Absetzung und die Ernennung des Maiorinus fielen somit in die Zeit nach Mai 308. - Ein indirektes Tyconius-Zitat bei Augustinus (ep. 93.43) besagt, dass Donatus mit einem gewissen Deuterius und anderen mauretanischen Bischöfen Kirchengemeinschaft gehalten hätte, „über 40 Jahre hinweg bis hin zur Verfolgung des Macarius“. Seeck verwendete diese Zeitangabe, um den Beginn des Schismas auf $307 \mathrm{zu}$ datieren. Abgesehen von einem Fehler in der Überlieferung (vgl. die Vermutungen bei Maier I, 130) sind die besagten 40 Jahre jedoch allenfalls als eine gerundete Jahresanzahl zu verstehen und somit für eine Datierung des Konzils von Karthago wertlos.

12 Die ausführlichste Darstellung der Ereignisse bei Kriegbaum, Kirche der Traditoren, 96-129. Vgl. ferner Congar, BA 28, 713 f.; Frend, Donatist Church, 18-21; Grasmück, Coercitio, 21-26; Mandouze, PAC, 1052-1054, s. v. Secundus 1; Mühlsteiger, ZRG KA 85, 1999, 11-13.

13 Vgl. breuic. III 26. Zur Quellengrundlage s. o. Kap. 6.1.2. 
Die Kleriker Botrus und Celestius aus persönlicher Missgunst heraus, da sie sich ebenfalls Hoffnung auf das Bischofsamt gemacht hätten, die reiche Lucilla, die von Caecilianus wegen einer dubiosen Märtyrerverehrung zurechtgewiesen worden sein soll und viele Bischöfe des Konzils bestochen habe, und schließlich einige Gemeindeälteste (seniores laici), die ihnen anvertrautes Kirchenvermögen nicht an Caecilianus hätten übergeben wollen. ${ }^{14}$ Wenngleich diese niederen Beweggründe, die Optatus und später Augustinus in ihrer Polemik herausstellen, sicher nicht den tatsächlichen Gegebenheiten entsprachen, ${ }^{15}$ ist dennoch die Existenz einer starken Opposition gegen Caecilianus unbestreitbar, die im Zusammenwirken mit den numidischen Bischöfen dessen Absetzung betrieb.

Die entscheidende Anklage, die auf dem Konzil gegen Caecilianus erhoben wurde, bezog sich indessen nicht auf irgendwelche persönlichen Verfehlungen, sondern auf den Akt seiner Bischofsweihe. Man behauptete, dass Caecilianus von Traditoren geweiht worden und deshalb seine Weihe unwirksam sei. Vor allem Felix von Abthugni wurde der traditio angeklagt. ${ }^{16}$ Zur Feststellung der Schuld wurden vermutlich Zeugen gehört, schriftliche Dokumente hingegen nicht vorgelegt. Nachdem die Schuld der Ordinatoren als erwiesen angesehen wurde, erklärten die anwesenden Bischöfe die Wahl und Weihe Caecilians für nichtig. Caecilianus hatte sich zuvor noch bereit erklärt, eine neuerliche Weihe durch die numidischen Bischöfe zu akzeptieren, wenn seine Würde allein aufgrund der Schuld des Felix angezweifelt würde. Doch dieses Angebot wurde zurückgewiesen. ${ }^{17}$ Die Bischöfe wählten den Lektor Maiorinus - einen domesticus der Lucilla, wie Optatus vermerkt - zum Bischof von Karthago. Jeder der anwesenden Bischöfe kündigte in einer eigenen Sentenz die Gemeinschaft mit Caecilianus auf. Die Begründungen betrafen die ungültige Weihe durch Traditoren, wenngleich die Berichte über Caecilians „Fehlverhalten“ während der Verfolgungszeit einen bestärkenden Einfluss gehabt haben dürften. ${ }^{18}$ Die in

14 Opt. I 18-19. Zur Bedeutung der seniores laici vgl. Frend, JThS 12, 1961, 280-284; Kriegbaum, Kirche der Traditoren, 127-129. Zu Lucilla: Mandouze, PAC, 649, s. v. Lucilla 1.

15 Augustins zugespitzte Darstellung in ep. 43.14-18 diente der Gegenüberstellung des Verfahrens in Rom (s. o. Kap. 4.2.1). Vgl. auch Kriegbaum, Kirche der Traditoren, 100102.

16 Augustinus nennt namentlich ferner Novellus von Thizica und Faustinus von Thuburbo (Maius oder Minor) als weitere Ordinatoren, denen allerdings die traditio nicht nachgewiesen werden konnte (c. Don. 38). Vgl. o. Kap. 6.1.3.

17 Opt. I 19.

18 In breuic. III 26 gibt Augustinus eine kurze Zusammenfassung der Urteilsbegründungen. Auf der Konferenz 411 wurden alle Sentenzen der Bischöfe vorgelesen. - Kriegbaum (Kirche der Traditoren, 114-118) verweist zu Recht auf die cyprianische Tradition und betont, dass die traditio der Ordinatoren der entscheidende Punkt gewesen sein müsse, um Caecilians Bischofswürde als null und nichtig zu beurteilen. Der Weiheakt war ungültig, da er wegen der traditio der Ordinatoren nach Verständnis der pars 
contra Fulgentium überlieferte Sentenz vermittelt einen Eindruck von den Urteilsbegründungen. Die Sentenz des Marcianus endet mit den Worten:

„So wie die unfruchtbaren Zweige abgeschnitten und weggeworfen werden, so können auch die Weihrauchopferer und die Traditoren, die sich von Gott losgesagt haben, nicht in der Kirche Gottes bleiben, es sei denn, sie werden durch Buße wieder aufgenommen, wenn ihr Bußruf bekannt geworden ist. Deshalb soll mit Caecilianus keine Gemeinschaft gepflegt werden, weil er im Schisma von Traditoren ordiniert worden ist." ${ }^{\text {19 }}$

Die Argumentation der Donatisten zur Zeit Augustins war entscheidend auf das Urteil des Konzils von Karthago ausgerichtet. Die näheren Umstände, die zu dem Konzil und dem Schisma führten, fanden bei den Donatisten wenig Interesse, so dass es keine Hinweise darauf gibt, wie sie die Situation der karthagischen Kirche im Vorfeld der Auseinandersetzung über die Wahl Caecilians einschätzten, welche Rolle sie etwa der Lucilla beimaßen. Alle Berichte über diese kirchlichen Streitigkeiten in Karthago, die Intrigen und gegenseitigen Anschuldigungen, finden sich allein in der katholischen Überlieferung. ${ }^{20}$

Auf der Konferenz von 411 verteidigten die Donatisten die Rechtmäßigkeit dieses Urteils, indem sie behaupteten, numidische Bischöfe hätten zur Weihe Caecilians hinzugezogen werden müssen. ${ }^{21}$ Bereits Augustinus kommentiert dies mit der Bemerkung, dass die Donatisten diesen Vorwurf doch Caecilianus sofort gemacht hätten, wenn es tatsächlich ein derartiges kirchliches Gewohnheitsrecht gegeben hätte. Aber von solchen Anschuldigungen war offenbar in den Akten von Karthago nirgends die Rede. Vermutlich bestanden für die Wahl und Weihe des karthagischen Bischofs zu Beginn des 4. Jahrhunderts keine eindeutigen Richtlinien, so dass der Anspruch des numidischen Primas auf Mitwirkung der eigenen Einschätzung entsprang. ${ }^{22}$

Um den rechtmäßigen Ablauf des Konzils zu bekräftigen, wiesen die Donatisten im Jahre 411 auch auf das Angebot Caecilians an die Konzilsteilnehmer hin, sich nochmals ordinieren zu lassen, falls die Weihe durch Felix von Abthugni unwirksam gewesen sein sollte. Dieses Zugeständnis, von dem bei Op-

Maiorini nicht innerhalb der Kirche stattgefunden hatte. Demzufolge hatte Caecilianus die Bischofswürde niemals besessen.

19 C. Fulg. 24 (RevBen 58, 1948, 221; Maier II, S. 284): sicut ergo palmites infructuosi amputati proiciuntur, ita turificati, traditores, abhorrentes deo manere in ecclesia dei non possunt, nisi, cognito ululatu suo, per paenitentiam reconcilientur. unde Caeciliano in schismate a traditoribus ordinato non comunicare oportet.

20 Insbesondere bei Optatus von Mileve (I 16-20), dessen Ausführungen Augustinus in seinen Schriften vor 405 aufnimmt und für seine Argumentation interpretiert (vgl. o. Kap. 4.2.1; 6.2).

21 Breuic. III 29.

22 Es gibt keine weiteren Quellen, die über die kirchenrechtliche Situation sicher Auskunft geben könnten. Vgl. dazu Kriebaum, Kirche der Traditoren, 98 f.; Grasmück, Coercitio, $23 \mathrm{f}$. 
tatus die Rede ist, werteten die Donatisten jedoch nicht nur als Anerkennung des Konzils durch Caecilianus, sondern auch als sein Schuldeingeständnis: Caecilianus hätte zugegeben, von Traditoren ordiniert worden zu sein. ${ }^{23}$

Tatsächlich scheint Caecilianus einen Versuch unternommen zu haben, mit den numidischen Bischöfen zu einer Einigung zu kommen, indem er seine Weihe zur Disposition stellte. Caecilianus bekannte sich insofern zur afrikanisch-cyprianischen Tradition, der zufolge die Sakramente eines unwürdigen Spenders nicht galten. Offenbar war er bereit, sich von Felix zu distanzieren, um sein erworbenes Amt zu verteidigen. Das Scheitern dieses Angebots zeigt indessen, dass es den Gegnern Caecilians nicht allein um die vermeintlich ungültige Weihe ging, sondern auch jene Ursachen zur Ablehnung seiner Person geführt hatten, von denen Optatus einen Eindruck vermittelt. Das Angebot Caecilians zeigt darüber hinaus, dass die theologischen Positionen in dieser ersten Phase des Schismas keineswegs so festgelegt waren, wie es aufgrund der späteren Darstellungen oftmals den Anschein hat. Ein Eingeständnis seiner eigenen Schuld oder ein Beweis für die traditio der Ordinatoren, wie die Donatisten 411 glauben machen wollten, war das Handeln Caecilians freilich nicht, wie bereits Augustinus in seinem Kommentar bemerkt. ${ }^{24}$

Die Argumentation der Donatisten im Jahre 411 macht deutlich, dass sie durchaus gewillt waren, die Rechtmäßigkeit des Konzils von Karthago zu begründen. Leider fehlen Quellen, in denen außer den genannten weitere Argumente ersichtlich werden könnten. Ausgehend von den Aussagen des Cresconius lässt sich jedoch feststellen, dass den Donatisten im Grunde nicht daran gelegen war, Hintergründe und Motive der Situation der Kirche in Karthago aufzudecken. Sie beriefen sich allein auf das Protokoll und die Sentenzen, um zu konstatieren, dass Caecilianus und seine Ordinatoren nachweislich Traditoren gewesen seien, folglich Caecilians Wahl und Ordination zum Bischof Karthagos rechtmäßig durch das Konzil des Secundus annulliert worden seien, eine Entscheidung, die als eindeutig und unanfechtbar anerkannt werden müsse. ${ }^{25}$

23 Cap. conl. Carth. III 374; breuic. III 29; vgl. Opt. I 19.

24 Breuic. III 29. Vgl. Grasmück, Coercitio, 24; ausführlich Kriegbaum (Kirche der Traditoren, 107-112), dessen Interpretation über die Motivation der beiden Parteien allerdings teilweise spekulativ ist. - Vgl. auch oben Kap. 5.3.1.

25 Vgl. Cresc. III 31, 34; IV 9. Dieses Verständnis der Donatisten wird auch deutlich in der Forderung im Jahre 411, aufgrund der Sentenzen des Konzils, die de jure Verurteilung Caecilians anzuerkennen (Cap. conl. Carth. III 367). 


\subsection{Der interventor von Karthago}

Einen der seltenen Hinweise auf mündliche donatistische Überlieferungen aus der Entstehungsphase des Schismas gibt Bischof Fortunius von Thubursicum Numidarum. ${ }^{26}$ Dieser erzählte Augustinus und den anderen katholischen Gesprächspartnern, dass seine Vorfahren zu Beginn der Auseinandersetzung durchaus bereit gewesen seien, die Schuld Caecilians auf sich beruhen zu lassen, um ein Schisma zu verhindern. Daher hätten sie noch vor der Ordination des Maiorinus einen interventor für ihre Gemeinde in Karthago eingesetzt. Dieser Mann sei jedoch inmitten seiner Gemeinde von den Gegnern ermordet worden. ${ }^{27}$ Augustinus selbst bemerkte, diese Geschichte noch niemals zuvor gehört zu haben, obwohl er viele Anklagen und Vorwürfe der Donatisten gegen die Katholiken kenne. Offensichtlich hielt er diese Darstellung für unglaubwürdig. ${ }^{28}$

In einer späteren Predigt erwähnt Augustinus jedoch, dass Secundus von Tigisi zunächst Kleriker nach Karthago geschickt hätte, die einen visitator eingesetzt und mit den Anhängern der Lucilla eigene Gottesdienste gefeiert hätten. ${ }^{29}$ Hier bezog sich Augustinus ganz offensichtlich auf Informationen, die Optatus von Mileve nicht besessen bzw. nicht für erwähnenswert gehalten hatte. Geht man nun davon aus, dass sich beide Aussagen auf dieselbe Person beziehen, bleibt zunächst die Frage, wie sie in den historischen Kontext einzuordnen sind. Augustins Notiz erscheint im Zusammenhang durchaus plausibel: Caecilians Gegner in Karthago brauchten Unterstützung und wandten sich an den einflussreichen numidischen Primas Secundus. Da aus Sicht der späteren pars Maiorini Caecilianus und seine Kleriker ihre Ämter unrechtmäßig ausübten, sandte Secundus vor seiner eigenen Reise numidische Kleriker nach Karthago. Diese wiederum ernannten einen Bistumsverweser, dem bis zur offiziellen Neuwahl eines Bischofs die provisorische Leitung der anticaecilianischen Gemeinde oblag. ${ }^{30}$

26 Ep. 44; vgl. o. Kap. 4.1.1.

27 Ep. 44.8: [Fortunius] Narrauit etiam in ipsa schismatis nouitate maiores suos, cum cogitarent culpam Caeciliani, ne schisma fieret, quoquo modo uelle sopire, dedisse quendam interuentorem populo suae communionis apud Carthaginem constituto, antequam Maiorinus aduersus Caecilianum ordinaretur. hunc ergo interuentorem in suo conuenticulo a nostris dicebat occisum.

28 Ep. 44.8 .

29 S. 46.39: de Numidia nata est pars Donati. ipsi missi sunt primo in dissensionem et tumultum et scandalum, quaerentes ingenium uulneri. Numidae miserunt. Secundus Tigisitanus misit. ubi sit Tigisi, notum est. qui missi sunt clerici, extra congregauerunt ab ecclesia, et clericos Carthaginis accedere noluerunt, uisitatorem posuerunt, a Lucilla excepti sunt. auctor totius huius mali Numida haereticus fuit. - Monceaux (VII, 289) datiert die Predigt mit guter Begründung auf Mitte des Jahres 410.

30 Zur Rekonstruktion des Verlaufs in Karthago vgl. Kriegbaum, Kirche der Traditoren, 100-104. 
Während die Existenz dieser Person unzweifelhaft sein dürfte ${ }^{31}$ stellt sich weiterhin die Frage nach ihrer Bedeutung. Die Bemerkung des Fortunius zeigt, dass die Donatisten später im interventor eine Vermittlerfigur zwischen den beiden Parteien sahen, dessen Ermordung aber eine Einigung unmöglich gemacht hätte. Zweifellos war einerseits vor der Verurteilung Caecilians durch das Konzil des Secundus die Situation der karthagischen Kirche ungeklärt und grundsätzlich offen. Andererseits waren die Abgrenzungen bereits soweit fortgeschritten, dass eine Einheit der Kirche mit einem Bischof Caecilianus kaum mehr zu erreichen gewesen sein dürfte. Sollte der interventor tatsächlich versucht haben, die zerstrittene Gemeinde zu vereinen, so konnte dies nur durch Überzeugung der Gläubigen geschehen. Caecilianus selbst war für die Rigoristen untragbar. Fortunius' Andeutung, dass seine Vorfahren die „Schuld Caecilians“ irgendwie ,einschläfern“ (sopire) wollten, ist allerdings unklar. Entweder ist sie als euphemistische Darstellung einer Absetzung Caecilians zu verstehen oder als eine Umschreibung, dass Caecilians Anhänger zu einer Abkehr von ihrem Bischof bewegt werden sollten. ${ }^{32}$

Unglaubwürdig ist dagegen die Behauptung, der interventor sei ermordet worden. Dass ein solch einschneidendes Vorkommnis bei Optatus fehlt, könnte noch mit Hinweis auf die tendenziöse Darstellung begründet werden. Jedoch wäre dieser Fall von den Donatisten selbst weitaus häufiger zur Sprache gebracht worden, nicht zuletzt bei der Konferenz von Karthago, wenn diese donatistische Überlieferung der Wahrheit entsprochen hätte. Abgesehen davon gehört der Vorwurf von Mord, ebenso wie andere Arten der Gewaltausübung oder Bestechung zu den gängigen Topoi in der Auseinandersetzung. Hier liegt offenbar ein Beispiel für die Herausbildung eines solchen Topos vor, mit dem die eigene Geschichte gerechtfertigt und die Schuld an den Gegner verwiesen werden sollte. ${ }^{33}$

31 Dies ist weitgehend communis opinio in der Forschung. Anders Seeck (Geschichte III, 329, 514) und Grasmück (Coercitio, 22 f. Anm. 45). - Zur Bedeutung der Wörter visitator / interventor vgl. Gaudemet, Église, $366 \mathrm{f}$.

32 Vgl. Kriegbaum, Kirche der Traditoren, 103 f. und 124: Mit der Entsendung des Vermittlers „konnte Secundus beabsichtigt haben, den Gläubigen von Karthago die Möglichkeit zu bieten, sich von dem in seinen Augen schismatischen Caecilian loszusagen und so die Einheit der Gemeinde zu bewahren."

33 Die donatistische Überlieferung des Mordes wurde unkritisch übernommen u.a. von Frend (Donatist Church, 19: „The first action Secundus took, therefore, was to consider Caecilian's election as unconfirmed, and to appoint an interim administrator (an interventor) to look after the see until the dispute was settled. The interventor was murdered in his church allegedly by the Caecilianists.") und Piétri (Geschichte, 247: „provisorischer Bistumsverweser“, der ermordet wurde). 


\section{Die Anklage der Donatisten gegen Caecilianus}

Indem der Streit über die Bischofswahl von Karthago vor den Kaiser getragen wurde, vollzog sich ein bedeutsamer Schritt, der langfristige Auswirkungen auf das Verhältnis zwischen Kirche und Staat haben sollte. ${ }^{34}$ Die Umstände, die dazu führten, werden bei Augustinus an zahlreichen Stellen mit klaren Worten zusammengefasst: Die Donatisten selbst hätten die causa Caeciliani vor Konstantin gebracht und somit eine Entscheidung des Kaisers gefordert. So eindeutig diese Aussage auch sein mag, so schwierig ist es, unter Einbeziehung aller Quellen den genauen Vorgang und die Motive der Anklage vor dem Kaiser zu rekonstruieren. Die in der Forschung vielfach diskutierte Frage soll hier vor allem unter dem Aspekt aufgegriffen werden, inwiefern Augustinus und die Donatisten den geschichtlichen Verlauf kannten und wie sie ihn in ihren Argumentationen verarbeiteten.

Bereits Optatus von Mileve argumentiert gegen die donatistische Anfrage, „was die Christen mit den weltlichen Herrschern zu tun hätten“, mit einem Zitat, das angeblich jener Petition (preces) der Donatisten entstammte, mit der diese sich schon kurz nach dem Schisma in Karthago an Kaiser Konstantin gewandt und um sein Eingreifen gebeten hatten. ${ }^{35}$ Augustinus verfolgt in seinen antidonatistischen Schriften das gleiche Argumentationsziel: Die Donatisten dürften sich über das Eingreifen der staatlichen Gewalt in den Auseinandersetzungen zwischen den beiden Parteien nicht beschweren, denn sie selbst hätten sich zuerst mit einer kirchlichen Angelegenheit an Konstantin gewandt. Augustinus verteidigte mit diesem Argument die Inanspruchnahme weltlicher Institutionen durch die Katholiken, sei es die Hilfe von Soldaten gegen Circumcellionen und donatistische Gewalttaten, sei es die Nutzung zivilrechtlicher Mittel, um gegen Donatisten vorzugehen.

Die Zäsur in der Beweisführung Augustins um das Jahr 405 ist im Zusammenhang mit der historischen Argumentation in den Briefen dargelegt worden. ${ }^{36}$ In seinen Schriften vor dem Jahr 405 berief sich Augustinus ganz offensichtlich auf die Darstellung des Optatus und dessen Zitat aus besagter Petition: Von Konstantin, so der stereotype Vortrag, hätten die Donatisten Bischöfe als Richter erbeten, woraufhin dieser das Konzil von Rom einberufen habe. ${ }^{37}$ Seinen Aussagen zufolge hatte Augustinus den Gesprächspartnern in Thubursicum den Wortlaut jener preces vortragen lassen und seinen Briefpartner Generosus weist er ebenfalls ausdrücklich auf dieses Zeugnis hin. ${ }^{38} \mathrm{Da}$ aber ansonsten diese

34 Allgemein dazu Instinsky, Kaiserstuhl, 47-82; Girardet, Kaisergericht, 6-51.

35 Opt. I 22.

36 Vgl. o. Kap. 4.2.2.

37 Ps. c. Don. v102; epp. 43.14; 53.5; 76.2; cath. fr. 46; retr. I 21.3.

38 Epp. 43.4-5; 53.5. 
preces als eigenständiges Dokument niemals genannt werden - weder in späteren Augustinusschriften noch auf der Konferenz von 411 - ist davon auszugehen, dass Augustinus lediglich das bei Optatus überlieferte Fragment kannte und an entsprechender Stelle daraus zitierte. ${ }^{39}$

Die Wende in der Argumentationsweise erfolgte um das Jahr 405: In den Archiven des Prokonsuls in Karthago entdeckte Augustinus den Bericht des Prokonsuls Anullinus an Konstantin, ${ }^{40}$ mit dem die Petition der Donatisten seinerzeit übermittelt worden war. Diese relatio Anullini avancierte fortan zu dem entscheidenden historischen Dokument in den Händen Augustins, auf das er an zahlreichen Stellen explizit hinwies. Mit Hilfe der relatio Anullini führte er den Beweis, dass sich die Donatisten als erste und vollkommen freiwillig an den Kaiser gewandt und Caecilianus bei Konstantin angeklagt hätten. Diese Anklage habe zu den folgenden Prozessen geführt, die allesamt zu Gunsten Caecilians ausgefallen seien. ${ }^{41}$ Diese juristische Terminologie beherrschte auch die Konferenz von 411, bei der die Katholiken eine Bestätigung des Freispruchs Caecilians in der causa Caeciliani erreichen wollten. ${ }^{42}$ Nach der Konferenz verzichtete Augustinus bezeichnenderweise wieder auf diese Formulierungen und betonte nunmehr die Verfolgung Caecilians durch die Donatisten. Damit griff er den Sprachgebrauch der Donatisten auf, die ihrerseits von der Verfolgung durch die Katholiken und den weltlichen Mächten sprachen. ${ }^{43}$ Augustinus berief sich also zu verschiedenen Zeiten auf unterschiedliche Quellen und variierte entsprechend seine Interpretation des geschichtlichen Vorgangs.

Wenden wir uns als erstes der relatio Anullini zu, die am deutlichsten über die Ereignisse Auskunft gibt und daher auch von Augustinus bevorzugt wurde: Der Text der relatio Anullini ist durch Augustinus und die Konferenzakten von Karthago überliefert. An der Echtheit und Glaubwürdigkeit des Dokumentes

39 Girardet, Chiron 19, 1989, 199 f. - Dass Augustinus im Gegensatz zu Optatus deutlich von „bischöflichen Richtern“ aus Gallien spricht, ist als eine Interpretation ex eventu zu verstehen. Insbesondere im Kontext von ep. 43 wird deutlich, wie Augustinus spätere Entwicklungen und Ereignisse heranzieht, um die aus seiner Sicht falsche Motivation der Donatisten herauszustellen; vgl. die Darstellung o. Kap. 4.2.1.

40 Als auf der Konferenz von 411 nach der Herkunft des Dokumentes gefragt wurde, verwies Augustinus auf das Archiv des Prokonsuls (gesta conl. Carth. III 220; breuic. III 8). Vgl. Girardet, Chiron 19, 1989, 196; Kriegbaum, AHP 28, 1990, 28 f.

41 Vgl. epp. 88.1-3; 89.3; 93.13-14; 105.8; Cresc. III 16, 67; IV 9; un. bapt. 28; s. Denis 19.8; s. Dolbeau 2.22; breuic. III 21, 24, 30; Gaud. I 53; gesta conl. Carth. I 16, 18 , 55 (SC 195, S. 668 Z. 351-358). Diese Veränderung ist besonders an den Briefen mit historischer Argumentation sichtbar (vgl. o. Kap. 4.2.2). Zur Argumentation im Jahre 411 vgl. o. Kap. 5.2.2. Vgl. auch Girardet, Chiron 19, 1989, 196-203.

42 Gesta conl. Carth. III 144, 176, 215-220; vgl. auch gesta conl. Carth. I 18, 55 (Z. 353); breuic. III 8, 24; vgl. o. Kap. 5.3.2.

43 Gaud. I 21; s. Caes. eccl. 7; c. Don. 53. 
ist nicht zu zweifeln. ${ }^{44}$ Augustinus verweist auf das Archiv des Prokonsuls in Karthago als Herkunftsort, die Datierung ist korrekt, nachprüfbar und selbst von den Donatisten ist kein Versuch überliefert, die Authentizität in Abrede zu stellen: Parmenianus bekannte sich laut Augustinus ausdrücklich zu der Anklageinitiative seiner Vorgänger ${ }^{45}$ und auch auf der Konferenz von 411 sprachen die Donatisten der relatio Anullini die Echtheit nicht ab. ${ }^{46}$

In dieser relatio, die auf den 15. April 313 datiert, berichtet Anullinus dem Kaiser zunächst, dass die Anordnung umgesetzt worden sei, die karthagische Kirche des Bischofs Caecilianus von den Abgabenpflichten (munera) zu befreien. Anschließend schreibt er:

„Nach wenigen Tagen aber erschienen, begleitet von einer Volksmenge, einige Leute, die glaubten, Caecilianus widersprechen zu müssen. Sie übergaben mir ein in Leder gebundenes und versiegeltes Päckchen sowie ein schriftliches Gesuch ohne Siegel und sie bitten mich dringend, diese an den heiligen und verehrungswürdigen Hof eurer kaiserlichen Hoheit weiterzureichen. Meine Wenigkeit hat dafür Sorge getragen, dass sie - während Caecilianus in seinem Stand verbleiben

44 Ep. 88. 2; Gesta conl. Carth. III 220; vgl. Maier I, Nr. 14, 144-146; von Soden, Nr. 10; vgl. Monceaux IV, 200; Seeck, ZKG 10, 1889, 515; Girardet, Chiron 19, 1989, 185 f; Barnes, New Empire, 240 f.; Corcoran, Empire, 155 f. - Mandouze unterscheidet den Verfasser dieses Berichts (PAC, $80 \mathrm{f}$, , s. v. Anulinus 2) von dem gleichnamigen Prokonsul, der zur Zeit der Verfolgung in Afrika amtierte (PAC, 78-80, s. v. Anulinus 1). Vgl. PLRE I, 79, s. v. Annius Anullinus; 78, s. v. Anullinus 2.

45 C. ep. Parm. I 10: ultro fassus est ipsos suos adisse etiam Constantinum et eius arbitrio a iudicibus episcopis causam esse cognitam, quibus praefuit Miltiades Romanae urbis episcopus.

46 Augustinus zufolge hatten die Donatisten die „Verfolgung“ Caecilians beim Kaiser zugegeben (c. Don. 53; vgl. breuic. III 30). Dies deutet ebenfalls darauf, dass sie die Anklage gegen ihn nicht leugneten, freilich ohne das Wort „Verfolgung“ zu gebrauchen. - Die Diskussion über die relatio Anullini auf der Konferenz von 411 stellt einen Sonderfall dar und lässt daher kaum Rückschlüsse auf den allgemeinen Umgang der Donatisten mit diesem Dokument zu. Zweimal lenkten sie von diesem Dokument ab, das erste Mal, indem sie die Grundsatzdebatte über die traditio begannen, das zweite Mal, als sie thematisch weit ausholten und ihre Ausführungen über Mensurius und die traditio in Karthago vortrugen. Diese Obstruktionen entsprangen taktischen Überlegungen: Im Gesamtzusammenhang der Debatte mussten die Donatisten der relatio Anullini entgegentreten, um nicht doch plötzlich in den Status des Anklägers zu geraten, was sie unbedingt vermeiden wollten. Dennoch wird auch der inhaltliche Hintergrund ihrer Argumentation deutlich: Aus ihrer Sicht war der entscheidende Aspekt der Anklage nicht die formale Supplik beim Kaiser, sondern der Angriff der katholischen Traditoren auf die Reinheit der Kirche. Die Anrufung des Kaisers verstanden sie entsprechend als ein Akt der Verteidigung der Kirche, nicht als Verfolgung Caecilians. Auch wenn die Donatisten es nicht aussprachen: Sie wussten, dass ihre Vorfahren die Option einer Petition an den Kaiser hatten wahrnehmen müssen, wenn sie als wahre Kirche anerkannt werden wollten. Hundert Jahre später jedoch mussten die Donatisten dieser Tatsache ausweichen, um nicht von den Gegnern, insbesondere Augustinus, in eine Argumentationsfalle zu geraten. Vgl. auch o. Kap. 5.2. 
sollte - unter Beifügung der Akten geschickt werden, damit eure Majestät alles zur Kenntnis nehmen könne. Zwei Schriften wurden versandt: eines in Leder mit der Überschrift: ,Klageschrift der katholischen Kirche bezüglich der Vergehen Caecilians übergeben von der Partei des Maiorinus', außerdem eine andere Schrift ohne Siegel, die mit der in Leder verbunden ist. Geschrieben in Karthago an den 17. Kalenden des Mai im III. Konsulat unseres Herren des Augustus Konstantin." ${ }^{* 47}$

Aus diesem Bericht lassen sich einige Informationen ableiten: ${ }^{48}$ Konstantin hatte der Kirche in Afrika Privilegien eingeräumt, darunter die Befreiung von munera. Anullinus trat daraufhin in Kontakt mit Caecilianus und informierte ihn über diese Privilegien, gleichzeitig mahnte er, für die Einheit der Kirche einzutreten. Gegen diese Zuwendung an die pars Caeciliani legten die Anhänger des Maiorinus Widerspruch ein, indem sie eine Petition an Konstantin verfassten und den Prokonsul baten, diese weiterzuleiten. Gleichsam als Begründung ihres Einspruchs fügten sie eine Schrift hinzu, in der offenbar die Verstöße Caecilians gegen kirchliches Recht aufgelistet wurde. Eindeutig bestätigt die relatio Anullini Augustins Darstellung, dass die Donatisten sich freiwillig in der causa Caeciliani an den Kaiser gewandt hätten. Aus welchen Motiven und mit welcher Intention sie handelten, wird später zu fragen sein. Zunächst soll noch die Schilderung des Optatus von Mileve betrachtet werden: $:^{49}$

Im 22. Kapitel des ersten Buches leitet Optatus einen neuen Abschnitt seiner historischen Darstellung ein, indem er die Glaubwürdigkeit donatistischer Schriften infrage stellt und demgegenüber die Zuverlässigkeit der katholischen Dokumente unterstreicht. Als Beispiel für die unwahren Aussagen der Donatisten führt Optatus die beliebte Anfrage der Donatisten an: „Was haben die Christen mit den Herrschern zu tun, was die Bischöfe mit den Palästen?" Diese Aussage, so Optatus, sei falsch, da die Gründer der pars Donati sich selbst an den Kaiser mit einer Petition gewandt hätten. Anschließend zitiert er aus dieser Petition mit den Worten:

„Wir wenden uns an dich, Konstantin, bester Kaiser, da du aus einem gerechten Geschlecht bist, dessen Vater unter all den anderen Kaisern keine Verfolgung

47 Ep. 88.2: uerum post paucos dies extiterunt quidam adunata secum populi multitudine, qui Caeciliano contradicendum putarent quique fasciculum in aluta signatum et libellum sine signo obtulerunt dicationi meae atque impendio postularunt, ut ad sacrum ac uenerabilem comitatum numinis uestri dirigerem, quae manente Caeciliano in statu suo subiectis eorundem actis, quo cuncta maiestas uestra possit dinoscere, paruitas mea dirigere curauit. transmissi libelli duo, unus in aluta suprascriptus ita: 'Libellus ecclesiae catholicae criminum Caeciliani traditus a parte Maiorini', item alius sine sigillo cohaerens eidam alutae, datus die XVII Kalendas Maias Carthagine domino nostro Constantino Augusto III.

48 Vgl. Girardet, Chiron 19, 1989, 185; ders., Historia 41, 1992, 105 f.; Kriegbaum, AHP 28, 1990, 28-30.

49 Vgl. Girardet (Chiron 19, 1989, 188-196) und Kriegbaum (AHP 28, 1990, 35-38) mit Analysen des literarischen Kontextes von Opt. I 22. 
durchführte. Von dieser Untat ist Gallien frei, denn in Afrika herrscht Streit zwischen uns und anderen Bischöfen. Wir bitten dich, deine Frömmigkeit möge verordnen, dass uns aus Gallien Richter gegeben werden. Eingereicht von Lucianus, Dignus, Nasutius, Capito, Fidentius und den übrigen Bischöfen der Partei des Donatus. “50

Optatus führt seine Darstellung fort, indem er eine abweisende Reaktion Konstantins zitiert und dann die Einberufung der Bischöfe zur römischen Synode beschreibt (I 23).

Aufgrund der zahlreichen sprachlichen Unebenheiten und sachlichen Ungereimtheiten in diesem Text ist sein Quellenwert bis heute in der Forschung umstritten. ${ }^{51}$ Der überwiegende Teil der Historiker geht davon aus, dass diese von Optatus zitierte Bittschrift entweder wörtlich, zumindest aber dem Sinn nach jener unversiegelten Petition entspreche, von der in der relatio Anullini die Rede ist. ${ }^{52}$ Ein geringerer Teil hält die preces für eine Fälschung ${ }^{53}$ oder bezweifelt zumindest den Zusammenhang mit der relatio Anullini. ${ }^{54}$

Wenngleich die Quellenlage wohl kein abschließendes Urteil zulässt, so scheinen mir doch die Argumente eindeutig zu überwiegen, die gegen eine Verbindung der relatio Anullini und der bei Optatus überlieferten preces sprechen. Insbesondere K. M. GiRARDET hat die Widersprüche herausgestellt und zu Recht gefolgert, dass „Optatus kein im Wortlaut oder wenigstens der Sache nach authentisches Zeugnis für die donatistische Petition im Frühjahr 313 überliefert hat. ${ }^{\text {"55 }}$ Daraus ergeben sich Konsequenzen sowohl für die Interpre-

50 Opt. I 22: rogamus te, Constantine, optime imperator - quoniam de genere iusto es, cuius pater inter ceteros imperatores persecutionem non exercuit et ab hoc facinore immunis est Gallia, nam in Africa inter nos et ceteros episcopos contentiones sunt - petimus, ut de Gallia nobis iudices dari praecipiat pietas tua. datae a Luciano, Digno, Nasutio, Capitone, Fidentio et ceteris episcopis partis Donati. - Zur Übersetzung vgl. Labrousse, SC 412, 222 Anm. 2.

51 Zur Problemstellung allgemein siehe Girardet (Chiron 19, 1989, 185-206) und Kriegbaum (AHP 28, 1990, 23-25; Mazzucco, Ottato di Milevi, 112-117.

52 So u.a. Barnes, Constantine, 56 f.; New Empire, 238-241; Corcoran, Empire, 156 f.; Drake, Constantine and the Bishops, 216 f.; Frend, Donatist Church, 147 f.; Grasmück, Coercitio 33 mit Anm. 107; Instinsky, Bischofsstuhl, 70 f.; Keresztes, Constantine, 61; Maier I, 146-148; Millar, Emperor, 584-590; Monceaux IV, 200 f.; Piétri, Geschichte, 248; Schindler, TRE 1, 656 (,[...] wahrscheinlich teilweise echte Schreiben“).

53 Zuerst Voelter (Donatismus, 136-144) gefolgt von Seeck (ZKG 10, 1889, 550 f.; 30, 1909, 196-198, 214-216).

54 Girardet; Kaisergericht, 17-26; Chiron 19, 1989, 188-196; ders., Historia 41, 1992, 104 116 bes. 109; Kriegbaum, AHP 28, 1990, 23-49.

55 Girardet, Historia 41, 1992, 109. - Es erübrigt sich hier, sämtliche Argumente ausführlich zu diskutieren; vgl. dazu die Übersicht bei Mazzucco (Ottato di Milevi, 112 117) und die genannten Darstellungen von Voelter, Seeck, Girardet und Kriegbaum (o. Anm. 53/54). Entscheidend sind folgende Feststellungen: 1. Die Bezeichnung pars Donati steht im Widerspruch zu der Angabe pars Maiorini in der relatio Anullini. 2. 
Keinesfalls hätten die Donatisten nach der Absetzung Caecilians von einem „Streit mit anderen Bischöfen" gesprochen, denn Caecilianus war in ihren Augen kein Bischof mehr. 3. Eine explizite Bitte um Richter aus Gallien ist nur schwer zu erklären. Geht man von bischöflichen Richtern aus, so steht dies im Widerspruch zu der endgültigen Synodalentscheidung von Karthago, von denen die Donatisten stets sprachen, geht man von weltlichen Richtern aus (wie zuerst Instinsky, Bischofsstuhl, 70), so findet dies keine Entsprechung im Prozessrecht. Warum sollten sich die Donatisten an den Kaiser wenden, um dann ein mehrfach besetztes Tribunal gegen Caecilianus zu fordern? (Girardet, Chiron 19, 1989, 192-196). 4. In den späteren Äußerungen Konstantins ist niemals von der Bitte um gallische Richter die Rede, und die Donatisten beschwerten sich - trotz zahlreicher anderer Einwände - niemals, dass ihre Bitte um gallische Richter missachtet worden sei. 5. Die unklare Chronologie in der Darstellung des Optatus: Anhand des vorhandenen Quellenmaterials versuchte Optatus zwar eine Ordnung zu schaffen, aber einerseits wusste er zu wenig Einzelheiten, andererseits war ihm die Polemik wichtiger als die historische Genauigkeit. Seine Unkenntnis über das Konzil von Arles sowie das aus dem Zusammenhang gerissene Konstantinzitat (in Opt. I 23) sind nur zwei Beispiele, die gegen einen vertrauenswürdigen Umgang mit dem vorliegenden Textfragment sprechen.

Kriegbaum (AHP 28, 1990, 49-58) geht davon aus, dass es sich bei dem Text der preces nicht um eine Fälschung handele, sondern Optatus seine vorliegende Quelle einem falschen Kontext zugeordnet habe. Ausgehend von den in den preces genannten Personen, die ähnlich in Opt. App. VIII genannt werden, vermutet Kriegbaum, dass der vorliegende Text eine zusammenfassende Notiz einer Petition sei, die von den Donatisten nach der Entscheidung von Rom eingereicht worden sei. Nachdem ihnen deutlich geworden sei, dass Konstantin nicht selber urteilen wollte, hätten sie um ein erneutes Bischofsgericht gebeten, das ohne die befangenen italischen Bischöfe abgehalten werden sollte. Da Optatus über das Konzil in Arles nicht informiert war, habe er seine Vorlage als Nachweis der ersten Anklage Caecilians verwendet. - Diesem interessanten Lösungsvorschlag stehen jedoch einige Einwände gegenüber, die Girardet (Historia 41, 1992, 114-116) in seiner Replik auf Kriegbaums These zu Recht geltend macht: 1. Die Donatisten sprachen dem Konzil von Rom die Berechtigung ab, in einer afrikanischen Kirchenangelegenheit zu entscheiden (Aug. ep. 43.14; Eus. HE X 5.22; vgl. u. Kap. 7.3). Eine Bitte, nun gallische Bischöfe entscheiden zu lassen, ist daher kaum vorstellbar. 2. In den Äußerungen Konstantins ist weder vor noch nach der Synode von Arles davon die Rede, dass die Donatisten dieses Konzil selbst gefordert oder eine schriftliche Petition eingereicht hätten. - Es ist daher äußerst unwahrscheinlich, dass Kriegbaums Hypothese zutrifft. Gleichwohl stimme ich mit Kriegbaum überein, dass kaum anzunehmen ist, Optatus habe den Text der preces gefälscht. Wenn man aber eine Fälschung (auch vor Optatus) ausschließt und Optatus auf eine historische Quelle zurückgreifen konnte, welche Möglichkeiten bleiben für den historischen Kontext? Eine denkbare Alternative wäre von einem Text aus dem unmittelbaren Vorfeld des römischen Konzils auszugehen. Auch Girardet gibt zu, dass sich die Donatisten zu einem bestimmten Zeitpunkt vor den dortigen Verhandlungen ,wohl oder übel“ auf das Bischofsgericht und die neue Sachlage eingestellt hätten (Historia 41, 1992, 112). Möglicherweise entwickelte die in den „preces“ genannte Gruppe Donatisten in dem kurzen Zeitraum zwischen der Entscheidung Konstantins, ein Bischofsgericht einzuberufen, und der tatsächlichen Einberufung (Brief an Miltiades, Eus. HE X 5.18-20) den Gedanken, den Kaiser zu bitten, gallische Richter (Bischöfe) hinzuzuziehen, da sie sich von den Galliern Zustimmung erhofften. Die „preces“ wären dann ein informelles Gesuch, das an 
tation des historischen Ereignisses als auch für das Verständnis der Argumentation Augustins.

Der Hintergrund der donatistischen Petition an den Kaiser wird durch zwei Briefe Konstantins an den Prokonsul Anullinus sowie einen an Bischof Caecilianus erhellt, die in der Kirchengeschichte des Eusebius überliefert sind. ${ }^{56}$ In dem ersten Brief an Anullinus, der vielleicht noch Ende 312 geschrieben wurde, weist Konstantin den Prokonsul an, der katholischen Kirche das konfiszierte Eigentum zurückzugeben. ${ }^{57}$ Mit dem zweiten Brief veranlasste der Kaiser die Befreiung der Kleriker von allen öffentlichen Verpflichtungen in der Provinz des Anullinus. ${ }^{58}$ Ausdrücklich wird Caecilianus als Vorsteher der Kirche genannt. Dass Konstantin inzwischen über die Spaltung in der Kirche Karthagos informiert worden war, geht eindeutig aus dem Schreiben an Caecilianus selbst hervor. ${ }^{59}$ Hier ist die Rede von Irrlehrern, die das Kirchenvolk verführten. Caecilianus solle sich bedenkenlos an die weltlichen Richter wenden, wenn diese Leute in ihrem Wahnsinn verharrten. Konstantin verfügt außerdem, dass Caecilianus eine große Geldsumme (3000 folles) erhalte, die er anhand einer vorgefertigten Namensliste an Kirchen der afrikanischen Provinzen verteilen

den Kaiser gestellt wurde. Freilich gilt auch bei dieser Möglichkeit der Einwand, dass von derartigen Forderungen in keiner Äußerung des Kaisers die Rede ist. Allerdings erklärt sich mit dieser Einordnung die Bezeichnung pars Donati und die Chronologie bei Optatus. Zu dem früheren Termin passt zudem die Hoffnung des gerade erst als Nachfolger des Maiorinus geweihten Donatus, doch noch die Anerkennung der überseeischen Kirchen zu erhalten.

56 Zur Sammlung konstantinischer Briefe bei Eusebius vgl. B. H. Warmington, The Sources of Some Constantinian Documents in Eusebius' Ecclesiastical History and Life of Constantine, Studia Patristica 18, 1985, 93-98; T. D. Barnes, The Constantinian Settlement, in: Eusebius, Christianity and Judaism, Leiden/New York/Köln 1992, 635 657. - E. Carotenuto (Six Constantinian Documents (Eus. H. E.10, 5-7), VChr 56, 2002, 56-74, hier: $67 \mathrm{f}$.) vermutet, dass die sechs Briefe in einem „antidonatistischen Milieu“ vor 315/16 zusammengestellt worden seien. Mit den Dokumenten sollte verdeutlicht werden, dass nur die katholische Kirche der Partei Caecilians Empfänger der kaiserlichen Zuwendungen sei und nicht die Donatisten. Eusebius habe später diese Zusammenstellung - vielleicht über einen Kontaktmann aus Rom - erhalten, ohne die $\mathrm{Zu}$ sammenhänge zu kennen. Für Carotenutos Vermutungen sprechen sowohl die Thematik der überlieferten Briefe als auch der Kontext bei Eusebius. Sicherheit lässt sich hierin aber kaum erlangen.

57 Eus. HE X 5.15-17; Maier I, Nr. 11, 138 f.; von Soden Nr. 7; vgl. Barnes, Constantine, 56; New Empire, 240 f.; Corcoran, Empire, 153; Dörries, Selbstzeugnis, 16; Monceaux IV, 200.

58 Eus. HE X 7.1-2; Maier I, Nr. 13, 142-44; Soden Nr. 9; vgl. Barnes, New Empire, 169 f., 240 f.; Corcoran, Empire, 155; Dörries, Selbstzeugnis, 18 f.; Monceaux IV, 200; Seeck, ZKG 10, 1889, 511. - Zur Privilegierung der Kleriker vgl. CTh XVI 2.1-2 (Befreiung der Kleriker von munera in Italien), dazu Corcoran, Empire, 155, 162.

59 Eus. HE X 6.1-5; Maier I, Nr. 12, 140-142; Soden Nr. 8; vgl. Barnes, New Empire, 240 f.; Corcoran, Empire, 153; Dörries, Selbstzeugnis, 17 f.; Monceaux IV, 200; Seeck, ZKG 10, 1889, $510 \mathrm{f}$. 
solle. Vermutlich war auch diese Zuwendung zur Förderung der kirchlichen Einheit gedacht.

Wie bereits dargestellt bestätigte Anullinus in seinem Bericht an den Kaiser die Durchführung der an ihn ergangenen Verfügungen und sah sich daraufhin den Protesten der Donatisten ausgesetzt.

Das Motiv der Donatisten, sich über den Prokonsul an den Kaiser zu wenden, wird durch diese zusätzlichen Quellen evident: Die pars Donati sah sich selbst als die wahre Vertreterin der katholischen Kirche und sie forderte nun, dass die Vergünstigungen und die finanzielle Unterstützung an ihre Adresse mit ihrem Bischof Maiorinus zu gehen hätten. Caecilianus war vom Kaiser offensichtlich als Vertreter der afrikanischen Kirche anerkannt worden. Dies konnten die Donatisten nicht akzeptieren. In ihren Augen war Caecilianus kein Bischof mehr und daher auch nicht berechtigt, die afrikanische Kirche zu vertreten. Deshalb begründeten sie ihren Einspruch mit einem Dossier, das sich allein auf die Person Caecilians bezog, jenem libellus criminum Caeciliani. ${ }^{60}$

Handelte es sich bei diesem Vorgang im juristischen Sinne um eine Anklageerhebung, eine förmliche Prozesseinleitung gegen Caecilianus? Die Mehrheit der Historiker vertritt diese Ansicht oder lässt die Frage offen, die aufgrund der mangelnden Kenntnisse über den Inhalt der beiden libelli nicht leicht $\mathrm{zu}$ beantworten ist. ${ }^{61}$ Die pars Maiorini war in einer für sie schwierigen Lage: Welche Argumente könnten Konstantin überzeugen, dass nicht Caecilianus, der rechtmäßig exkommuniziert worden war, sondern Maiorinus als Bischof von Karthago gelten müsse und daher Anspruch auf die Privilegien hätte? K. M. Girardet geht davon aus, dass die Anklagen, die zur Absetzung Caecilians geführt hatten, nicht mehr Gegenstand der Anklage beim Kaiser gewesen seien, da die ,kirchlich zu ahndenden crimina durch die allein zuständige Instanz", nämlich durch das Konzil von Karthago, endgültig erledigt worden seien. Die pars Maiorini hätte daher eine Zivilklage erhoben, mit der Begründung, Caecilianus habe - da er ja kein Bischof gewesen sei - rechtswidrig Kirchenbesitz, Privilegien und Geldzuwendungen des Kaisers in Anspruch genommen.

60 Kriegbaum, AHP 28, 1990, 30 f.; Grasmück, Coercitio, 32.

61 So etwa Seeck, Geschichte III, 328 („Anklageschrift gegen Caecilianus“); insbesondere aber Girardet, Kaisergericht, 17-20, 26 f.; Chiron 19, 1989, 204-206; und Grasmück, Coercitio, 32-39 (,Zivilklage gegen Caecilian“). - Ein Teil der Forschung geht indessen aufgrund von Opt. I 22 (fälschlicherweise) von dem Wunsch nach weltlichen iudices dati aus, so Instinsky, Bischofsstuhl, 70; Frend, Donatist Church, 146-148; Maier I, 147. Anders urteilen zwangsläufig jene, die von dem Wunsch nach einem Bischofsgericht ausgehen, etwa Monceaux IV, 21; Barnes, JThS 26, 1975, 20 f.; Constantine, 57; Congar, BA 28, 15 f.; Drake, Constantine and the Bishops, 57; Keresztes, Constantine, 58-61; Piétri, Geschichte, 24. - Zur Rechtsgrundlage der Litisdenuntiation vgl. Kaser/Hackl, Zivilprozessrecht, 566-570. 
Möglicherweise sei ihm auch gewaltsame Amtsanmaßung und Mord vorgeworfen worden. ${ }^{62}$

Im Gegensatz zu dieser Deutung ist es allerdings ebenso möglich, dass die pars Maiorini zunächst den Kaiser grundsätzlich über den Sachverhalt des Schismas, die Lage in Karthago und auch über die Person Caecilians aufklären wollte. Die crimina Caecilians umfassten demnach nicht nur die Vorwürfe der Amtsanmaßung, sondern die auch später noch stereotyp vorgetragenen Anklagen gegen Caecilianus: Seine traditio, seine Kollaboration während der Verfolgung, seine Weihe durch einen Traditor und die daraus resultierende Absetzung auf einem ordentlichen Konzil in Karthago. Trifft diese Vermutung $\mathrm{zu}$, dann beinhaltete der libellus criminum Caeciliani die Sammlung aller bestehenden Vorwürfe gegen Caecilianus, die dem Kaiser übermittelt werden sollte, verbunden mit der Bitte, diese Anschuldigungen zur Kenntnis zu nehmen. Die pars Maiorini erwartete vom Kaiser keinen Prozess gegen Caecilianus und auf keinen Fall die Einberufung einer Synode, sondern lediglich eine Revision seiner bisherigen Entscheidung, nachdem er über die wahren Sachverhalte aufgeklärt worden war. ${ }^{63}$

Der weitere Verlauf der Ereignisse unterstützt die letztgenannte Möglichkeit und spricht somit gegen eine förmliche Anklage. Wenn nämlich Konstantin eine zivilprozessrechtliche Anklage gegen Caecilianus mit säkular justiziablen Anschuldigungen erhalten hätte, dann wäre dies wahrscheinlich auch in entsprechender Form durchgeführt und entschieden worden. Der Kaiser oder ein Stellvertreter (iudex datus) hätten ein Urteil gefällt, wie es im Falle des Felix von Abthugni geschah. Genau das ist aber nicht geschehen, sondern Konstantin berief ein kirchliches Gremium ein und beauftragte es, zwischen Donatus und Caecilianus zu entscheiden. Dieses Vorgehen erklärt sich am besten, wenn man von einem grundsätzlichen Protest und generellen Anschuldigungen der pars Maiorini gegen Caecilianus ausgeht. Konstantin sah sich offensichtlich nicht in der Lage, die von Anullinus weitergereichten Anschuldigungen zu beurteilen, da es um Kirchenfragen ging. Er war zwar daran interessiert, die Spaltung zu überwinden und Unruhen zu vermeiden, doch wollte er die Entscheidung über kirchenrechtliche Fragen der Kirche selbst überlassen. ${ }^{64}$ Es war somit Kon-

62 Girardet, Kaisergericht, 19 f.; Chiron 19, 1989, 205. Girardet betont allerdings den hypothetischen Charakter seiner Interpretation.

63 Vgl. Kriegbaum, AHP 28, 1990, 33-35, insbesondere Anm. 40 u. 41. - Girardet (Chiron 19, 1989, 204) ist der Meinung, diese Interpretation stehe im Widerspruch zu dem bereits gefällten Urteil des Konzils von Karthago. Dies ist aber nicht der Fall, denn die Donatisten wollten schließlich kein neues Urteil über Caecilianus, sondern lediglich eine Bestätigung ihrer Entscheidung durch den Kaiser. Sollte Konstantin ihren Ausführungen folgen, erübrigte sich ein Prozess gegen Caecilianus.

64 Diese Tendenz zeigt sich in den Äußerungen Konstantins gegenüber Miltiades (Eus. HE X 5.18-20) und Aelafius (Opt. App. III). Zu diesen Texten vgl. u. Kap. 7.3. 
stantin, der ein Verfahren gegen Caecilianus einleitete, indem er erstmals aufgrund kaiserlicher Gewalt eine Bischofssynode einberief, die an seiner statt urteilen sollte. ${ }^{65}$

Sollte diese Annahme richtig sein, dann stellt sich die Frage, warum in den Schriften Augustins nach 405 und auf der Konferenz von 411 stets von „Anklage“ die Rede ist. GiRARDET sieht darin eine Bestätigung für den juristischen Vorgang der Prozesseinleitung. ${ }^{66}$ Tatsächlich formuliert Augustinus seine Aussagen im Zusammenhang mit der relatio Anullini stets mit den juristischen Termini accusare oder accusatio. ${ }^{67}$ Mit welcher Intention aber spricht er von dieser Anklage? Der Blick auf das Argumentationsgefüge zeigt, dass Augustinus an den entsprechenden Stellen ohne Ausnahme die spätere Durchführung von Prozessen bzw. die Anwendung von staatlicher Gewalt gegen Donatisten rechtfertigen will. Er begründet die antidonatistische Gesetzgebung seiner Gegenwart mit der Konstruktion einer rechtlichen Kontinuität, die in der Anklage der pars Maiorini ihren Ausgangspunkt genommen haben soll. Er wird nicht müde $\mathrm{zu}$ wiederholen: Vos imperatoris iudicium flagitastis ! ${ }^{68}$ Augustins juristische Formulierungen sind daher kein Beleg für eine Prozesseinleitung. Seine Wortwahl ist vielmehr einer Argumentationsabsicht unterworfen, in der die späteren rechtlichen Konstellationen in erheblichem Maße auf die Vorgänge des Aprils 313 projiziert werden. ${ }^{69}$

Die juristischen Formulierungen, die in den Texten aus dem Umfeld der Konferenz von $411 \mathrm{zu}$ lesen sind, lassen sich ebenfalls aus dem Argumentati-

65 Vgl. Girardet (Chiron 19, 1989, 205 f.), der (trotz der m.E. falschen Annahme einer Prozesseinleitung durch die pars Maiorini) zu Recht davon ausgeht, dass Konstantin selbst entschied, die causa Caeciliani als causa ecclesiastica zu behandeln und daraufhin das Bischofsgericht berief. Zu Girardets Verständnis des Prozesses in Rom vgl. u. Kap. 7.3.

66 Girardet, Chiron 19, 1989, $202 \mathrm{f}$.

67 Augustins verwendet entweder die Wörter accusare / accusatio oder eine Formulierung mit (ad Constantinum) deferre. Vgl. die Stellenangaben o. Anm. 41.

68 S. Denis 19.8. Zur Darstellung der gesetzgeberischen Kontinuität in der Argumentation Augustins vgl. o. Kap. 4.2.2.

69 Wenngleich Augustinus einer wahrheitsgetreuen Wiedergabe der Geschichte einen hohen Stellenwert einräumt, so hält er sich in seiner Polemik einen Interpretationsrahmen offen. Im Bezug auf die Prozesse gegen Caecilianus lässt sich dies gut erkennen, wenn man seine Vergleiche mit den Maximianisten heranzieht: Obwohl er den gleichen Sachverhalt wiedergibt und zum Teil die gleichen Vorwürfe der Donatisten bekämpft (nämlich die „Verfolgung“ der Donatisten), ist an diesen Stellen (auch mit Kenntnis der relatio Anullini) von juristischen Formulierungen nichts mehr zu lesen. Weder unterscheidet er die Verurteilung Caecilians in Karthago von den Urteilen in Europa noch die Urteile der Bischöfe von dem des Kaisers. Die „Prozesseinleitung“ spielt bei seiner Gegenüberstellung Primianus - Caecilianus keine Rolle. Vgl. Cresc. III 16; IV 9; Emer. 9; c. Don. 37; explizit in Cresc. IV 9: pro quo [sc. Caeciliano] non unum, sicut pro Primiano, sed quattuor posteriora iudicia recitantur. Dazu o. Kap. 3.4.2.2. 
onszusammenhang erklären: Zum einen trug die gesamte Struktur der historischen Argumentation der Katholiken die Handschrift Augustins mit den genannten Implikationen, ${ }^{70}$ zum anderen unterstand die Debatte einer klaren juristischen Forderung, da Marcellinus explizit den Nachweis der „ersten Anklage" gefordert hatte. Beide Parteien mussten dieser Forderung nachkommen. ${ }^{71}$ Verständlicherweise zogen die Katholiken die relatio Anullini heran und wiesen es als Dokument der ersten Anklage aus. Es ist jedoch zu berücksichtigen, dass von Donatisten und Katholiken auch Aktenstücke vorgelegt wurden, die eindeutig keine Anklageschriften im juristischen Sinne darstellten, die aber genauso die „erste Anklage“ belegen sollten. ${ }^{72}$ Aufgrund der verwendeten Formulierungen lässt sich insofern nicht folgern, dass die relatio Anullini eine formelle Anklageschrift gewesen sei. ${ }^{73}$

Außer der relatio Anullini existierten im Jahre 411 weitere Dokumente, die heute nicht erhalten sind, damals aber zusätzliche Informationen über den Weg der Anklageerhebung liefern konnten. So waren die Katholiken im Besitz einer weiteren relatio des Anullinus, in der über die Entsendung von Vertretern beider Parteien nach Rom Auskunft gegeben wurde, ${ }^{74}$ darüber hinaus standen die gesamten Akten der römischen Synode zur Verfügung, einschließlich der Urteilssprüche. ${ }^{75}$ Über die Form der Anklageerhebung konnten die Protokolle aus Rom keine weiterführenden Auskünfte geben, da ein völlig anderer Pro-

70 Vgl. Gesta conl. Carth. I 14, 16, 55 (SC 195, Z. 332 ff.). Die katholische Strategie ist folgende: Wenn die Donatisten sich über Gewalt und Verfolgung beschweren, dann antworten die Katholiken (neben dem biblischen Zeugnis) auch mit den menschlichen Dokumenten, die zeigten, dass die Donatisten zuerst beim Kaiser geklagt hätten. Vgl. oben Kap. 5.1.2.

71 Gesta conl. Carth. III 117, 120.

72 Die Akten über eine donatistische Gesandtschaft nach Ravenna im Jahr 406 (gesta conl. Carth. III 124, 128) und die Petition katholischer Bischöfe mit Bitte um Religionsgespräche aus dem Jahr 403 (gesta conl. Carth. III 141). - Die Zusammenhänge sind o. Kap. 5.3. ausführlich dargestellt worden.

73 Vgl. auch die Argumente Kriegbaums (AHP 28, 1990, 30-35), der zu Recht darauf hinweist, dass die erste Instanz eines Zivilprozesses der Prokonsul hätte sein müssen. Gleichwohl könnte man in diesem Fall auch eine Ausnahme annehmen (Girardet, Historia 41, 1992, 106). Kriegbaum hält es für möglich, dass die Klagen gar „keine prozessuale Relevanz" besaßen. Ebenso sei denkbar, dass zunächst die Katholiken die pars Maiorini beim Prokonsul angeklagt und daraufhin die Donatisten eine Klageerwiderung (libellus contradictoribus) abgefasst hätten. Aufgrund von Überforderung in der Sache hätte Anullinus die Sache dann an den Kaiser weitergeleitet. Gegen die letzte Einschätzung spricht jedoch die ausdrückliche Forderung der pars Maiorini um Weiterleitung in der relatio Anullini. Vgl. auch Girardet, Historia 41, 1992, 105-107.

74 Breuic. III 24; vgl. Monceaux IV, 201; Seeck, ZKG 10, 1889, 515 f.; Grasmück, Coercitio, 39.

75 Cap. conl. Carth. III 315-320, 402; breuic. III 24; vgl. o. Kap. 5.3.2. 
zessrahmen gesteckt worden war, als die Donatisten gefordert hatten. ${ }^{76}$ Die zweite relatio Anullini scheint in dieser Frage ebenfalls nicht weiterführend gewesen zu sein. Wenn aus diesem Dokument klar hervorgegangen wäre, dass Caecilianus zivilrechtlich verklagt worden war, dann wäre dies mit Sicherheit auf der Konferenz thematisiert worden. Die Donatisten hätten mit ganz anderen Argumenten die Unzuständigkeit der römischen Synode anprangern können, als sie es taten. Die zusätzlichen Dokumente konnten also die Kenntnisse der Parteien über den Inhalt der Anklageschrift nicht erweitern. Die Argumentationen erfolgten auf der gleichen Basis und mit den gleichen Intentionen wie zuvor.

Das Wort „Anklage“ im Zusammenhang mit der relatio Anullini wird folglich sowohl bei Augustinus als auch auf der Konferenz von 411 entweder nicht im juristischen Sinne oder mit einer eindeutigen, auf die Gegenwart bezogenen Argumentation, verwendet. Es lässt sich entsprechend kein sicherer Rückschluss über die tatsächliche Form der Anklage der pars Maiorini ziehen. Am wahrscheinlichsten bleibt die Möglichkeit, dass der libellus criminum eine Sammlung von Vorwürfen gegen Caecilianus enthielt, ohne dass die Einleitung eines Zivilprozesses intendiert war.

Für Augustinus war die Frage nach der juristischen Intention der Anklagen zu keinem Zeitpunkt entscheidend. Auch er kannte nicht den genauen Inhalt der donatistischen Eingaben und ging von einer wie auch immer gearteten Anklage Caecilians beim Kaiser aus, die er mit der relatio Anullini begründete. Für seine Argumentation betonte er, dass die Donatisten als erste und freiwillig den Kaiser um Unterstützung in einer kirchlichen Angelegenheit ersucht hätten. Seine historische Darstellung ist somit richtig im Hinblick auf den äußeren Vorgang des donatistischen Bittgesuchs. Es ist jedoch bemerkenswert, dass Augustinus niemals auf die vorangegangenen finanziellen Zuwendungen Konstantins an die katholische Kirche eingeht. Damit unterschlägt er den tatsächlichen Grund des donatistischen Protestes und rückt die persönlichen Vorwürfe gegen Caecilianus in den Vordergrund; er übergeht geflissentlich, dass die Katholiken bereits vom Kaiser bevorzugt wurden und mit ihm kooperierten, indem sie finanzielle Zuwendungen entgegennahmen. Dadurch gelingt es ihm, die Widersprüche in der donatistischen Argumentation noch deutlicher zu kennzeichnen. Es bleiben aber jene historischen Hintergründe blass, die Augustinus aufgrund seiner Quellenbasis ausführlicher hätte darstellen können.

Aus den wenigen Stellen, die Aussagen von Donatisten enthalten, geht nicht hervor, ob und in welcher Weise die Petition an den Kaiser in der donatistischen Tradition eine Rolle spielte, ob Hintergründe und Motive überliefert wurden. Sicher ist allerdings, dass es den Donatisten zur Zeit Augustins nicht gelegen 
kam, mit den Verbindungen ihrer Vorgänger zu Kaiser Konstantin konfrontiert zu werden. Es passte nicht zu ihrem grundsätzlichen Verständnis der verfolgten Kirche. Gleichwohl mussten die Donatisten in der konkreten Auseinandersetzung reagieren, vor allem auf Augustins Versuche, mit Verweis auf die relatio Anullini die aktuellen staatlichen Eingriffe gegen die Donatisten zu rechtfertigen. Allerdings versuchten sie erst gar nicht, den Inhalt dieses Dokuments in Zweifel zu ziehen, sondern sie verlagerten die Debatte und setzten einen anderen Akzent. Während Augustinus stets den Zusammenhang zwischen jener ersten Anklage gegen Caecilianus im Jahre 313 und den gegenwärtigen Auseinandersetzungen betonte, beurteilten die Donatisten die Ereignisse getrennt voneinander: Ihre traditio-Anklagen gegen Felix und Caecilianus vor weltlichen Instanzen betrachteten sie als eine notwendige Maßnahme zur Verteidigung der Kirche. Ihre Verfolgung durch die Katholiken und den Kaiser dagegen stellte aus donatistischer Perspektive einen abzulehnenden Angriff auf die wahre Kirche dar. Auf diese Weise konnten die Donatisten ausweichen, wenn Augustinus ihnen vorwarf, mit zweierlei Maß zu messen, indem sie einerseits selbst säkulare Hilfe in Anspruch nähmen, andererseits gegen die staatlichen Entscheidungen aufbegehrten. Ihre Ekklesiologie erlaubte es den Donatisten, nach diesem eklektizistischen Prinzip zu verfahren: Die Reinheit der Kirche konnte auch mit Hilfe weltlicher Mittel verteidigt werden, ohne dass damit eine generelle Anerkennung weltlicher Verfügungen einhergehen musste.

\section{Die Konzile von Rom und Arles}

Der Verlauf der Konzile in Rom und Arles spielte in der historischen Argumentation beider Seiten bis auf wenige Ausnahmen eine untergeordnete Rolle. Entscheidend waren lediglich die Urteile dieser Synoden in der causa Caeciliani. Die Weigerung der Donatisten, die in Rom und Arles gefällten Freisprüche Caecilians anzuerkennen, nahm Augustinus zum Anlass, scharf gegen das Schisma und die Verletzung der Kircheneinheit durch die Donatisten zu polemisieren. $^{77}$

Über den Verlauf des Konzils von Rom berichtet Augustinus ausführlicher nur in dem Brief an seine Gesprächspartner von Thubursicum (ep. 43), obwohl er über die Vorgänge sehr gut informiert war. Augustinus kannte nachweislich die gesamten Konzilsakten, darüber hinaus einen Brief Konstantins an den römischen Bischof Miltiades und den Bericht des Anullinus über die Entsendung

77 Ps. c. Don. 105-107; c. litt. Pet. II 205; III 29; c. ep. Parm I 10-11; II 30; cath. fr. 46; Cresc. III 44; IV 9; un. bapt. 28; c. Iul. 7; epp. 43. 4-5, 14-16; 53.5; 76.2; 88.3; 89.3; 93.13; 105.8; breuic. III 24, 31, 37; c. Don. 17, 19, 56; correct. 47; s. Denis 19.8; vgl. auch bapt. II 14 . 
der beiden Streitparteien nach Rom. Da heutzutage von den genannten Quellen nur noch der Brief an Miltiades existiert, kommt der Interpretation von $\mathrm{Au}-$ gustins ep. 43 eine besondere Bedeutung zu.

Neben Augustinus geben nur wenige Quellen Auskunft über die römische Synode: Optatus von Mileve erwähnt in einem kurzen Bericht den Versammlungsort und das Datum; zudem listet er die Namen der Teilnehmer auf. ${ }^{78}$ Einige Rückschlüsse lassen sich aus den erhaltenen Briefen Konstantins ziehen, die vor und nach der Synode geschrieben worden sind, und schließlich geben die Konferenzakten von 411 bzw. Augustins Breviculus zusätzliche Hinweise. ${ }^{79}$ Die Rekonstruktion der Ereignisse bleibt jedoch aufgrund der wenigen Anspielungen und Fragmente problematisch.

Das Konzil von Rom, das in der causa Caeciliani entscheiden sollte, fand Ende September und Anfang Oktober 313 auf dem Lateran statt. ${ }^{80}$ Außer dem römischen Bischof Miltiades waren noch 18 weitere Bischöfe als Richter anwesend, drei von Konstantin ausgewählte Bischöfe aus Gallien ${ }^{81}$ sowie 15 Bischöfe aus Italien, die Miltiades wohl eigenständig hinzugezogen hatte. Aus dem Brief Konstantins an Miltiades, der durch die Kirchengeschichte des Eusebius erhalten ist, gehen einige Motive und Erwartungen des Kaisers hervor ${ }^{82}$ Kon-

78 Opt. I 23-24.

79 Cap. conl. Carth. III 317-320, 402, 404; breuic. III 24, 31; vgl. c. Don. 56.

$80 \mathrm{Zu}$ diesem Konzil vgl. Girardet, Kaisergericht, 26-35; Historia 41, 1992, 104-116; Grasmück, Coercitio, 39-49; Instinsky, Bischofsstuhl, 74-82; Lietzmann, Geschichte III, 72-74; Maier I, Nr. 17, 151 f.; Monachino, AHP 2, 1964, 11-16; Roethe, Synoden, 51-81; Mühlsteiger, ZRG KA 85, 1999, 21-30. - Die wichtigsten Quellen versammelt von Soden, Nr. 13, 14-16. - Zur Identifizierung des Versammlungsortes vgl. Ernest Nash, Convenerunt in domum Faustae in Laterano S. Optati Milevitani I, 23, RQA 71, 1976, 1-21. - Zum Datum vgl. Roethe (Synoden, 64 f. mit Anm. 44), der zu Recht ausgehend von c. Don. 56 den 2. Oktober als letzten Tag der Synode mit Urteilsverkündung zählt. So auch Mandouze (PAC, 169 Anm. 38) und Mühlsteiger (aaO, 24); gegen die weit verbreitete Datierung 2.-4. Oktober etwa bei Monceaux (IV 22, 338) und Seeck, Geschichte III, 329 f.; vgl. auch Maier I, 151 Anm. 3.

81 Reticius von Autun, Maternus von Köln und Marinus von Arles. Alle drei Bischöfe sind auch Teilnehmer des Konzils von Arles ein Jahr später (vgl. Gaudemet, SC 241, 56-60). Roethe (Synoden, 55 f.) vermutet wohl zu Recht, dass diese Bischöfe Konstantin persönlich bekannt waren und sein Vertrauen besaßen.

82 Eus. HE X 5.18-21; Maier I, Nr. 16, 148-150; von Soden Nr. 12; vgl. Monceaux IV, 201; Seeck, ZKG 10, 1889, 512 f.; Dörries, Selbstzeugnis, 20 f.; Barnes, New Empire, 241; Corcoran, Empire, 160. - Das Datum des Briefes ist nicht überliefert; er dürfte jedoch in einem nicht allzu großen Abstand nach der relatio Anullini geschrieben worden sein, im Frühjahr oder Sommer 313 (von Trier aus). - Die Adresse nennt neben Miltiades einen gewissen Marcus als zweiten Adressaten. Eine Identifizierung dieser Person ist schwierig. Seeck (aaO, 512) vermutet einen Übertragungsfehler: der ursprüngliche zweite Adressat sei vermutlich Merocles, der Bischof von Mailand gewesen, der am Konzil in Rom teilnahm. Doch Augustinus überliefert ebenfalls den Namen Marcus (s. 
stantin lässt erkennen, dass ihm die Kirchenspaltung in der erst kürzlich erworbenen Provinz sehr große Sorgen bereitete; eine Ausweitung des Streites sollte unbedingt verhindert werden. Er informierte Miltiades über die Anklagen gegen Caecilianus und über seine Anordnungen, die drei gallischen Bischöfe sowie je zehn Bischöfe der beiden Parteien nach Rom zu beordern. Den Konzilsteilnehmern übersandte er Kopien der beiden donatistischen libelli, damit sie sich vorab ein Bild über die Sachlage machen konnten. Vom römischen Bischof forderte der Kaiser eine gewissenhafte Untersuchung und auf jeden Fall eine Beendigung des Schismas. Unter Beachtung des kirchlichen Rechts überließ er jedoch Miltiades die Entscheidung über die weitere Verfahrensweise. ${ }^{83}$

Konstantin verstand den Fall als innerkirchlichen Streit über die Rechtmäßigkeit des Bischofsamtes Caecilians. Er sah sich aber auch dem Gott der Christen gegenüber verpflichtet, derartige Streitigkeiten zu unterbinden und die rechte Ausübung des christlichen Kultes zu gewährleisten. ${ }^{84}$ Daher delegierte er die Aufgabe an ein kirchliches Gremium, das ihm geeignet schien, den Konflikt möglichst schnell, und zum Wohl von Staat und Kirche zu schlichten. ${ }^{85}$

Nachdem sich das Konzil offenbar ohne Schwierigkeiten konstituiert hatte und die beiden Parteien in Rom eingetroffen waren, begannen die Verhandlungen. Im Breviculus der Konferenz von 411 gibt Augustinus auf Grundlage der römischen Akten ein kurzes Resümee über den Verlauf des ersten Verhandlungstages. Demnach hätten die Ankläger Caecilians verweigert, zu den Anklagen Stellung zu nehmen. Außerdem sei Donatus von Casae Nigrae in Anwesenheit überführt worden, in Karthago ein Schisma verursacht zu haben, zu der Zeit, als Caecilianus noch Diakon war. ${ }^{86}$ Optatus von Mileve spricht ebenfalls von dem „Eingeständnis“ der donatistischen Zeugen, nichts gegen

Denis 19.8). Möglicherweise handelte es sich um einen Diakon (so auch Kraft, Entwicklung, 168 f.); vgl. Maier I, 149 Anm. 4 und Pietri, PIC 2, 1389, s. v. Marcus 1.

83 Vgl. Roethe, Synoden, $59 \mathrm{f}$.

$84 \mathrm{Zu}$ diesem Motiv s. Konstantins Brief an den Vikar Aelafius, Opt. App. III (hier: ed. Ziwsa, S. 206 Z. 9 ff.); Maier I, Nr. 18, 153-158; von Soden Nr. 14. Der Brief ist nur in einer schlechten Handschrift überliefert und der Text teilweise unverständlich. Die Authentizität wurde häufig angezweifelt. Zur Problematik vgl. Kraft, Entwicklung, 172 183; Grasmück, Coercitio, 51 f. Anm. 226; Dörries, Selbstzeugnis, 21-24; Monceaux IV, 202; Seeck, ZKG 30, 1909, 200-207.

85 Es ist unergiebig, darüber zu spekulieren, ob und in welcher Weise Ossius von Cordova den Kaiser gegen die Donatisten beeinflusst haben könnte. So u.a. bei Maier I, 148 Anm. 1; Girardet, Kaisergericht, 29 f.; Instinsky, Bischofsstuhl, 72; Seeck, ZKG 10, 1889, 513. - Vgl. u. Kap. 7.4.2.2.

86 Breuic. III 24: atque inde ex ordine legi coepit etiam episcopale iudicium Miltiadis Romani episcopi et aliorum cum illo Gallorum et Italorum episcoporum in eadem urbe Romae factam, cuius iudicii prima parte, id est gestis primi diei recitatis, ubi accusatores Caeciliani qui missi fuerant negauerunt se habere quod in eum dicerent, ubi etiam Donatus a Casis Nigris in praesenti conuictus est adhuc diacono Caeciliano schisma fecisse Carthagine [...]. 
Caecilianus in der Hand zu haben. Donatus dagegen habe „gestanden“, wiedergetauft und gefallenen Bischöfen die Hand aufgelegt zu haben. ${ }^{87}$

Diese Aussagen lassen erkennen, dass Donatus zum Auftakt des ersten Verhandlungstages die Rolle eines Anklägers gegen Caecilianus übernommen hatte und das Plädoyer der Anklage hielt. Darin erläuterte er dem Gericht die Situation der Kirche in Karthago und Afrika. Er legte dar, dass seiner Ansicht nach Traditoren als Bischöfe nicht ohne Buße in ihrem Amt verbleiben könnten und deshalb Wiedertaufen praktiziert worden seien. Ausgehend von dieser Grundlage dürfte Donatus die bekannten Beschwerden gegen Caecilianus (vor allem die Weihe durch Traditoren) vorgebracht haben. ${ }^{88}$ Im Anschluss daran sollten weitere Zeugen die Anklagen bestätigen, was laut Auskunft der Protokolle aber nicht geschah.

Zur Feststellung weiterer Einzelheiten führen die Aussagen Augustins in ep. 43 weiter. Dort schreibt er über die Verhandlungen in Rom:

„Seht, mit welcher Sorge um die Bewahrung und Wiederherstellung von Frieden und Einheit alles besprochen wurde, auf welche Weise die Person der Ankläger untersucht wurde und aufgrund welcher Mängel etliche von ihnen zurückgewiesen wurden; und dass aufgrund der Aussagen der Anwesenden mit Gewissheit festgestellt wurde, dass [die Ankläger] nichts hatten, was sie gegen Caecilianus sagen konnten, sondern dass sie die ganze Sache den Anhängern der pars Maiorini - das heißt einem aufrührerischen und vom Frieden der Kirche entfremdeten Pöbel zuschieben wollten, damit nämlich Caecilianus von dieser tobenden Menge angeklagt werden sollte. Sie, so glaubten sie, werde allein mit tumultartigem Geschrei, ohne den Beweis von Dokumenten und ohne eine Untersuchung der Wahrheit, die Herzen der Richter zu ihren Gunsten verdrehen können, [...]." ${ }^{89}$

Es folgen eine Polemik gegen das Konzil von Karthago und ein Vergleich der Urteile von Secundus und Miltiades. In Rom, so betont Augustinus nochmals, hätten die Richter nicht zugelassen, dass Caecilianus durch die anonyme Masse der pars Maiorini anstatt durch einen ordentlichen Kläger angeklagt werde.

Diese Aussagen Augustins beziehen sich zwar eindeutig auf die vorliegenden Konzilsakten von Rom, jedoch erscheint die Darstellung offensichtlich übertrieben. Augustins primäres Argumentationsziel in diesem Brief war es, die

87 Opt. I 23: [...] quod confessus sit se rebaptizasse et episcopis lapsis manum inposuisse, quod ab ecclesia alienum est.

88 Vgl. Roethe, Synoden, 66.

89 Ep. 43.14: uidete, quanta cura pacis atque unitatis conseruandae uel restituendae cuncta discussa sint, quem ad modum accusatorum persona tractata et quorundam eorum quibus maculis inprobata sit praesentiumque uocibus liquido constiterit nihil eos habuisse, quod in Caecilianum dicerent, sed totam causam in plebem de parte Maiorini, hoc est seditiosam et ab ecclesiae pace alienatam multitudinem transferre uoluisse, ut ab ea uidelicet turba Caecilianus accusaretur, quam solis tumultuosis clamoribus nulla documentorum adtestatione, nullo ueritatis examine ad suam uoluntatem animos iudicum detorquere posse arbitrabantur, [...]. 
Legitimität der europäischen Urteile zu bekräftigen. Er stellt die sorgfältige Untersuchung in Rom dem vom Pöbel geforderten Urteil in Karthago gegenüber. Dies spiegelt sich in seiner Auslegung wider, die zugespitzt lautet: Die Donatisten hätten auf die Fragen des Gerichts nicht geantwortet und anstelle einer sorgfältigen Untersuchung wiederum ein tumultartiges Verfahren haben wollen. $^{90}$

Die historische Grundlage für Augustins Interpretation zeichnet sich zwischen den Zeilen ab: Offensichtlich wurden gegen Donatus und seine Mitstreiter Vorwürfe erhoben, die überprüft und als wahr angesehen wurden. Sie selbst wurden zu Angeklagten, wie es auch das spätere Urteil verdeutlichte. Jene Aussage, die Augustinus mit „der pars Maiorini zuschieben“ bezeichnet, bezieht sich auf jenes donatistische Argument, das genauso noch im Jahre 411 vorgetragen wurde: Die Donatisten verwiesen auf das in ihren Augen kirchenrechtlich bindende Urteil des Konzils von Karthago und forderten die Anerkennung dieser Entscheidung anstelle einer neuen Untersuchung der Anklagen gegen Caecilianus. ${ }^{91}$ Die römischen Richter lehnten diese Forderung als Grundlage des Prozesses ab und erwarteten von Donatus einen Vortrag der Beschuldigungen gegen Caecilianus und Zeugen, die dies im Einzelnen bestätigen konnten. ${ }^{92}$ Dieses wiederum verweigerte Donatus, eine Entscheidung, die zu den späteren Formulierungen beitrug, die Zeugen hätten gestanden, nichts gegen Caecilianus sagen zu können.

Für die Verhandlung des ersten Tages lässt sich also zusammenfassen, dass Donatus in seinem Plädoyer zunächst das Verständnis seiner Kirche in der Häretikertaufe darlegte, sodann die Gründe für die Aberkennung der Weihe Cecilians nannte und schließlich die Unzuständigkeit des bischöflichen Gerichts mit der bereits gefällten Entscheidung von Karthago begründete. Allen weiteren Forderungen verweigerte er sich.

Die Weigerung der pars Donati, das Gericht anzuerkennen, setzte sich im weiteren Prozessverlauf fort. Am zweiten und dritten Verhandlungstag, so Augustins Angabe im Breviculus, seien Donatus und die anderen Ankläger nicht mehr erschienen, obwohl sie zuvor noch versprochen hätten, andere Zeugen vorzuführen. ${ }^{93}$ In ep. 43 erwähnt Augustinus die Vermutung, Donatus habe die Zeugen wegbringen lassen und so an der Aussage gehindert. Augustinus deutet dieses Verhalten in seinem Sinne aus: Donatus sei nicht mehr erschienen, da er wohl einer Verurteilung entgehen wollte, doch sei seine Schuld bereits in seiner Gegenwart festgestellt worden. Dies entsprach Augustins po-

90 Zur historischen Argumentation in ep. 43 vgl. o. Kap. 4.2.1.

91 Auch der Kontext in ep. 43.14-16 zeigt deutlich, dass das Konzil des Secundus ein Hauptargument des Donatus in Rom war.

92 Vgl. Grasmück, Coercitio, 44 Anm. 177; Roethe, Synoden, 70.

93 Breuic. III 24. 
lemischen Ansatz, die Ungültigkeit von Caecilians Verurteilung in Abwesenheit zu unterstreichen. ${ }^{94}$ Tatsächlich beabsichtigte Donatus wohl gezielt, die Handlungsfähigkeit des Gerichtes zum Erliegen zu bringen, indem er seine Zeugen nicht vorführte und selbst nicht mehr erschien. Wahrscheinlich spekulierte er zu diesem Zeitpunkt bereits mit einer erneuten Beschwerde beim Kaiser. ${ }^{95}$

Während die Bischöfe, nunmehr in Abwesenheit der Klägerpartei, über die causa Caeciliani berieten, wurde nochmals in schriftlicher Form eine Klageschrift gegen Caecilianus eingereicht, die Anlass für erneute Diskussionen gab. Leider überliefert Augustinus weder Genaueres über den Inhalt noch über die Verfasser dieser Anklageschrift. ${ }^{96}$ Es scheint aber, dass nicht Donatus selbst, sondern eine Gruppe seiner Anhänger mit diesem libellus einen erneuten Versuch unternahm, ihr Anliegen zu verdeutlichen und die Anklagen gegen Caecilianus zu begründen. Möglicherweise handelte diese Gruppe in Dissens zu Donatus und seiner Strategie, das Gericht nicht anzuerkennen. Wie auch immer, die enthaltenen Anklagen wurden ebenso verworfen wie zuvor die Ausführungen des Donatus. ${ }^{97}$

Am dritten Tag wurden die Urteile gefällt. Caecilianus wurde durch die Urteilssprüche aller 19 Bischöfe freigesprochen, mit der Begründung, es seien keine Anklagen vorgetragen worden. Donatus dagegen wurde in Abwesenheit als Urheber des Schismas verurteilt und damit exkommuniziert. Optatus zitiert das Schlussurteil des Miltiades:

„Da es feststeht, dass Caecilianus von denen, die mit Donatus gekommen sind, ihrer eigenen Erklärung gemäß nicht angeklagt wird, und ebenfalls feststeht, dass

94 Vgl. o. Kap. 4.2.1.

95 Von vorsätzlichen Obstruktionen gehen auch Roethe (Synoden, 70), Girardet (Kaisergericht, 35) und Mühlsteiger (ZRG KA 85, 1999, 28) aus. Roethe (aaO, 70-72) und ihm folgend Girardet (aaO, $35 \mathrm{f}$.) glauben, die Donatisten wollten eine Verlagerung des Prozesses nach Karthago bzw. ein erneutes Urteil einer afrikanischen Synode erreichen. Gegen diese Annahme spricht jedoch der Kontext von ep. 43.14-15 (s.o. Kap. 4.2.1): Schon die Formulierung pars Maiorini weist darauf, dass Augustinus von dem bereits gefällten Urteil in Karthago spricht und nicht von einem neuen Prozess in Karthago.

96 Ep. 43.15: accessit aliud, ut quibusdam aduersus Caecilianum denuntiationis libellus daretur. Post quod factum quem ad modum sit rursus agitata cognitio et quae personae illum libellum dederint quoque modo nihil Caecilianum probari potuerit, quid dicam, cum et audieritis omnia et, quotiens uolueritis, legere possitis? - Die Formulierung lässt keinen Zweifel daran, dass die römischen Akten über diesen Vorgang Auskunft gaben.

97 Anders die Überlegungen Girardets (Kaisergericht, 36 f.), der ausgehend von seiner Hypothese, der erste libellus habe zivilrechtliche Anklagen beinhaltet, nunmehr von kirchlichen Anklagen ausgeht, die taktisch geschickt eingesetzt worden seien. Roethe (Synoden, 73 f. mit Anm. 78) und Grasmück (Coercitio, 43) halten es für möglich, dass der libellus criminum Caeciliani eingereicht wurde, da er zuvor noch nicht verlesen worden sei. 
er in keiner Weise von Donatus überführt worden ist, urteile ich, dass er verdientermaßen unangetastet in der kirchlichen Gemeinschaft verbleiben soll.“"98

Das Urteil fiel eindeutig auf Grundlage der theologisch-dogmatischen Vorentscheidung, dass eine Wiedertaufe von lapsi nicht notwendig sei. Indem Donatus vor der Synode ein Bekenntnis zur Wiedertaufe abgelegt hatte, hatte er sich in den Augen der Richter selbst überführt und galt als Verursacher des Schismas. ${ }^{99}$ An der Wahl und Weihe Caecilians war folglich nichts auszusetzen, entsprechende Einreden des Donatus wurden ebenso zurückgewiesen wie das Urteil des Konzils von Karthago. Caecilianus wurde als rechtmäßiger Bischof Karthagos bestätigt. Die Bischöfe in Rom formulierten auch Regelungen für die Wiederherstellung der Kircheneinheit in Afrika. Allein Donatus sollte aus der Kirche ausgeschlossen bleiben. Alle anderen donatistischen Bischöfe sollten Gemeinschaftsbriefe erhalten und ihre Gemeinden behalten, sofern sie früher geweiht worden waren als ihre katholischen Kollegen. Die Übrigen sollten andere Gemeinden übernehmen. ${ }^{100}$

Der Verlauf und das Urteil verdeutlichen sowohl die Parallelen als auch die Ambivalenz von weltlicher und kirchlicher Gerichtsbarkeit. Auf der einen Seite entsprach der Prozess vor dem bischöflichen Gremium einer Synode mit der kirchenrechtlich relevanten Exkommunizierung des Donatus und der Anerkennung Caecilians. Auf der anderen Seite entsprach der Prozess einem zivilrechtlichen Kognitionsverfahren. Miltiades übernahm dabei formal die Funktion eines Einzelrichters, seine Kollegen bildeten das beratende consilium. Am Ende der Verhandlungen gaben alle 19 Mitglieder ihre Sentenzen ab, zuletzt

98 Opt. I 24: cum constiterit Caecilianum ab his, qui cum Donato uenerunt, iuxta professionem suam non accusari nec a Donato conuictum esse in aliqua parte constiterit, suae communioni ecclesiasticae integro statu retinendum merito esse censeo. - Vgl. breuic. III 31; ep. 43.16.

99 Die Aussage in breuic. III 24, Donatus habe in Karthago ein Schisma verursacht, bevor Caecilianus Bischof geworden sei, kann daher nur bedeuten, dass Donatus bereits nach Beendigung der Verfolgung in Karthago wirkte und die Taufe von Gefallenen praktizierte. Es ist dagegen auszuschließen (vgl. Mandouze, PAC, $293 \mathrm{f}$.), dass Donatus unter den Gegnern Caecilians zu Beginn der Auseinandersetzung bereits eine herausragende Stellung einnahm. Ansonsten wäre sein Name sicher schon vor dem Konzil in Rom genannt worden. Vgl. auch Roethe, Synoden, 74.

100 Ep. 43.16. - Trotz der rhetorischen Überhöhung des ,vorausschauenden und friedfertigen“ Urteils des Miltiades, dürften Augustins Informationen über diese Regelungen den Akten entnommen sein. Sie entsprechen zudem den Anweisungen Konstantins, ein schnelles Ende der Spaltung herbeizuführen. - Für seine Darstellung des Konzils von Rom übernimmt Grasmück (Coercitio, 41-45) völlig unkritisch die Aussagen Augustins aus ep. 43, wodurch ein verzerrtes Bild von den Absichten der pars Donati in Rom entsteht. 
Miltiades, durch dessen Urteil die Entscheidung Rechtsgültigkeit erhielt (iudicium Miltiadis). ${ }^{101}$

Das gesamte Verfahren, die Beauftragung durch den Kaiser, die Durchführung durch die Bischöfe und schließlich die Anerkennung des Ergebnisses durch den Kaiser, war ein Novum in der Geschichte der Kirche. Insofern war das Konzil von Rom Auftakt und Modell für nachfolgende Konzile und kirchenpolitische Entscheidungen in ihrer Verquickung von Staat und Kirche. ${ }^{102}$

Es stellt sich die Frage, warum Augustinus so wenig aus den Akten des Konzils zitiert, obwohl ihm die Dokumente bekannt waren. Es ist kaum anzunehmen, dass er etwas über bestimmte Vorgänge verschweigen wollte, dann hätte er schließlich ganz auf das Dokument verzichtet und nicht seinen Gegnern daraus vorlesen lassen. Vielmehr konzentrierte er sich aufgrund der ekklesiologischen Perspektive in seiner Argumentation auf das Urteil des Miltiades. Die Entscheidung der europäischen Bischöfe wollte er als Entscheidung der $\mathrm{Ca}$ tholica vermitteln. Ganz im Sinne Cyprians stellte er die Einheit der Kirche über die unterschiedlichen theologischen Ansichten. Die Donatisten sollten am römischen Urteil sehen, dass sie sich von der kirchlichen Einheit und damit von der Wahrheit abgetrennt hatten und nicht umgekehrt. Die einzigen bekannten Ausnahmen von dieser Argumentation sind die Ausführungen über das römische Konzil in ep. 43 und während der Konferenz von 411. In beiden Fällen verfolgte Augustinus jedoch bestimmte Ziele: In dem Brief ging es um die Kontrastierung des Prozesses in Rom mit den Vorgängen in Karthago und der Absetzung Caecilians. Auf der Konferenz sollte durch die Verlesung der Protokolle von Rom die Unanfechtbarkeit des iudicium Miltiadis bekräftigt werden. ${ }^{103}$

Für die Donatisten bedeuteten die Akten des Konzils lediglich eine Bestätigung ihrer Auffassung über die Kirche der Traditoren. In Karthago 411 deklarierten die Donatisten die römische Synode als ungültig, da sie für die afrikanische Angelegenheit nicht zuständig gewesen und das Urteil durch den

101 Dazu ausführlich Girardet, Kaisergericht, 27-35; vgl. Instinsky (Bischofsstuhl, 77 f.) und Roethe (Synoden, 74-79). Girardet postuliert allerdings, dass letztlich der Kaiser als iudex, nachdem er über die Entscheidung in Rom informiert worden sei, das eigentliche Urteil gesprochen habe. Gleichwohl, so Girardet (aaO, 33), war Konstantin gewillt, ,seinem consilium aus Bischöfen eine höhere Autorität zuzuerkennen als einem Sachverständigenrat." Diese umständliche Argumentation ist nicht überzeugend. Die Reaktionen Konstantins nach den bischöflichen Entscheidungen (vgl. Opt. App. III und V) zeigen deutlich, dass er den Bischöfen das Urteil für diese kirchliche Angelegenheit überlassen hatte und zunächst nicht selbst urteilen wollte (vgl. Gaudemet, Église, 457). Nochmals anders beurteilen Grasmück (Coercitio, 45-48) und Mühlsteiger (ZRG KA 85, 1999, 25) den Prozess. Sie gehen davon aus, dass Miltiades nicht als Vorsitzender, sondern als primus inter pares in einem bischöflichen Kollegialgericht geurteilt habe.

102 Roethe, Synoden, $53 \mathrm{f}$.

103 Vgl. o. Kap. 4.2.1. und 5.3.2. 
Traditor Miltiades gesprochen worden sei. Dabei betonten sie, dass aus diesem Grund bereits ihre Vorfahren das Urteil abgelehnt hätten. ${ }^{104}$ Doch erweist sich diese Aussage als sehr gewagt, wenn man den weiteren Verlauf der Ereignisse betrachtet, wie er sich aus den Quellen ergibt. Denn die traditio des Miltiades spielte bei den donatistischen Appellen gegen die Entscheidung von Rom ganz offensichtlich keine Rolle. ${ }^{105}$ In donatistischen Quellen vor der Konferenz von 411 fehlen entsprechende Hinweise. Bei Cresconius und Parmenianus findet sich lediglich der Vorwurf, die Bischöfe seien bestochen worden. Damit verwendeten beide einen üblichen Topos zur Diskreditierung eines Urteils. ${ }^{106}$ Demzufolge ist es wahrscheinlich, dass die Ablehnung des römischen Urteils aufgrund von traditio-Vorwürfen gegen Miltiades entgegen der donatistischen Behauptungen erst zur Zeit Augustins aufkam und sich verfestigte. ${ }^{107}$

Über das Konzil von Arles waren die Kenntnisse bei Donatisten und Katholiken zur Zeit Augustins gering. Im Gegensatz zur römischen Synode waren weder Akten bekannt noch jene Briefe Konstantins, die im Zusammenhang mit dem Konzil von Arles geschrieben wurden und heute erhalten sind. Da auch Optatus von Mileve nichts über Arles berichtet, war die einzige Quelle offenbar der Brief Konstantins an den Vikar Eumalius vom November 316, den Augustinus für die Auseinandersetzung heranzog. Diesem Schreiben entnahm er Informationen über die Appelle der Donatisten bei Konstantin, die Einberufung der Synode von Arles und den erneuten Freispruch Caecilians durch die Bischöfe. ${ }^{108}$ Für seine Argumentation verarbeitete Augustinus diese wenigen Angaben, indem er das zweifache Urteil der Bischöfe für Caecilianus dem einfachen Urteil gegen Caecilianus in Karthago entgegenstellte. Die Entscheidung von Arles wie das spätere Urteil des Kaisers sollten die eindeutige Klärung des Streites demonstrieren..$^{109}$

Zur genaueren Klärung der Umstände stehen heute einige weitere Quellen zur Verfügung: Die Briefe Konstantins an den Vikar Aelafius ${ }^{110}$ und an den

104 Cap. conl. Carth. III 471; vgl. breuic. III 34; un. bapt. 28; vgl. o. Kap. 5.3.2.

105 Vgl. u. S. 299 - Auch Augustinus macht deutlich, dass er die Anschuldigungen gegen Miltiades für haltlos erachtet (un. bapt. 28).

106 Cresc. III 67; c. ep. Parm. I 11; vgl. o. Kap. 3.4.1; u. Kap. 7.4.2.2.

107 Zur traditio des Miltiades vgl. auch o. Kap. 6.1.4.

108 Breuic. III 37. - Augustins Gegner Parmenianus erwähnte die Synode von Arles in seinen Schriften (vgl. c. ep. Parm. I 11). Wie ausführlich er darüber berichtete, lässt sich nicht sagen; möglicherweise zog aber Augustinus Informationen zu Arles aus den Aussagen Parmenians. - Maier (I, S. 16 mit Anm. 28) meint, Augustinus habe seine Kenntnisse über das Konzil von Arles nicht aus den Briefen Konstantins. Dabei übersieht er, dass Augustinus schon in frühen Briefen das Schreiben an Eumalius explizit heranzieht.

109 Vgl. die Stellenangaben o. Anm. 77.

110 Opt. App. III; zum Text s. o. Anm. 84. 
Bischof Chrestus von Syrakus ${ }^{111}$ geben Auskunft über die Beschwerden der Donatisten nach der Entscheidung von Rom und über die Einberufung der Synode nach Arles. Die Konzilsakten selbst sind nur noch fragmentarisch erhalten. So ist im Anhang des Optatus ein Schreiben der versammelten Bischöfe an Silvester von Rom überliefert. ${ }^{112}$ Darüber hinaus existieren noch einige Beschlüsse sowie eine Unterschriftenliste aller Teilnehmer. ${ }^{113}$

Aus den vorhandenen Quellen ergibt sich folgendes Bild: Nachdem die Synode in Rom ihr Urteil gefällt hatte, wurden Konstantin die Ergebnisse mitgeteilt. Vermutlich waren es die von ihm bestimmen gallischen Bischöfe, die zu ihm nach Trier kamen, die Akten am Hof übergaben und Bericht erstatteten, in dem sie die rechtmäßige und gründliche Durchführung des Prozesses in Rom hervorhoben. ${ }^{114}$ Die Donatisten indessen ließen das Urteil von Rom nicht lange auf sich beruhen. Wahrscheinlich noch Ende des Jahres 313 reichten sie beim Kaiser Beschwerde ein und forderten, Konstantin möge, wie ursprünglich erbeten, sich selbst mit dem Fall beschäftigen. Gegen das Konzil von Rom wandten sie ein, es hätten nur wenige Bischöfe ihr Urteil abgegeben, und es sei ohne vollständige Prüfung aller Fragen $\mathrm{zu}$ schnell geurteilt worden. Sie behaupteten zudem, die Richter hätten sich eingeschlossen und dann nach ihrem Gutdünken geurteilt. Caecilianus aber, darauf insistierten die Donatisten, sei des Bischofsamtes unwürdig. ${ }^{115}$ Zum einen argumentierten die Donatisten also kirchenrechtlich, indem sie wie zuvor die Absetzung Caecilians durch das afrikanische Konzil als Grundlage betrachteten, zum anderen kehrten sie ihre eigenen Obstruktionen gegen das Gericht, indem sie ihre Weigerungen auszusagen als nicht erfolgte Anhörung interpretierten. ${ }^{116}$

111 Eus. HE X 5.21-24; Maier I, Nr. 19, 158-160; von Soden, Nr. 15; Dörries, Selbstzeugnis, 24-28; Kraft, Entwicklung, 169-172; vgl. Monceaux IV, 202; Grasmück, Coercitio, $56 \mathrm{f}$.

112 Opt. App. IV; Gaudemet, SC 241, 40-45; Maier I, Nr. 20 A, 160-165; von Soden, Nr. 16; vgl. Monceaux IV, 345-348; Grasmück, Coercitio, 60-62; Mühlsteiger, ZRG KA 85, 1999, 36-38.

113 Zusammengestellt bei Gaudemet, SC 241, 46-67.

114 Konstantins Brief an Aelafius (Opt. App. III, von Soden, Nr. 14, Z. 13 ff.); vgl. Roethe, Synoden, $57 \mathrm{f}$.

115 Opt. App. III (von Soden, Nr. 14, Z. 33-35): nam id quoque te scire conuenit, quod ex hisdem uenerunt, adserentes, quod minus dignus idem Caecilianus cultu sanctissimae religionis habeatur, [...].

116 Brief an Aelafius (Opt. App. III); Brief an Chrestus (Eus. HE X 5.22); vgl. ep. 88.3. Vgl. Girardet, Historia 41, 1992, 110-113. Girardet beurteilt die Einwände der Donatisten in juristischer Hinsicht als Versuch, eine Nichtigkeitserklärung des Urteils herbeizuführen. Da das Urteil von Rom bereits ein Kaiserurteil gewesen sei, sei es inappellabel gewesen; daher dürfe man nicht von einer Appellation der Donatisten sprechen Gegen diese Einschätzung spricht jedoch die Feststellung, dass Konstantin sich gerade nicht als oberster Richter eines bischöflichen consilium verstanden hatte, sondern zunächst den Fall an die Kirche delegierte. Von dieser Grundlage ausgehend lässt sich 
Konstantin reagierte zwar mit deutlicher Missbilligung auf die erneute Klage der Donatisten, entschied aber dennoch, den Fall nochmals untersuchen zu lassen. Wahrscheinlich hatte er den Donatisten nach dem Urteil von Rom untersagt, nach Afrika zurückzukehren. ${ }^{117}$ Möglicherweise hatte er bereits zu diesem Zeitpunkt von neuen Unruhen zwischen den Kirchen in Afrika gehört und suchte nun nach weiteren Lösungswegen. ${ }^{118}$ Nachdem entschieden worden war, auch Caecilianus die Rückkehr nach Karthago zu untersagen, setzte Konstantin eine Untersuchungskommission ein, die in Afrika vor Ort die Lage klären sollte. Die beiden beauftragten Bischöfe bestätigten zwar das Urteil des Miltiades, jedoch beugten sich die Donatisten dieser Entscheidung ebenso wenig wie zuvor. ${ }^{119}$

Nach dem Scheitern dieses Versuchs entschied sich Konstantin im Frühjahr 314, erneut ein Bischofskonzil mit der Untersuchung der causa Caeciliani zu beauftragen. Mit Berücksichtigung der donatistischen Einwände sollte diesmal eine möglichst große Anzahl von Bischöfen beteiligt sein. Alle Beschwerden sollten gründlich angehört werden, um eine Lösung zur Wiederherstellung der Kircheneinheit zu finden. Offensichtlich erwartete Konstantin, dass ein solcher Prozess ein unanfechtbares Urteil hervorbringen werde, dem sich die beiden Parteien beugen würden. Er selbst verordnete den Bischöfen aus seinem Herrschaftsgebiet, zum 1. August 314 nach Arles zu kommen. ${ }^{120}$ Zum festgesetzten Termin traten die geladenen Bischöfe und Diakone in Arles unter

auch von einem Appell sprechen. Untechnisch verwendet Augustinus auf der Basis seiner Quelle (Konstantin an Eumalius) das Wort appellatio (vgl. s. Denis 19.8) Vgl. auch Grasmück (Coercitio, $48 \mathrm{f}$.), der von der falschen Annahme ausgeht, es habe ein „Appellationsgerichtsverfahren“" stattgefunden.

117 Konstantin an Aelafius (Opt. App. III). Aufgrund der problematischen Textüberlieferung ist die Stelle mit Unsicherheit behaftet. Turner (JThS 27, 1926, 286) spricht sich dafür aus, statt prohiberent, d.h., die Bischöfe in Rom untersagten die Rückkehr, prohiberem zu lesen, d.h. der Kaiser selbst verbot die Rückkehr, was wesentlich wahrscheinlicher ist. Ebenso Dörries, Selbstzeugnis, 21 Anm. 3; Kraft, Entwicklung, $180 \mathrm{f}$. Siehe auch Maier I, 155 Anm. 11; Monceaux IV, 343; von Soden, 17 Anm. 1; Grasmück, 52 f. Anm. 231; Kriegbaum, AHP 28, 1990, 57.

118 Über diese Unruhen in Afrika berichtete Aelafius in einem nicht erhaltenen Schreiben an den Kaiser bzw. einem gewissen Nicasius (dessen Identifizierung ist unklar, vgl. Kraft, Entwicklung, 181; Mandouze, PAC, 789, s. v. Nicasius 1; Corcoran, Empire, 168 Anm. 217). Vgl. die Antwort Konstantins, Opt. App. III.

119 Opt. I 26. Zur chronologischen Einordnung und zur Problematik der „Brescia-Episode“ bei Optatus vgl. u. Kap. 7.4.2.1.

120 Vgl. die Anordnungen in dem Brief Konstantins an Chrestus von Syrakus (Eus. HE X 5.21-24). - Nach Auskunft der Unterschriftenliste (vgl. SC 241, 56-63) waren aus allen westlichen Diözesen (Italien, Gallien, Viennensis, Britannien, Pannonien, Spanien und Afrika) Vertreter in Arles. Die genaue Zahl der Teilnehmer ist jedoch unsicher, da die Quellenmanuskripte unterschiedlich Auskunft geben. Vgl. Gaudemet, SC 241, 36. Zu Chrestus (Crescens) vgl. Pietri, PIC 1, 431 f., s. v. Chrestus 1. 
Vorsitz des dortigen Bischofs Marinus zusammen Die beiden Streitparteien waren wiederum mit Delegationen ihrer Anhänger vertreten. ${ }^{121}$

Über den Verlauf der Verhandlungen ist wenig bekannt. Aus dem Synodalbrief an den römischen Bischof Silvester, der zu Beginn des Jahres die Nachfolge des verstorbenen Miltiades angetreten hatte, geht hervor, dass die Bischöfe erneut den Ausführungen der Donatisten nicht folgten, ein klares Urteil zu Gunsten Caecilians sprachen und dessen Ankläger als Feinde von Glauben und Tradition verurteilten. ${ }^{122}$ Zudem wurden die theologischen und ekklesiologischen Grundfragen des Schismas debattiert. Die Wiedertaufe von Häretikern wurde abgelehnt; stattdessen sollten einem bereits getauften Häretiker die Hände aufgelegt werden. ${ }^{123}$ Hinsichtlich der Traditoren wurde beschlossen, durch Dokumente der traditio überführte Kleriker aus ihrem Amt zu entlassen. Verleumdungen und falschen Anklagen sollte dagegen keinesfalls Gehör geschenkt werden. Gegen das donatistische Verständnis bekräftigten die Bischöfe, dass von Traditoren vollzogene Weihen ihre Gültigkeit nicht verlieren sollten. ${ }^{124}$ Auf dieser Grundlage blieb den Gegnern Caecilians notwendigerweise ein Erfolg verwehrt.

121 Zum Konzil von Arles vgl. Congar, BA 28, 726 f.; Girardet, Kaisergericht, 37-39; Grasmück, Coercitio, 51-65; Kraft, Entwicklung, 37-41; Lamirande, BA 32, 732 f.; Lietzmann, Geschichte III, 74-76; Maier I, Nr. 20, 160-167; Mandouze IV, 343-349; Monachino, AHP 2, 1964, 16-21; Mühlsteiger, ZRG KA 85, 1999, 30-39; von Soden, Nr. 17. - Unter anderem Seeck (ZKG 10, 1889, 508-510; Regesten, 162) und in neuester Zeit wieder Barnes (New Empire, 72; Constantine, 58) vertreten aufgrund einer allgemeinen Notiz des Eusebius zum Verhältnis Konstantins zur Kirche (VC I 44) die Ansicht, dass Konstantin persönlich am Konzil in Arles teilgenommen habe. Gegen diese Interpretation sprechen jedoch die zur Verfügung stehenden Quellen zur Synode von Arles. - Zur Bedeutung von Arles als Residenzstadt Konstantins vgl. Grünewald, Constantinus, 35-38.

122 Opt. App. IV. Maier I, Nr. 20, 161-165; Gaudemet, SC 241, 40-45; von Soden, Nr. 16. Während Seeck (ZKG 10, 1889, 542-545) von der Echtheit des Schreibens ausging, hält Kraft (Entwicklung, 38-41) den Brief für ein literarisches Produkt: „Es handelt sich um einen für den historischen Bericht komponierten Brief.“ Der Sachverstand lasse aber auf einen Konzilsteilnehmer als Verfasser schließen. - Zu Bischof Silvester: Pietri, PIC 2, 2971, s. v. Silvester 1. Aus welchen Gründen Silvester der Synode in Arles ferngeblieben war, lässt sich nicht beantworten. Vgl. die Diskussion bei Monachino, AHP 2, 1964, 17 f.; Grasmück, Coercitio, 60 f.; Mühlsteiger, ZRG KA 85, 35.

123 Canon VIII (bzw. IX); Opt. App. IV; vgl. von Soden, Nr. 16 Z. 33 ff.; Gaudemet, SC 241, S. 44 u. 50.

124 Canon XIII (bzw. XIV); von Soden Nr. 17; Gaudemet, SC 241, 52-54: de his qui scripturas sanctas tradidisse dicuntur uel uasa dominica uel nomina fratrum suorum, placuit nobis ut quicumque eorum ex actis publicis fuerit detectus, non uerbis nudis, ab ordine clerici amoueatur. nam si idem aliquos ordinasse fuerint depraehensi et de his quos ordinauerunt ratio subsistit, non illis obsit ordinatio. et quoniam multi sunt qui contra ecclesiam repugnare uidentur et per testes redemptos putant se ad accusationem admitti debere, omnino non permittantur, nisi ut supra diximus, actis publicis docuerint. 
Die Synode von Arles besaß in rechtlicher Hinsicht keinen anderen Charakter als das Verfahren in Rom. Zwar sprach man niemals von einem iudicium Marini, doch dürfte dies an dem übereinstimmenden Ergebnis mit dem vorhergehenden iudicium Miltiadis liegen. Die Bischöfe in Arles überprüften nicht nur die donatistischen Vorwürfe gegen das römische Verfahren, sondern verhandelten die causa Caeciliani neu, freilich mit dem gleichen Ergebnis. Damit bestätigten sie das einmal gefällte Urteil und formulierten nochmals die theologischen Grundlagen, die zu der Verurteilung der Donatisten geführt hatten. Auf der einen Seite erfüllten sie somit den Auftrag Konstantins, durch eine neue Verhandlung die donatistischen Einwände gegen die Rechtmäßigkeit des römischen Verfahrens auszuräumen, auf der anderen Seite legten sie als Gesamtsynode kirchenrechtlich verbindliche Leitlinien für die Zukunft fest. ${ }^{125}$

Die Entscheidung von Arles blieb in Afrika nicht ohne Wirkung. Augustinus zufolge gab es einige donatistische Bischöfe, die sich wieder der katholischen Kirche anschlossen. ${ }^{126}$ Die Mehrheit der Anhänger des Donatus akzeptierte jedoch das Ergebnis von Arles ebenso wenig wie jenes von Rom. Sie wollten nach wie vor vom Kaiser als katholische Kirche Afrikas anerkannt werden. Diese erneuten Appelle bei Konstantin stellt Augustinus in seiner antidonatistischen Polemik heraus. Er deutet die Ablehnung des Urteils von Arles als Zeichen der Unbelehrbarkeit und Hartnäckigkeit der Donatisten, die allein dazu geführt habe, dass Konstantin selbst zu einem Urteil gezwungen worden sei.

In der Argumentation der Donatisten spielte die Synode von Arles keine Rolle. Anders als zum Urteil des Miltiades wurden auch keine konkreten Vorwürfe gegen die in Arles versammelten Bischöfe laut. Dies bestätigt die Annahme, dass die tatsächlichen Kenntnisse zum Ablauf und zum Ergebnis sehr gering waren. Auch auf der Konferenz von 411 blieb das Konzil von Arles mit der Bestätigung des Urteils von Rom lediglich eine Randnotiz. Nur durch den Eumaliusbrief wurde diese Entscheidung überhaupt ins Gedächtnis gerufen. ${ }^{127}$ Die Donatisten scheinen auf die Aussagen des Briefes nicht eingegangen zu sein, sondern stellten sogleich das spätere Urteil des Kaisers in den Mittelpunkt. Es bleibt somit unklar, wie sie das Ergebnis des Konzils von Arles im Einzelnen deuteten, jedoch dürfte sicher sein, dass sie diese Synode ebenso wie die römische als unzuständig ansahen.

$125 \mathrm{Zu}$ diesem ambivalenten Charakter vgl. Grasmück, Coercitio, 57 f. Anm. 250.

126 Ep. 88.3; breuic. III 37.

127 Cap. conl. Carth. III 515; breuic. III 37. 


\section{Das Urteil Konstantins}

Das Urteil Konstantins begegnet bei Augustinus als Schlussstrich unter dem Fall Caecilianus. Während das iudicium Miltiadis und die Bestätigung dieses Urteils durch die Bischöfe in Arles seine Grundlage für das Plädoyer zur Kircheneinheit bildete, nahm Augustinus die Entscheidung des weltlichen Herrschers zu Gunsten Caecilians gleichsam als komplementäres Urteil, um damit die Unterstützung der katholischen Kirche durch weltliche Gewalten zu rechtfertigen. Gegen die donatistische Theorie der vom Staat verfolgten Kirche entwickelte er nach und nach seine Theorie des christlichen Staates. In dem Ergebnis des kaiserlichen Prozesses lag für Augustinus die entscheidende Bedeutung. Das Urteil Konstantins, so stellt er stets den Zusammenhang klar, sei die notwendige Konsequenz der donatistischen Appelle an den Kaiser gewesen. Jede Kritik am Eingreifen der Kaiser sei folglich unbegründet, da die Donatisten selbst dieses Eingreifen gefordert hätten. Auf diese Weise bildete das Urteil Konstantins in der Argumentation Augustins die Gelenkstelle zwischen Vergangenheit und Gegenwart. ${ }^{128}$

Bei den Donatisten zeigt sich einmal mehr ein fragmentarisches sowie uneinheitliches Bild. Parmenianus ging davon aus, dass Konstantin zwar ein Urteil gegen Donatus und damit gegen die wahre Kirche gefällt hätte, jedoch von donatistischen Gegnern bestochen und beeinflusst gewesen sei. ${ }^{129}$ Dagegen erklärten Cresconius und später die Donatisten auf der Konferenz von 411, es hätte entgegen der Darstellung der Katholiken ein Konstantinurteil gegen Caecilianus gegeben. Außerdem behaupteten sie, Konstantin hätte eine Religionsfreiheit für die Donatisten verkündet, und forderten, diese Tatsache in die aktuelle Auseinandersetzung einzubeziehen. ${ }^{130}$

Um die unterschiedlichen Aussagen und Interpretationen beider Seiten besser beurteilen zu können, soll im Folgenden zunächst der chronologische Verlauf der Ereignisse rekonstruiert werden, wie er sich aus den zur Verfügung stehenden Quellen ergibt. Auf dieser Grundlage können anschließend die Interpretationen der Donatisten und Augustins dargestellt und im Hinblick auf ihre Aussagekraft überprüft werden.

128 Vgl. c. litt. Pet. II 205; III 29; c. ep. Parm. I 11, 13, 15-16; Cresc. III 16, 67, 82; IV 9; cath. fr. 46, 50; epp. 43.4, 20; 53.5; 76.2; 88.3; 89.3; 93.13; 105.8; 141.11; s. Denis 19.8; s. Dolbeau 2.22; breuic. III 37-38, 41; c. Don. 19-20, 56; dazu o. Kap. 4.2.2.

129 C. ep. Parm. I 10-11; vgl. u. Kap. 7.4.2.2.

130 Vgl. zum Verlauf der Debatte o. Kap. 5.3.2. 


\subsection{Vom Konzil von Arles zum Urteil Konstantins in Mailand}

Wie bei dem Konzil von Rom sind es vor allem Augustins ep. 43 und der Breviculus der Konferenz von 411, die wichtige Informationen über die letzte Phase im Prozess gegen Caecilianus enthalten. Außer diesen Quellen stehen nur wenige Dokumente aus dem Anhang bei Optatus zur Verfügung, die Auskunft über die Zeit zwischen dem Urteil von Arles im August 314 und dem Urteil Konstantins im Herbst 315 geben. ${ }^{131}$ Aufgrund zum Teil widersprüchlicher Aussagen und fehlender Datierungen ist es sehr problematisch, eine stringente Abfolge der Ereignisse zu rekonstruieren. Folglich weichen die Interpretationen der Historiker zu dieser Phase der Geschichte zum Teil erheblich voneinander ab. Die nachfolgende Darstellung ist ein neuer Versuch, den vorhandenen Informationen einen schlüssigen Ereignisverlauf abzugewinnen. ${ }^{132}$

Auch nach dem Konzil von Arles wandte sich die unterlegene Partei mit Einsprüchen an den Kaiser. ${ }^{133}$ Konstantins wiederholter Versuch, die causa Caeciliani als Kirchenangelegenheit durch ein bischöfliches Gremium zu einem Ende zu bringen, war damit gescheitert. Bereits vor der Einberufung zur Synode nach Arles war Konstantin einer der donatistischen Anschuldigungen gezielt nachgegangen: dem traditio-Vorwurf gegen Felix von Abthugni. Inzwischen war es sowohl allen beteiligten europäischen Bischöfen als auch den Verantwortli-

131 Der Brief Konstantins an die katholischen Bischöfe nach dem Konzil von Arles (Opt. App. V), ein Brief an donatistische Bischofe (App. VI), ein Brief an den Vikar von Afrika Celsus (App. VII) sowie der Brief an den Prokonsul Probianus (Aug. Cresc. III 81; ep. 88.4).

132 Die neuere Forschung beruft sich im Wesentlichen auf Grasmück (Coercitio, 70-80), der einen recht gelungenen und ausführlichen, wenngleich nicht widerspruchsfreien Rekonstruktionsversuch vorgelegt hat. Grasmück hat u. a. richtig erkannt, dass die bei Optatus überlieferte „Brescia-Episode“ nicht in den Rahmen der Ereignisse des Jahres 315 einzupassen ist. Allerdings kann sein Lösungsansatz nicht überzeugen, den Bericht des Optatus zeitlich nach das Kaiserurteil zu setzten. Die geschilderten Ereignisse passen wesentlich besser in das Frühjahr des Jahres 314 (s. u. Anm. 163). - Ältere und z.T. abweichende Darstellungen der Entwicklungen der Jahre 315/316 bei Lietzmann, Geschichte III, 74-77; Monceaux IV, 24 f.; Seeck, Geschichte III, 332-335; Frend, Donatist Church, 155-159, die zum Teil auch für neuere Darstellungen übernommen wurden.

133 Vgl. den Brief Konstantins an die Bischöfe von Arles (Opt. App. V). Maier I, Nr. 21, 167-171; von Soden, Nr. 18. Ebenso wie der Brief an Aelafius ist dieser Text in seiner Authentizität umstritten und gilt zumindest als redaktionell bearbeitet. Den Grundtenor dieses Briefes wird man jedoch nicht in Abrede stellen können. Vgl. die Textanalysen von Dörries (Selbstzeugnis, 28-33) und Kraft (Entwicklung, 185-191). Grasmück (Coercitio, 254-256) vermutet, dass Konstantin einen Kleriker mit der Abfassung des Schreibens betraut habe. Zuletzt für die Glaubwürdigkeit des Schreibens: C. Odahl, Constantine's Epistle to the Bishops of the Council of Arles, JRH 17, 1993, 274-289. Vgl. auch E. D. Digeser, Lactantius and Constantine's Letter to Arles, Dating the Divine Institutes, JECS 2, 1994, 33-52. 
chen am Hofe deutlich geworden, dass der Streit um die Weihe Caecilians den Anlass zum Schisma gegeben hatte. Der Prozess gegen Felix, den der Kaiser an den Vikar Aelius Paulinus delegiert hatte, sollte folglich durch die Klärung des Hauptvorwurfs einen entscheidenden Beitrag zur Überwindung der Spaltung leisten. Der Freispruch des Felix in diesem Prozess am 15. Februar 315 trug dazu bei, dass Konstantin in den folgenden Monaten seine Bemühungen um ein Ende des Streites verstärkte. ${ }^{134}$

Ganz offensichtlich beabsichtigte Konstantin nicht, sofort ein eigenes Urteil zu fällen, nachdem wiederum Beschwerden der Donatisten über die Richter und die Entscheidung von Arles eingetroffen waren. Vielmehr belegen die überlieferten Aussagen, dass er zunächst andere Versuche unternahm, die Donatisten zum Einlenken zu bewegen und auf diese Weise die Einheit der Kirche wiederherzustellen. Als erstes beorderte Konstantin die donatistischen Vertreter, die nach dem Konzil von Arles appelliert hatten, in seine Residenz nach Trier. Den amtierenden vicarius Africae Aelius Paulinus wies er außerdem an, renitente donatistische Bischöfe $\mathrm{zu}$ ihm zu schicken, damit diese ihren Widerstand in Afrika nicht fortsetzen könnten. ${ }^{135}$ Es ist weder bekannt, auf welche Weise diesen Donatisten die Rückkehr zur katholischen Kirche nahegelegt wurde, noch, ob tatsächlich auf Befehl des Statthalters weitere Donatisten nach Gallien geschickt wurden. Vermutlich waren aber Kleriker am Hofe beauftragt worden, die Donatisten fernab von Afrika mit allen Mitteln von ihrem „Irrweg“ abzubringen.

Überliefert ist ein Informationsschreiben der Prätorianerpräfektur in Trier an den vicarius Africae Celsus vom 28. April 315. ${ }^{136}$ Daraus geht hervor, dass vier donatistische Bischöfe und ein Priester die kaiserliche Genehmigung erhalten hatten, nach Arles zu reisen und von dort zurück nach Afrika zu segeln. Folglich waren sie in den vorangegangenen Monaten tatsächlich am kaiserlichen Hof festgehalten worden. ${ }^{137} \mathrm{Ob}$ Donatus sich $\mathrm{zu}$ diesem Zeitpunkt noch in Gallien befand, lässt sich wiederum nicht sicher sagen. Es ist aber durchaus wahrscheinlich, dass ihm nach wie vor die Rückkehr verweigert wurde und er mit einigen Anhängern am Hof verbleiben musste.

134 Zum Prozess gegen Felix vgl. o. Kap. 6.1.3.

135 Brief an die katholischen Bischöfe (Opt. App. V); vgl. Grasmück, Coercitio, $64 \mathrm{f}$.

136 Opt. App. VIII; Maier I, Nr. 23, 187-189; von Soden, Nr. 22. - Zum Datum vgl. Habicht, Hermes 86, 1958, 367-373; gegen Seeck (ZKG 30, 1909, 211-213), der das Dokument auf das Jahr 316 datiert und in Zusammenhang mit App. VII nach dem Konstantinurteil einordnet.

137 Mit Grasmück (Coercitio, 70) ist das Dokument zu diesem Zeitpunkt einzuordnen, und zwar unabhängig von den Bitten der Donatisten um Rückkehr in Opt. App. VI, wie etwa Barnes (New Empire, 243) postuliert. Es ist denkbar, dass die Erlaubnis zur Rückkehr mit dem Urteil im Prozess gegen Felix im Zusammenhang stand; vgl. Habicht, Hermes 86, 1958, $372 \mathrm{f}$. 
Auf jeden Fall gab es donatistische Vertreter, die noch (oder wieder) im Frühjahr und Sommer 315 bei Konstantin ihre Kritik an den bisherigen Entscheidungen vorbrachten, wie aus dem Reskript des Kaisers an den Prokonsul Probianus hervorgeht. ${ }^{138} \mathrm{Um}$ diese Donatisten von der Zwecklosigkeit ihrer Appelle zu überzeugen, verfügte Konstantin, dass Ingentius, der überführte Fälscher im Prozess gegen Felix von Abthugni, an seinen Hof kommen solle. Damit unternahm er einen weiteren Versuch, die Donatisten durch die bereits bestehenden Urteile zur Kircheneinheit zu bewegen. Vermutlich hoffte er, dass außer den beiden bischöflichen Urteilen zu Gunsten Caecilians nun durch das prokonsularische Urteil zu Gunsten des Felix der entscheidende Anklagepunkt der Donatisten ausgeräumt werden könnte: Ingentius sollte allen demonstrieren, dass Felix kein traditio-Vergehen nachgewiesen werden konnte.

Konstantin, der sich noch bis ins Frühjahr 315 in Trier aufhielt, begab sich im frühen Sommer auf den Weg nach Rom, wo er am 21. Juli zur Feier seiner Decennalien eintraf. ${ }^{139}$ Möglicherweise kam es in Rom zu der Begegnung des Ingentius mit den donatistischen Anklägern. Obwohl nichts über die Durchführung dieses Vorhabens bekannt ist, lässt sich aus dem weiteren Verlauf erkennen, dass die Donatisten nicht von ihrer Position abwichen, ob sie nun mit Ingentius konfrontiert worden waren oder nicht.

In dieser Zeit erhielt Konstantin wiederholt Nachrichten aus Afrika über aufrührerisches Treiben, das mit dem Kirchenstreit im Zusammenhang stand. Einem Bericht des afrikanischen Vikars Celsus konnte er entnehmen, dass ein gewisser Menalius, wahrscheinlich ein numidischer Bischof, mit anderen Donatisten Unruhen schürte und, obwohl Celsus auf Befehl des Kaisers Maßnahmen ergriffen hatte, anhaltend Widerstand leistete. Inzwischen sprach man bei den donatistischen Anhängern bereits von Märtyrern und Verfolgung. ${ }^{140}$ Derartige Vorkommnisse mussten alarmierend wirken, da das Schisma die öffentliche Ruhe zu gefährden drohte, und sie veranlassten den Kaiser zu neuen

138 Brief an Probianus, Aug. ep. 88.4; vgl. o. Kap. 3.4.2.2. Monceaux (IV, 490) datiert dieses Reskript bereits auf Anfang des Jahres 315. Demnach hätte die Vorladung des Ingentius noch vor der in Opt. App. VIII beschriebenen Rückreise gelegen. Sachlich fügte sich diese Datierung sehr gut ein. Allerdings ist der Vorgänger des Probianus, Aelianus Paulinus, durch CTh XI 36.3 noch für den 26. April 315 als Prokonsul recht sicher nachweisbar. Probianus' Amtsantritt und somit der terminus post quem für seinen Brief an Konstantin sind folglich frühestens in den Mai 315 zu datieren. Barnes, New Empire, 170; Seeck, Regesten, 161, 163; vgl. auch o. Kap. 5 Anm. 232.

139 Seeck, Regesten, 163; Barnes, New Empire, 72; Grünewald, Constantinus, 104, 107; Grasmück (Coercitio, 71 f.) vermutet, dass die Donatisten den Kaiser in Rom erwarteten und dort mit neuen Anklagen bestürmten.

140 Der Brief des Celsus an Konstantin ist bezeugt durch das Reskript des Kaisers (Opt. App. VII). Vgl. Monceaux IV, 202; Grasmück, Coercitio, $74 \mathrm{f}$. Zur Datierung s. u. Anm. 143 - Menalius war möglicherweise jener numidische Bischof, der an der Bischofsweihe des Silvanus (Opt. I 13) beteiligt war. Mandouze, PAC, 747, s. v. Menalius. 
Überlegungen, die Probleme zu lösen: In seinem Reskript an Celsus ${ }^{141}$ erwähnt Konstantin, dass nach seinem Entschluss, die Sache einer neuerlichen Untersuchung zu unterziehen, die Donatisten aus seiner Umgebung geflohen seien. ${ }^{142}$ Ferner äußert Konstantin den Gedanken, selbst nach Afrika zu kommen, um vor Ort die causa Caeciliani zu klären und so zu demonstrieren, welche Verehrung der höchsten Gottheit gebühre und welcher Kult sie erfreue. Den Vikar wies er an, bis zu dieser Entscheidung Nachsicht gegenüber den Unruhestiftern zu üben. ${ }^{143}$

Die Konsequenzen, die eine Reise Konstantins nach Afrika für die Geschichte des Donatismus und sicherlich auch darüber hinaus gehabt hätte, sind

141 Der Brief Konstantins an Celsus (Opt. App. VII). Maier I, Nr. 26, 194-196; von Soden, Nr. 23; vgl. Monceaux IV, 202 f.; Dörries, Selbstzeugnis, 35-37; Kraft, Entwicklung, $193-195$.

142 Opt. App.VII: [...] cum statuissem inter ipsos atque Caecilianum plenissime super allegationibus diuersis requirere, praesentiae meae susceptam fugam subtrahere laborarunt.

143 Opt. App. VII: at cum constet minime unumquemque propria penitus delicta lucrari, etiamsi paulisper eorum fuerit coercitio dilata, mandandum grauitati tuae duxi ut interim quidem eosdem omittas et dissimulandum super ipsos esse cognoscas. uerum lecta hac epistula, tam Caeciliano quam hisdem palam facias quod, cum fauente pietate diuinam Africam uenero, plenissime uniuersis, tam Caeciliano quam his qui contra eum agere uidentur, lecto dilucido iudicio demonstraturus sum quae et qualis summae diuinitati sit adhibenda ueneratio et cuiusmodi cultus delectare uideatur. - Das Reskript an Celsus ist nicht datiert, wird jedoch von den meisten Historikern in den Herbst 315 oder erst in das Jahr 316 gelegt. Begründet wird dies zum einen mit der Erwähnung eines „Fluchtversuchs" der Donatisten am Hof, der mit jenem Fluchtversuch identifiziert wird, den Augustinus in ep. $43.20 \mathrm{im}$ Zusammenhang mit dem Mailänder Urteil erwähnt. Zum anderen werden die besagten Unruhen für das Ausbleiben Caecilians in Rom verantwortlich gemacht, von dem ebenfalls in ep. 43.20 die Rede ist (vgl. die Argumente bei Grasmück, Coercitio, 74 Anm. 341 und Barnes, New Empire, 244 f.). Demgegenüber halte ich eine frühere Einordnung und eine Datierung des Reskriptes in den Juli 315 für wesentlich sinnvoller: 1. Caecilianus hielt sich dem Brief zufolge in Afrika auf. Von einer Vorladung, die verhindert worden sei, ist aber nicht die Rede. Die angesprochenen Unruhen fanden nicht in Karthago, sondern in der numidischen Provinz statt und stehen in keinem Zusammenhang mit Caecilianus. Folglich stammt der Brief aus der Zeit vor der Ladung Caecilians nach Rom, die im Spätsommer ausgesprochen wurde. 2. Der Entschluss des Kaisers, nach Afrika zu reisen, passt wesentlich besser in den Sommer 315 als später. Konstantin war auf dem Weg nach Rom und konnte erwägen, von dort in kurzer Zeit weiter nach Afrika überzusetzen. 3. Nachdem Caecilianus trotz Vorladung nicht in Rom eingetroffen war, überlegte Konstantin, „Freunde“ nach Afrika zu senden (vgl. Opt. App. VI). In die gleiche Zeit auch Überlegungen einer eigenen Reise zu stellen, ist zwar möglich, wahrscheinlicher ist es aber, dass Konstantin von diesen Vorhaben längst wieder abgekommen war. 4. Die „Fluchtversuche“ der Donatisten sind keineswegs zwingend mit jenen in ep. 43.20 beschriebenen gleichzusetzen. Vielmehr dürfte die Notiz im vorliegenden Schreiben an Celsus im Zusammenhang mit dem Vorhaben der Afrikareise des Kaisers stehen. Die Donatisten erachteten es unter den neuen Gegebenheiten einer Afrikareise Konstantins für angebracht, selbst schnellstmöglich nach Afrika zurückzukehren. 
nicht zu unterschätzen. Doch diese Reise fand nicht statt. Der Tenor des Briefes lässt indessen aufhorchen: Die bisherige Zurückhaltung gegenüber der kirchlichen Angelegenheit weicht hier dem Willen, als Herrscher für Ordnung zu sorgen, eingeschlossen klare Anweisungen zur Ausübung des christlichen Kultes. Die politische Erwägung, eine Ausweitung der Auseinandersetzung zu einem Aufruhr und damit die Gefahr von bürgerkriegsähnlichen Zuständen zu unterbinden, veranlasste den Kaiser, die causa Caeciliani durch ein eigenes Urteil zu entscheiden. ${ }^{144}$

Nachdem die Pläne der Afrikareise aus unbekannten Gründen aufgegeben worden waren, der Wille zu einem abschließenden Urteil aber nach wie vor bestand, erging wohl noch im Sommer des Jahres 315 die Aufforderung an Caecilianus und Donatus, nach Rom zu kommen. ${ }^{145}$ Während Caecilianus nach dem Konzil von Arles nach Karthago zurückgekehrt war und seitdem in Afrika weilte, ist der Aufenthaltsort des Donatus zu diesem Zeitpunkt unklar. Entweder befand er sich bereits am Hof in Italien oder er war doch zwischenzeitlich nach Afrika zurückgekehrt und wurde ebenso wie sein Kontrahent angewiesen, sich nach Rom zu begeben.

Augustinus berichtet nun, dass Caecilianus aus unbekannten Gründen nicht in Rom eintraf. Die Donatisten am Hof versuchten dies offensichtlich zu ihren Gunsten zu nutzen und forderten eine Entscheidung des Kaisers in Abwesenheit Caecilians. ${ }^{146}$ Da dies abgelehnt wurde, erbaten sie die Erlaubnis zur Rückkehr nach Afrika. Offenbar erwog man daraufhin am Hof, hochrangige Vertreter zur Untersuchung und Urteilsfindung nach Afrika zu schicken, und den anwesenden Donatisten wurde die Rückkehr gestattet. Doch schon kurze Zeit später widerrief Konstantin diese Entscheidung. Es hatte sich die Meinung durchgesetzt, dass es besser sei, nicht unmittelbar am Unruheherd in Afrika die kaiserliche Untersuchung durchzuführen, sondern die Verhandlungen doch in Europa anzusetzen. Die donatistischen Bischöfe sollten am Hof verbleiben und die Ankunft Caecilians abwarten. ${ }^{147}$

144 In dieser Hinsicht zutreffend die Beurteilung von Kraft (Entwicklung, 59, 195). Demgegenüber betont Grasmück (Coercitio, $78 \mathrm{f}$.) das Verantwortungsbewusstsein Konstantins in seiner Funktion als pontifex maximus.

145 Ep. 43.20: iussit [sc. Constantinus] enim ille, ut ei partes ad agendam causam Romam occurrerent. Vgl. Opt. App. VI. - Da sich Konstantin in den Jahren 314-316 lediglich im Sommer 315 in Rom aufhielt, ergibt sich auch die Datierung aus der Ortsangabe. Vgl. Seeck, Regesten, 162-165.

146 Ep. 43.20. Diese Interpretation der donatistischen Anliegen durch Augustinus ist durchaus plausibel.

147 Zum Vorigen vgl. Konstantins Brief an die donatistischen Bischöfe an seinem Hof (Opt. App. VI). Maier I, Nr. 25, 192 f.; von Soden, Nr. 21; vgl. Dörries, Selbstzeugnis, 33 f.; Kraft, Entwicklung, 192 f. - Zur Einordnung von App. VI in den September 315 vgl. Seeck (ZKG 30, 1909, 208 f.) und Grasmück (Coercitio, 72-74) gegen Barnes (New 
Damit enden die Informationen aus den überlieferten Konstantinbriefen. Über den vorerst letzten Akt in der causa Caeciliani, das Urteil Konstantins, bleibt als einzige Quelle Augustinus, der wiederum sich selbst nur auf ein Dokument stützt, das heute verloren ist: den Brief Konstantins an den Vikar Eumalius vom 10. November 316. ${ }^{148}$ Dieser Brief, der sich schon bald nach seinem Amtsantritt als Bischof in Augustins Händen befand, entstammte einem städtischen Archiv, wahrscheinlich dem Archiv des Vikars in Karthago. ${ }^{149}$ Bereits in seinem Gespräch in Thubursicum ließ er das Dokument vortragen, in seiner Abhandlung gegen Cresconius zitiert Augustinus aus dem Brief einige Worte des Kaisers und auf der Konferenz von 411 war es das einzige Dokument der Katholiken, das über das iudicium Constantini Auskunft geben konnte. ${ }^{150}$

Konstantin informierte in diesem Brief den Vikar über das bisherige Verfahren und die Entscheidung in der causa Caeciliani. Vermutlich war eine Anfrage des Eumalius über den Umgang mit Donatisten hinsichtlich neuerlicher Beschwerden, Streitigkeiten oder Unruhen vorausgegangen, wie sie in ähnlicher Form bereits im Jahr zuvor durch seinen Vorgänger Domitius Celsus eingebracht worden war. Entsprechend enthielt das Schreiben keine langen Ausführungen über die Verhandlungen, sondern vielmehr einen kurzen Bericht über die einzelnen Schritte, die zum endgültigen Freispruch Caecilians geführt hatten. Wahrscheinlich forderte Konstantin Eumalius abschließend auf, sich dieser Entscheidung entsprechend zu verhalten und mit allen Mitteln donatistische Umtriebe $\mathrm{zu}$ verhindern. ${ }^{151}$

Die im Brief enthaltenen Aussagen sind schnell zusammengefasst: Ende September brach Konstantin von Rom auf und begab sich nach Mailand. ${ }^{152}$ Ein Teil der anwesenden Donatisten war offensichtlich nicht gewillt, noch länger vertröstet zu werden und versuchte zu entkommen. Das Unternehmen misslang und die Donatisten wurden unter Bewachung nach Mailand gebracht. ${ }^{153} \mathrm{Nach}$

Empire, 243), der App. VI im Zusammenhang mit App. VIII betrachtet und auf den 1. Mai 315 datiert.

148 Maier I, Nr. 27, 196-198; von Soden, Nr. 25; vgl. Dörries, Selbstzeugnis, 37; Seeck, ZKG $10,1889,522 \mathrm{f}$.

149 C. Don. 20: [...] imperatoris litteras, quibus se inter partes audisse testatur, [...] prolatas de archiuo publico recitauimus.

150 Ep. 43.4, 20; Cresc. III 82; Cap. conl. Carth. III 515.

151 Über den Inhalt des Briefes an Eumalius finden sich in Augustins ep. 43 mehrere Hinweise: So enthielt das Schreiben einen Gesamtüberblick über die causa Caeciliani (ep. 43.5), dazu gehörten Informationen über das Konzil von Rom und das iudicium Miltiadis (43.14), über die Appelle nach dieser Entscheidung (43.15) sowie über das Konzil von Arles, die erneuten Klagen und schließlich über das Urteil des Kaisers (43.20).

152 Vgl. Seeck, Regesten, 164; Barnes, New Empire, 72.

153 Ep. 43.20: quo cum Caecilianus nescio qua causa non occurrisset, interpellatus ab eis praecepit, ut Mediolanium sequerentur. tunc se aliqui eorum subtrahere coeperant [...]. 
einiger Zeit traf dann Caecilianus am Hof Konstantins ein, und es kam in Mailand, wohl im Oktober oder November 315, zu der vorgesehenen Verhandlung. Nach Anhörung der beiden Parteien fällte Konstantin sein Urteil, das erwartungsgemäß die bisherigen Urteile bestätigte. An Eumalius schrieb er:

„Dabei [in der Anhörung] habe ich erkannt, dass jener Mann Caecilianus vollkommen unschuldig ist und die schuldigen Pflichten seiner Religion bewahrt und ihr dient, wie es sich gebührt. Es ist in aller Klarheit deutlich geworden, dass bei ihm keine Straftat gefunden werden konnte, wie sie ihm in seiner Abwesenheit durch die Verstellung seiner Gegner angehängt worden war.“"154

Der kurz gefasste Inhalt des Briefes an Eumalius bedingte, dass Augustinus und die Katholiken nicht mehr über das Urteil Konstantins aussagen konnten als die genannten Informationen. Von dem Verlauf der kaiserlichen Kognition, den vorgetragenen Argumenten und den Plädoyers der beiden Seiten besaßen sie keine Kenntnisse. Folglich kann auch heutzutage nur vermutet werden, welche Gründe den Ausschlag zum Urteil Konstantins gaben. Entscheidend waren wohl die eindeutigen Stellungnahmen der katholischen Bischöfe, die das donatistische Verständnis von Taufe und Weihehandlungen ablehnten. Zur Erhaltung der kirchlichen und damit staatlichen Einheit konnten keine Sonderkulte gestattet werden. Wie bereits bei den bischöflichen Urteilen bedeutete eine solche Vorentscheidung zwangsläufig das Scheitern der Argumente der Donatisten. Ihre Einsprüche gegen die bisherigen Untersuchungsmethoden wurden hinfäl-

quod ubi cognouit prouidus imperator, reliquos ab officialibus custoditos fecit Mediolanium peruenire.

154 Cresc. III 82: in quo peruidi [...] Caecilianum uirum omni innocentia praeditum ac debita religionis suae officia seruantem eique ita ut oportuit seruientem nec ullum in eo crimen repperiri potuisse euidenter apparuit, sicut absenti fuerat aduersariorum suorum simulatione compositum. - Die Datierung des iudicium Constantini auf den späten Herbst 315 ist nicht unumstritten. Terminus ante quem ist Augustins Datierung des Konstantinbriefes an Eumalius auf den 10. November 316. Aus diesem Grund nehmen Monceaux (IV 25, 196 f.) und Frend (Donatist Church, 158 f.) an, dass das Urteil erst im Laufe des Jahres 316 gefallen sei. Mit Grasmück (Coercitio, 79) sind jedoch die von Augustinus angeführten Orte, erst Rom, dann die cognitio in Mailand, als entscheidende Hinweise zu werten. Der Aufenthalt Konstantins in Mailand im Oktober 315 ist aufgrund von Frag. Vat. 273 (vgl. Seeck, Regesten, 164) recht sicher nachweisbar. Auf jeden Fall befand sich Konstantin im Januar 316 wieder in Trier (vgl. CTh I 22.1). Für das Jahr 316 ist kein Aufenthalt in Mailand bekannt. Möglich wäre eine Durchreise auf dem Weg von Arles nach Osten im August/September 316 vor der Schlacht gegen Licinius bei Cibalae. Ein erneuter Aufenthalt in Rom ist dagegen weder bezeugt noch wahrscheinlich zu machen. D. h., man müsste davon ausgehen, dass die beiden Streitparteien (zumindest aber die Donatisten) fast ein Jahr in Mailand festgehalten wurden, ehe es zur Verhandlung kam. Dies ist zwar nicht grundsätzlich auszuschließen, aber durch die gesamte Vorgeschichte im Jahre 315 mit den in Rom getroffenen Vorentscheidungen ist es wesentlich naheliegender an der Datierung des iudicium Constantini im Oktober/ November 315 festzuhalten. Zu dem Itinerarium Konstantins vgl. Barnes, New Empire, 72 f; Grünewald, Constantinus, 108-112. 
lig, da Konstantin der katholischen Dogmatik folgte. Darüber hinaus lag dem Kaiser der Freispruch des Felix von Abthugni vor. Die Anklage, Caecilianus sei von einem Traditor geweiht worden, war damit offensichtlich widerlegt. Schließlich hatte die Entwicklung der vergangenen Monate und Jahre gezeigt, welches Unruhepotenzial die Donatisten zu entwickeln in der Lage waren. Um die Stabilität und öffentliche Ruhe nicht zu gefährden, fiel Konstantins Entscheidung zu Gunsten der Katholiken.

Nach dieser Entscheidung des Kaisers scheint es bald zu Maßnahmen gegen die Donatisten in Afrika gekommen zu sein. Augustinus spricht von einem Gesetz Konstantins, in dem erstmals verfügt wurde, donatistischen Bischöfen die Kirchen zu entziehen. Außerdem wurde donatistischen Anhängern, die sich hartnäckig gegen eine Rückführung zur katholischen Kirche wehrten, die Konfiszierung ihrer Vermögen angedroht. ${ }^{155}$ Die späteren donatistischen Legenden, die von der Verfolgung unter Konstantin berichteten, zeugen ihrerseits von zum Teil gewaltsam durchgeführten Maßnahmen, die die Kircheneinheit wieder herstellen sollten. ${ }^{156}$

\subsection{Donatistische Traditionen und Deutungen}

Die donatistischen Darstellungen und Beurteilungen des iudicium Constantini weichen in einigen Bereichen vom oben dargestellten Verlauf ab. Es stellt sich die Frage, wie die Aussagen der Donatisten zustande kamen und auf welchen historischen Quellen und Überlieferungen sie basierten. Grundlagen bieten zum einen die Ausführungen der Donatisten auf der Konferenz von 411, in denen sich auch die Aussagen des Cresconius wiederfinden. Sie sollen im ersten Abschnitt analysiert werden. Zum anderen lassen sich aus Augustins Schrift gegen Parmenianus einige donatistische Überlieferungen zum Urteil Konstantins erschließen. Diese Quelle wird im zweiten Abschnitt diskutiert.

\subsubsection{Geschichtsdeutungen auf der Konferenz von Karthago}

Der Blick auf die historischen Dokumente, die während der Konferenz von den Donatisten vorgelegt wurden, zeigt sehr deutlich, dass diese Quellen erst im Nachhinein zur Untermauerung bereits bestehender Ansichten herangezogen worden sind. Die donatistischen Bischöfe verwendeten einen Textausschnitt aus Optatus, eine Supplik ihrer Vorfahren an Konstantin, das dazugehörige Reskript des Kaisers an den Vikar Verinus sowie den Brief Konstantins an den Prokonsul Probianus. Diese Auswahl lässt vermuten, dass den Donatisten außer diesen

155 Ep. 88.3; vgl. c. litt. Pet. II 205; c. ep. Parm. I 13, 18; epp. 93.14; 105.9. Vgl. o. Kap. 4.2.2. 156 Vgl. o. Kap. 6.3.1. 
Dokumenten keine anderen, zumindest keine besseren, zur Verfügung standen und sie sich zwangsläufig nicht nur zu ihrer Verteidigung gegen die Katholiken, sondern auch zu ihrer eigenen historischen Rechtfertigung und Selbstvergewisserung auf diese Dokumente stützen mussten. ${ }^{157}$ Diese vier Zeugnisse stellten die schriftlichen Beweise für drei verschiedene Traditionslinien der Donatisten dar, die erst auf der Konferenz von 411 miteinander verknüpft wurden, um dort eine stringente Argumentation vorlegen zu können.

\section{Die erste Traditionslinie: Die Verbannung Caecilians nach Brescia}

Die erste Traditionslinie ist die Idee der Verbannung Caecilians nach Brescia. Hier handelt es sich offenbar lediglich um die donatistische Lesart des Werkes von Optatus. Erwähnt wird diese Tradition auch von Cresconius, ${ }^{158}$ wodurch deutlich wird, dass sie nicht erst für die Konferenz von 411 entwickelt wurde, sondern bereits seit längerem einen Bestandteil der donatistischen Überlieferung bildete.

Die entscheidende Textstelle bei Optatus ist heute kaum leichter zu deuten als zur Zeit Augustins. Da in keiner anderen Quelle über den Brescia-Aufenthalt Caecilians berichtet wird, kann lediglich - wie bereits auf der Konferenz von Karthago - zunächst nur der Zusammenhang bei Optatus selbst näheren Aufschluss bringen: Dieser beschreibt den Verlauf der Ereignisse folgendermaßen: Nachdem er die Entscheidung des römischen Konzils mit der Sentenz des Miltiades berichtet hat (I 24), spricht Optatus von einem Appell des Donatus, woraufhin sich der Kaiser über die Kühnheit erregt habe, dass ein Bischof nach Art der Heiden appelliere (I 25). Optatus zitiert hier aus einem Brief Konstantins an katholische Bischöfe, der im Anhang seines Werkes erhalten ist und vermutlich nach dem Konzil von Arles geschrieben wurde. Da Optatus das Urteil von Arles nicht erwähnt, bleibt der genaue chronologische Zusammenhang zum nachfolgenden Bericht über Caecilians Aufenthalt in Brescia unklar. ${ }^{159}$

Donatus, so berichtet nun Optatus, habe um die Erlaubnis gebeten, nach Karthago zurückkehren zu dürfen, was ihm aber verwehrt worden sei. ${ }^{160}$ Filu-

157 Zum Verlauf der donatistischen Argumentation auf der Konferenz s. o. Kap. 5.3.2-3.

158 Cresc. III 80, 83; vgl. o. Kap. 3.4.1.

159 Opt. App. V. - Optatus zitiert bereits in I 23.1 im Zusammenhang mit den preces der Donatisten aus diesem Brief eine Antwort Konstantins. Folglich diente ihm dieser Brief als eine Fundgrube, aus der er an geeigneten Stellen den Kaiser zitieren konnte. Dabei nahm Optatus keine Rücksicht auf die chronologische Einordnung (die er vermutlich gar nicht kannte). Vgl. Girardet, Chiron 19, 1989, 189-191; Labrousse, SC 412, 63; Monceaux IV, 215.

160 Opt. I 26: Eodem tempore idem Donatus petiit ut ei reuerti licuisset * * ad Carthaginem accederet (ed. Ziwsa, Optatus, S. 28). Labrousse (SC 412, S. 226) bevorzugt die Lesart der Hs. P: [...] ut ei reuerti licuisset nec ad Carthaginem accederet. Augustinus, der die 
minus, ein Anhänger des Donatus, habe daraufhin dem Kaiser nahegelegt, dass unter diesen Umständen um des Friedens willen auch Caecilianus nicht nach Karthago zurückkehren sollte. Diesem Vorschlag sei stattgegeben worden und Caecilianus sei in Brescia zurückgehalten worden. Während der Abwesenheit beider Bischöfe sei dann eine Untersuchungskommission der Bischöfe Eunomius und Olympius nach Karthago aufgebrochen, mit dem Auftrag die Situation der Kirche zu prüfen und einen der beiden Gegner in seinem Amt zu bestätigen. Nach 40 Tagen Überprüfung hatten die Gesandten schließlich mit der pars Caeciliani kommuniziert, das Urteil von Rom bestätigt und seien anschließend heimgekehrt. Aufgeschreckt durch dieses Ergebnis sei Donatus als erster, wenig später auch Caecilianus wieder nach Karthago zurückgekehrt. ${ }^{161}$

Zum Abschluss dieser Darstellung weist Optatus darauf hin, dass er Aktenmaterial als Informationsquelle verwendet habe, das seinem Werk beigefügt und somit von jedem nachzulesen sei. Diese Akten waren jedoch schon zu Augustins Zeiten nicht mehr greifbar und sind auch heute nicht erhalten.

Textstelle selbst als unklar bezeichnet (c. Don. 54), gibt die Textstelle bei Optatus folgendermaßen wieder (breuic. III 38; vgl. Lancel. CCL 149A, 302): ,[...] ut ei reuerti licuisset et ad Carthaginem accedere. Der inhaltliche Zusammenhang bei Optatus ergibt eindeutig, dass Donatus nach seinem Gesuch an den Kaiser nicht nach Karthago zurückgekehrt war, sondern in Abwesenheit beider Bischöfe (Caecilianus und Donatus) eine Untersuchungskommission dorthin geschickt wurde und anschließend Donatus wieder in Afrika eintraf (Opt. I 26). Außerdem erschließt sich die Motivation des Donatus, auch Caecilians Rückkehr nach Karthago zu unterbinden und seine Festsetzung in Brescia zu fordern, am besten aus der Tatsache, dass ihm selbst die Rückkehr verwehrt worden war. Hinsichtlich der unsicheren Überlieferung der Optatusstelle bleiben somit zwei Möglichkeiten: Entweder die Lesart der Hs. P enthält (zumindest sinngemäß) den ursprünglichen Text, oder der ursprüngliche Text ließ offen, ob Donatus zurückkehren durfte oder nicht. Mit Labrousse (SC 412, 228 f. Anm. 1; Grasmück, Coercitio, 80) ist die erste Möglichkeit als die wahrscheinlichere anzunehmen. Vgl. auch Monceaux IV, 209; Mandouze, PAC, 298; 456, s. v. Filuminus; Lancel, SC 194, 99; Edwards, Optatus, 25 Anm. 101. Weniger wahrscheinlich erscheint mir der Vorschlag Turners (JThS 27, 1926, 292), der ausgehend von Hs. P die Lesart empfiehlt: petiit ut ei reuerti licuisset et ne C[aecilianus] ad Carthaginem accederet.

161 Opt. I 26: tunc duo episcopi ad Africam missi sunt, [...] ut remotis binis singulos ordinarent. In der Forschung wird verbreitet die Lesart der Hss. RBV bevorzugt: ut remotis binis unum ordinarent. Davon ausgehend wird postuliert, dass die Gesandten anstelle von Caecilianus und Donatus einen Dritten zum Bischof hätten erheben sollen (vgl. u.a. Frend, Donatist Church, 156; Grasmück, Coercitio, 81; Mandouze, PAC, 171; Monceaux IV, 24, 210; Monachino, AHP 2, 1964, 21 f.; Seeck, ZKG 30, 1909, 217; von Soden, Nr. 24, 36; Ziwsa, Optatus, 28). In diesem Fall stellt sich jedoch die Frage, warum kein neuer Bischof ordiniert wurde. Wenig überzeugend ist die Darstellung, dass die Unruhen der Donatisten dies verhindert hätten (so Monceaux und Grasmück). Die Entscheidung der Gesandten zu Gunsten der pars Caeciliani zeigt vielmehr, dass es von Anfang an um eine Entscheidung zwischen den zwei konkurrierenden Bischöfen gegangen war. Mit Edwards, Optatus, 26; Labrousse, SC 412, 229 Anm. 2; Turner, JThS 27 , 1926, 292. 
Dennoch ist es unangebracht, wegen der mangelnden Überprüfbarkeit Optatus' Darstellung grundsätzlich in Zweifel zu ziehen. Obwohl sich der Bericht nur schwer in den sonst bekannten Ereignisverlauf einfügen lässt und Augustinus ihn nicht für seine Argumentation benutzte, fehlen doch überzeugende Argumente, um eine Fälschung annehmen zu können. ${ }^{162}$

Wann aber wurde die Untersuchungsfahrt der Bischöfe Eunomius und Olympius durchgeführt und wann hielt sich Caecilianus in Brescia auf? In der Forschung ordnet man dieses Ereignis bisher in das Umfeld des kaiserlichen Urteils zu Gunsten Caecilians ein, also Mitte bis Ende des Jahres 315 bzw. 316. ${ }^{163}$ Aufgrund der Quellenlage ist eine gesicherte Datierung nicht

162 Seeck (ZKG 10, 1889, 562-566; 30, 1909, 216-220) hält die Akten über die bischöfliche Gesandtschaft nach Afrika für eine Fälschung und vermutet, dass Optatus selbst der Fälscher gewesen sei. In Unkenntnis des tatsächlichen Verlaufs nach dem römischen Konzil habe Optatus die kaiserliche Entsendung der Bischöfe erfunden, um ein schriftliches Zeugnis für die Bestätigung des römischen Urteils durch Konstantin und damit die Unumstößlichkeit des Freispruchs Caecilians vorlegen zu können. Folgende Indizien führt Seeck an: Die Katholiken hätten auf der Konferenz 411 auf eine Beweisführung mit Hilfe dieser Optatusstelle verzichtet, wodurch ihre Vorbehalte gegen die Darstellung des Optatus deutlich würden. Ferner hätten die Gesandten die weltweite Ausbreitung der Kirche als Kriterium zur Feststellung der Katholizität angeführt, eine Definition, die zur Zeit Konstantins noch nicht gegolten hätte. Schließlich hätte die Gesandtschaft nur vor der Durchführung der Synode von Arles stattfinden können, da sich die beiden Bischöfe ansonsten auf das Urteil dieser Synode berufen hätten und nicht auf das römische. Dies wäre aber nur sinnvoll gewesen, wenn die Gesandten in Arles ihren Bericht vorgelegt hätten. Da sie aber nicht unter den Teilnehmern aufgeführt werden, erweise sich die gesamte Episode als Schwindel. Dieses letzte Argument Seecks ist rein hypothetisch: Weder muss ein Bericht der Bischöfe in Arles vorgelegt worden sein noch lässt sich anhand des Quellenmaterials im Detail nachvollziehen, welche Informationen in Arles tatsächlich verwendet wurden. Seecks Zweifel, dass ein Hinweis auf die weltweite Verbreitung der Kirche die Katholizität bestätigen könne, sind zwar nicht ganz von der Hand zu weisen, doch greift auch Optatus in seiner $c a$ tholica-Vorstellung bereits auf ältere Traditionen zurück (vgl. Schindler, AL 1, 815 f., s. v. Catholicus, -a). Seecks Beobachtungen zu den Verhandlungen von 411 sind zwar richtig, allerdings genügen sie nicht, um die Fälschung einer Quelle zu erweisen. Nachdem er eigene Forschungen angestellt hatte, berief sich Augustinus nicht mehr auf Optatus, da er dessen Defizite erkannt hatte. Der Eumaliusbrief war nun das entscheidende Dokument für die Katholiken, so dass die bei Optatus berichtete Gesandtschaft, die sich nicht durch weitere Akten belegen ließ, als das schwächere Argument außen vor blieb. Diese Strategie zeigt sich auch auf der Konferenz von 411 (vgl. o. Kap. 5.3.2). Es darf auch nicht übersehen werden, dass die Katholiken und Augustinus die Tatsache des Brescia-Aufenthalts Caecilians niemals abstritten. Schließlich ist die von Seeck unterstellte Motivation des Optatus nicht schlüssig. Die unklaren Formulierungen zum Brescia-Aufenthalt und der wenig stringente Verlauf der Untersuchungsreise sprechen eher gegen eine gezielte Fälschung als dafür. Vgl. auch Grasmück, 82 Anm. 389.

163 Die Brescia-Episode wird entweder in das Jahr 315 vor das Urteil Konstantins (etwa Barnes, New Empire, 244; Frend, Donatist Church, 156-158; Keresztes, Constantine, 
möglich, aber entgegen bisheriger Vorschläge erscheint mir eine frühere Einordnung im historischen Zusammenhang plausibler: Es ist nahezu auszuschlieBen, dass die Inspektionsfahrt der Bischöfe nach dem iudicium Constantini im Herbst 315 stattfand. Zum einen bestätigten die Inspektoren nach Abschluss der Untersuchungen das Urteil des Miltiades. Damit bezogen sie sich auf das bisher einzige Urteil in der causa Caeciliani. Wäre bereits vom Kaiser selbst ein Urteil gesprochen worden, dürfte dieses der Bezugspunkt der Untersuchungskommission gewesen sein. Zum anderen ist es nicht einsichtig, warum Konstantin nach seinem Urteilsspruch über Caecilianus nochmals die Frage der RechtmäBigkeit von dessen Bischofsamt hätte überprüfen lassen sollen. ${ }^{164}$ Die Aufgabe von Eunomius und Olympius, lediglich die Lage der Kirchengemeinden in Karthago zu inspizieren und $\mathrm{zu}$ schlichten, deutet ganz offensichtlich auf eine frühere Phase hin, in der man am Hofe noch weitere Informationen anforderte und eine schnelle Einigung erhoffte.

Geht man nun von einer Datierung im unmittelbaren Vorfeld des kaiserlichen Urteils aus, ergibt sich ein anderes Problem: Optatus berichtet, dass nach Abschluss der Untersuchungskommission zunächst Donatus, dann auch Caecilianus sich eiligst auf den Weg nach Karthago machten, um zu ihren Gemeinden zu kommen. Folglich müsste man annehmen, dass beide Bischöfe bereits im Jahr $315 \mathrm{zu}$ Verhandlungen am Hof vorgeladen und eingetroffen waren, dann zurückkehrten und nochmals offiziell vor das kaiserliche Gericht geladen wurden. Dies ist zwar theoretisch möglich, aber in dem von Augustinus überlieferten Abriss über die Vorladung nach Rom ist davon nicht die Rede. ${ }^{165}$ Wesentlich einleuchtender ist die Annahme, dass Caecilianus und Donatus im Anschluss an das Konzil von Rom noch in Italien weilten, als die Entscheidung zur Bildung

79; Kraft, Entwicklung, 42 f.; Mandouze, PAC, 170-173; Monachino, AHP 2, 1964, 21 f.), oder sogar nach das Urteil gelegt (Duchesne, Dossier, 646; de Veer, BA 31, 822 824; Grasmück, Coercitio, 79-83; Mühlsteiger, ZRG KA 85, 1999, 45 f.). Monceaux (IV, 209 f.) datiert vor das iudicium Constantini, allerdings erst in das Jahr 316; vgl. auch Labrousse, SC 412, 64 Anm. 3; Maier I, 196 f. - Grasmück beruft sich auf die Aussagen der Donatisten und Augustins, die das „Exil“ von Brescia stets „,in direkter Beziehung zu dem Gericht und der Entscheidung des Kaisers" stellten (Coercitio, 82, Anm. 389). Doch gerade diese Beziehung ist von den Donatisten für ihre Argumentation forciert worden, so dass sie kein Argument für das tatsächliche historische Geschehen darstellt (s.o. Kap. 5.3.2). Ferner geht auch Grasmück davon aus, in Karthago hätte ein ganz neuer Bischof gewählt werden sollen und dies sei nach den bischöflichen Urteilen schwieriger zu akzeptieren gewesen als nach dem kaiserlichen Urteil. Doch gerade nach dem kaiserlichen Urteil zu Gunsten Caecilians wäre es sinnlos gewesen, die ganze Sache nochmals aufzurollen. Es ist wesentlich wahrscheinlicher, dass Konstantin nach seinem Urteil vorerst keine neuen Untersuchungen oder Entscheidungen fällte.

164 Vgl. die Argumente von Monceaux IV, $209 \mathrm{f}$.

165 Aus ep. 43.20 geht klar hervor, dass es nur eine Vorladung nach Rom gab (zur Problematik vgl. o. Kap. 4.2.1). 
der Untersuchungskommission fiel, die alsbald durchgeführt wurde. ${ }^{166}$ Insofern sind die Inspektionsreise und damit der Aufenthalt Caecilians in Brescia in das Frühjahr $314 \mathrm{zu}$ datieren. Diese Datierung wird nicht zuletzt durch Optatus bestätigt, der mit seiner Formulierung eodem tempore keinen großen Abstand zum römischen Konzil sieht. ${ }^{167}$

Die Entscheidung für die bischöfliche Untersuchungskommission in der causa Caeciliani fiel sehr wahrscheinlich am Hofe. Aus Optatus geht keineswegs hervor, dass jener Filuminus die Sache initiierte. ${ }^{168}$ Vermutlich sollten zunächst nur Donatus und seine Anhänger in Italien zurückgehalten werden, bis das weitere Verfahren geklärt war. Filuminus jedoch protestierte gegen die Ungleichbehandlung und es wurde entschieden, dass auch Caecilianus nicht nach Karthago zurückkehren durfte, sondern in Brescia die weitere Entwicklung abwarten musste. ${ }^{169}$ Die Gründe für das Einschreiten des Filuminus bleiben ungeklärt. Es ist keineswegs zwingend, die Polemik des Optatus zu übernehmen und Filuminus als Handlanger des Donatus zu titulieren. Es könnten auch andere, rechtliche oder politische Motive eine Rolle gespielt haben.

Konstantin versuchte, sich mit Hilfe der bischöflichen Gesandten einen Überblick über die verworrene Lage in Karthago zu verschaffen, die Ursachen des Streites aufzuspüren und eine Lösung anzustreben. In der Situation bot es sich an, die Gemeinden in Karthago in Abwesenheit der Kontrahenten besuchen zu lassen. Vermutlich stand die Hoffnung dahinter, Agitationen und Unruhen vorzubeugen und so leichter zu einer Schlichtung zu gelangen. Nach Abschluss der Untersuchung und der Bestätigung des römischen Urteils kehrten beide Bischöfe nacheinander zurück, ohne dass sich an der Lage etwas geändert hätte. Die weitere Entwicklung macht deutlich, dass die Donatisten ihre Position in Afrika weiter ausbauen konnten und weiterhin auf eine Entscheidung des Kaisers drängten.

Kommen wir zurück zur Argumentation der Donatisten. Optatus von Mileve besaß bei der Abfassung seines Werkes keine zusammenhängenden Informationen über das weitere kaiserliche Verfahren nach dem Urteil von Rom. Er wusste von Appellen der pars Donati beim Kaiser sowohl Caecilianus als auch Felix von Abthugni betreffend, er kannte den Prozessausgang gegen Felix und

166 So bereits Lietzmann, Geschichte III, $73 \mathrm{f}$.

167 Opt. I 26. Häufig werden die Unruhen, die während der Anwesenheit der Untersuchungskommission aufgetreten sein sollen, mit jenen Unruhen identifiziert, die Celsus im Jahre 315 an den Kaiser meldete (vgl. Opt. App. VII). Ebenso lassen sich aber die seditiosa der Donatisten (Opt. I 26) mit den Unruhen identifizieren, von denen Aelafius wohl im Frühjahr 314 aus Afrika berichtete (Opt. App. III).

168 So Frend, Donatist Church, 156; Pietri, Geschichte, 252 f.; Mühlsteiger (ZRG KA 85, 1999, 45): „Ein letzter von Donatus ausgeheckter Kompromissvorschlag“.

169 Über den Aufenthaltsort des Donatus wird nichts gesagt. Ob er ebenfalls in Brescia festgehalten wurde (so Pietri, Geschichte, $252 \mathrm{f}$.), muss offen bleiben. 
die besagten Akten über die Legation von Eunomius und Olympius. Optatus wusste, dass Caecilianus freigesprochen worden war, aber wann und unter welchen Umständen bleibt in seinem Werk offen. ${ }^{170}$

Die Donatisten nutzten nun den Mangel an chronologischer und inhaltlicher Präzision bei Optatus für ihre Zwecke aus. Für sie ging aus dessen Darstellung klar hervor, dass Caecilianus in Brescia auf kaiserliche Anweisung festgehalten worden war. Optatus, so interpretierten sie, habe in seiner Polemik eine euphemistische Formulierung gewählt, um die Wörter „Verbannung“ oder „Exil““ $\mathrm{zu}$ vermeiden. In Wahrheit habe es sich aber um ein Exil gehandelt, und dies impliziere ein kaiserliches Urteil gegen Caecilianus. Diese Auffassung vertraten Cresconius ebenso wie die donatistischen Vertreter auf der Konferenz von 411.

Die donatistische Beweisführung auf der Konferenz gibt indessen keine Auskunft über das Entstehen dieser donatistischen Tradition. In Karthago standen die Donatisten unter dem Zwang, einen Beweis ihrer Darstellung vorzulegen, und für diesen Zweck kam ihnen der Optatustext - letztlich mehr schlecht als recht - entgegen. Ohne diesen Beweiszwang genügte auch die eigene mündliche Tradition, unabhängig von Optatus, in der die Umstände von Caecilians Aufenthalt in Brescia als Erfolg ihrer Kirche beim Kaiser gedeutet wurden.

Auch wenn die Hintergründe von Caecilians Aufenthalt in Brescia sich nicht vollständig klären lassen, so wird dennoch deutlich, dass die donatistische Interpretation nicht den historischen Gegebenheiten entsprach. Selbst wenn man davon ausginge, dass Caecilianus nicht freiwillig „um des Friedens willen“ in Brescia weilte, so erlaubt der Zusammenhang mit der Untersuchung der Bischöfe Eunomius und Olympius keinesfalls den Schluss, es habe sich um ein Exil nach einem kaiserlichen Urteil gehandelt. Im weitesten Sinne könnte man Brescia vielleicht als Ort einer „Untersuchungshaft“ verstehen. Das entscheidende Dokument gegen die donatistische Auffassung bleibt jedoch heute wie im Jahre 411 der Eumaliusbrief vom November 316, in dem der Freispruch Caecilians nach der von Optatus berichteten Episode bezeugt ist.

\section{Die zweite Traditionslinie: Die Toleranz Konstantins}

Die zweite Traditionslinie, auf die sich die donatistischen Bischöfe im Jahre 411 beriefen, war die Gewährung einer religiösen Toleranz gegenüber den Donatisten, die Kaiser Konstantin im Jahre 321 erlassen hatte. ${ }^{171}$ Die beiden Dokumente, mit denen sie ihre Ansicht begründeten, sind heute nicht mehr erhalten, sondern lediglich durch Inhaltsangaben Augustins und die Informationen aus den Capitula der Konferenzakten fassbar.

170 Zur Chronologie bei Optatus vgl. Labrousse, SC 412, 68-72; Monceaux V, 276.

171 Vgl. o. Kap. 5.3.2. 
Es handelt sich hierbei um eine Bittschrift der donatistischen Partei an Kaiser Konstantin (libellus ad Constantinum) und das dazugehörige Reskript, das an den Vikar Verinus adressiert war. ${ }^{172}$ Die in Karthago vorliegenden Kopien dieser Dokumente waren nicht datiert, worauf in der Debatte allerdings kein Bezug genommen wurde. Der libellus beinhaltete Einwände und Klagen der Donatisten gegen die bisherigen Entscheidungen und Maßnahmen des Kaisers: Sie wehrten sich gegen ihre Verfolgung und betonten zugleich, dass sie trotz derartiger Repressionen Caecilianus niemals als Bischof anerkennen würden. Zudem wurde die causa Felicis thematisiert, ${ }^{173}$ vermutlich um die Anklagen gegen Caecilianus zu begründen. In seinem Reskript an den vicarius Africae äußerte sich Konstantin abfällig über die Hartnäckigkeit der Donatisten und ihre andauernden Appelle. Gleichwohl sprach er davon, dass verbannte Donatisten aus dem Exil zurückkehren und die donatistischen Gemeinden nicht weiter verfolgt werden sollten. Welche Gründe ihn dazu bewogen, ist aus den überlieferten Fragmenten nicht ersichtlich.

Nach der Konferenz ermittelte Augustinus den 5. Mai 321 als Datum des Reskriptes, als er anhand von Archivmaterial die Chronologie mehrerer Dokumente überprüfte. Diese Datierung dürfte richtig sein, da sowohl die formalen Angaben korrekt sind als auch Verinus durch andere Gesetze als Vikar vom 16. November 318 bis zum 29. August 321 nachzuweisen ist. ${ }^{174}$ Anhand dieser zeitlichen Einordnung wird deutlich, ${ }^{175}$ dass der donatistische libellus und das Reskript nicht mehr in den unmittelbaren Zusammenhang der Urteile über Caecilianus gehören, sondern in eine fortgeschrittene Phase der Auseinandersetzung. Zwangsmaßnahmen gegen die Donatisten waren bereits durchgeführt

172 Der Zusammenhang zwischen dem libellus und dem Reskript ist aus Augustins Darstellung (breuic. III 39-40; c. Don. 54; ep. 141.9) nicht zwangsläufig zu schließen, wird jedoch durch Cap. conl. Carth. III 543-548 evident. Seeck (ZKG 10, 1889, 533 f.) glaubte zunächst, es handele sich bei dem libellus um die Appellation der Donatisten gegen das Miltiadesurteil, da Konstantin offenbar erst dadurch mit der causa Felicis bekannt gemacht worden sei. Allerdings korrigierte er sich später (ZKG 30, 1909, 191; Geschichte III, 336) und stellte den libellus in den Zusammenhang mit der Toleranz von 321. Dies ist auch communis opinio in der Forschung. Vgl. zu den Dokumenten Monceaux IV 29, 198, 203, 208 f.; Pietri, Geschichte, 254 f.; Lamirande, BA 32, 734; Maier I, $239 \mathrm{f}$; mit Einschränkung allerdings von Soden, Nr. 30, $50 \mathrm{f}$.

173 Diesen wichtigen Hinweis aus Cap. conl. Carth. III 543 unterschlägt Augustinus in seinen kurzen Inhaltsangaben.

174 C. Don. 56: imperator ad Valerium [= Verinum] litteras dedit Crispo et Constantino iterum consulibus III Nonas Maias. - Zum Datum und zur Person (mit der Problematik des Namens Valerius bei Augustinus): Seeck, Regesten, 170 f.; ZKG 10. 1889. 534 f.; Barnes, New Empire, 146; PLRE I, 951 f., s. v. Verinus 2; Enßlin, RE VIII A 2, 1549 f., s. v. Verinus 3.

175 Monceaux (IV, $490 \mathrm{f}$.) datiert den libellus an Konstantin auf Anfang 321, folglich in das Frühjahr desselben Jahres das „Toleranzedikt“ gegenüber den Donatisten, von dem schließlich Verinus am 5. Mai in Kenntnis gesetzt wurde. 
worden, die unter anderem zur Verbannung einiger Bischöfe geführt hatten. ${ }^{176}$ Es ist davon auszugehen, dass Vertreter und Sympathisanten der Donatisten immer wieder versucht hatten, am Hof für ihre Sache einzutreten und gegen die Unterdrückung zu protestieren. Der 411 in Karthago vorgelegte libellus war folglich nur eine von vielen Petitionen, mit der Besonderheit, dass diese zu einem gewissen Erfolg geführt hatte. Denn es ist nicht in Abrede zu stellen, dass Verinus in dem Reskript über eine Änderung der kaiserlichen Politik gegenüber den Donatisten informiert wurde und die Anweisung erhielt, keine weiteren Maßnahmen gegen die Donatisten in seinem Verwaltungsbereich durchzuführen. Möglicherweise erhielt der amtierende Prokonsul Afrikas einen gleichlautenden Brief Konstantins.

Unter den Appendizes bei Optatus befindet sich ein Brief Konstantins an die katholischen Bischöfe und Gemeinden, der sehr wahrscheinlich in diese Zeit gehört. Der Kaiser räumt hier ein Scheitern der bisherigen Maßnahmen ein und überlässt die „Korrektur“ der „Verirrten“ nunmehr Gott selbst. Die katholischen Adressaten bittet er gleichzeitig um Toleranz und Geduld, auch gegenüber Gewalttaten der Donatisten. ${ }^{177}$

Im Hinblick auf mögliche Ursachen für die neue Politik Konstantins seit 321 wird in diesem Brief zumindest ein Grund benannt: Die bisherige Art und Weise der Bekämpfung der Donatisten hatte keinen nennenswerten Erfolg gebracht, sondern zum Teil sogar das Gegenteil hervorgerufen, weil die Verfolgten sich in ihrer Rolle als Märtyrer gefielen. Außer diesem Eingeständnis eines Misserfolgs dürften allerdings auch andere politische Erwägungen Konstantin beeinflusst haben. So war die Befriedung der Provinz Afrika sicherlich eine wichtige Voraussetzung für anstehende militärische Auseinandersetzungen sowohl im Feldzug gegen Licinius als auch hinsichtlich notwendiger Verteidigungen im Donauraum. ${ }^{178}$

$176 \mathrm{Zu}$ dieser Phase vgl. Grasmück, Coercitio, 85 ff.; Tilley, Bible, 57-69; s. o. Kap. 7.4.1.

177 Opt. App. IX. Zum Dokument: von Soden Nr. 31; vgl. Dörries, Selbstzeugnis, 38 f.; Maier I, Nr. 30, 239-242; Monceaux IV, 203; Grasmück, Coercitio, 91-93. - Seeck datiert den Brief auf das Frühjahr 316 (ZKG 30, 1909, 213). Gegen diese Datierung im direkten Zusammenhang mit dem Urteil in der causa Caeciliani spricht allerdings, dass Konstantin offensichtlich erst seine kompromisslose Haltung gegen die Donatisten aufgab, nachdem sie einige Zeit bekämpft worden waren.

178 Ein entsprechender Zusammenhang mit dem Kampf gegen Licinius deutet sich in einem Brief des Kaisers an, den er Ende des Jahres 324 an den alexandrinischen Bischof Alexander und dessen Priester Arius gesandt hatte. Konstantin schreibt dort, dass er die Lage in Afrika beruhigen wolle und nun, nach seinem Sieg über Licinius, Anstrengungen zur Wiederherstellung der Einheit treffen werde (Eus. VC II 64-68; vgl. Maier I, Nr. 31, 242-245; Monceaux IV, 203). - S. Bralewski (Est-ce que l'empereur Constantin le Grand accorda la tolérance à l'égard des donatistes?, Eos 88, 2001, 127-132) plädiert dafür, den Begriff „Toleranz“ für die Phase seit 321 nicht zu verwenden, da es sich im Gegensatz zur Toleranz gegenüber den Christen in den Jahren 311 und 313 
Die donatistischen Bischöfe im Jahre 411 beriefen sich somit hinsichtlich einer Toleranz Konstantins durchaus auf historische Tatsachen. Mit dem Reskript an Verinus konnten sie nachweisen, dass der Kaiser zu einem bestimmten Zeitpunkt den Donatismus geduldet und zuvor verbannte Bischöfe freigelassen hatte. Augustinus und die Katholiken kannten bis zu diesem Zeitpunkt weder den libellus der Donatisten noch das Reskript noch die Toleranzmaßnahmen des Kaisers an sich. Augustinus ging jedenfalls grundsätzlich von einer kontinuierlichen Gesetzgebung gegen die Donatisten aus. ${ }^{179}$ Insofern hatten die Donatisten im Jahre 411 ein Überraschungsmoment auf ihrer Seite. Allerdings verlor dieses schnell an Überzeugungskraft, da Marcellinus und die katholischen Bischöfe dem Reskript Konstantins in juristischer Hinsicht keine aktuelle Relevanz beimaßen und in historischer Hinsicht kein neues Argument zu einem Urteil gegen Caecilianus erblickten. ${ }^{180}$ Das Scheitern der donatistischen Argumentation lag insofern in diesem Fall nicht an der fehlenden Authentizität der vorgelegten Dokumente, sondern an der fälschlichen Vereinnahmung dieser Dokumente für die causa Caeciliani.

Während die donatistische Tradition einer Verbannung Caecilians nachweislich bereits vor der Konferenz von 411 existierte, lässt sich nicht eindeutig feststellen, ob Bittgesuch und kaiserliches Reskript den Donatisten schon längere Zeit als Zeugnisse ihrer Argumentation dienten. Gegen eine solche Annahme spricht, dass die Donatisten kaum mit kaiserlichen Dokumenten argumentierten und Augustinus im Gegensatz zu anderen donatistischen Zeugnissen niemals mit diesen Schreiben konfrontiert worden war. Die ältere donatistische Tradition war durch die Märtyrerakten geprägt, zu denen auch Opfer der Verfolgung unter Konstantin gehörten. ${ }^{181}$ Es ist daher sehr wahrscheinlich, dass die Zeugnisse, die Konstantin als einen Kaiser auf Seiten der Donatisten darstellen sollten, erst in der Vorbereitung zur Konferenz von 411 von den Donatisten herangezogen und ausgewertet worden sind.

\section{Die dritte Traditionslinie: Der Freispruch des Felix von Abthugni}

Die dritte Traditionslinie schließlich war die donatistische Version der causa Felicis. Felix von Abthugni galt als Urheber des Schismas und die Überzeugung von seiner Schuld gehörte zu den ältesten Überlieferungen der Donatisten. Es wurde bereits dargelegt, auf welche Weise die Donatisten auf der Konferenz von 411 versuchten, Felix von Abthugni als Traditor zu überführen und seine Re-

lediglich um eine Unterbrechung der Verfolgung, nicht aber um eine Anerkennung gehandelt habe. Zweifellos müssen die religionspolitischen Entscheidungen der Jahre 311, 313 und 321 differenziert betrachtet werden, eine Änderung der üblichen Begrifflichkeit ist jedoch in der Sache nicht weiterführend.

179 C. Don. 54.

180 Cap. conl. Carth. III 550, 552.

181 Vgl. o. Kap. 6.3.1. 
levanz für die Ordination Caecilians nachzuweisen. Der Brief des Kaisers an Probianus diente ihnen als Beweis, dass gegen Felix eine Revisionsverhandlung vor dem Kaiser mit einer Verurteilung abgeschlossen worden sei. Der Inhalt des Briefes bestätigt diese Interpretation jedoch nicht. ${ }^{182}$

Die Besonderheit der donatistischen Darstellung auf der Konferenz von 411 lag in der Zusammenführung dieser drei genannten Traditionslinien zur Präsentation eines möglichst geschlossenen Geschichtsbildes, in dem auf der einen Seite Felix von Abthugni und Caecilianus als kirchlich und weltlich verurteilte Frevler, auf der anderen Seite die Donatisten als rechtmäßige Vertreter der Kirche erscheinen sollten. In dieses vorgefasste Bild passte natürlich die Tradition einer Verbannung Caecilians nach Brescia, die Verurteilung des Felix sowie ein Dokument, das die Aufhebung von Verfolgungsmaßnahmen und eine Rückkehr von Donatisten aus dem Exil verkündete.

Während der Optatustext und der Probianusbrief tatsächlich in den Kontext der causa Caeciliani passten, versuchten die Donatisten, mit der Vorlage des Bittgesuchs ihrer Vorfahren und des Reskriptes an Verinus für sie günstige Dokumente in ihrer Argumentation einzusetzen, obwohl sie einem anderen Kontext entstammten. Die Donatisten ignorierten die tatsächliche chronologische Einordnung; möglicherweise legten sie bewusst Abschriften ohne Datierung vor, um sich in dieser Hinsicht nicht festlegen zu lassen. Auf diese Weise suggerierten die Donatisten einen direkten Zusammenhang der Petition ihrer Vorfahren und dem Reskript an Verinus mit den kaiserlichen Entscheidungen über Caecilianus und Felix von Abthugni. In der Summe sollte deutlich werden, dass der im Brief an Eumalius berichtete Inhalt, auf den sich die Katholiken stützten, nicht dem letzten Stand der Dinge entsprach. Denn, so die dreifache Begründung der Donatisten: Laut Optatus musste Caecilianus in die Verbannung, laut Brief an Probianus hatte der Kaiser auch die Schuld des Felix erkannt und dem Brief an Verinus zufolge hatte die donatistische Kirche ihre Anerkennung durch Konstantin erreicht.

Wenn nun Augustinus dieser Argumentation mit der Bemerkung entgegentrat, dass doch auch die donatistischen Zeugnisse eine Verurteilung der Donatisten belegten und keinesfalls eine Verurteilung Caecilians, ${ }^{183}$ dann verkannte oder überdeckte er absichtlich die tatsächlichen Argumentationsabsichten der Donatisten. Diese leugneten nämlich nicht ausdrücklich, dass Konstantin schon einmal ein Urteil zu Gunsten Caecilians gesprochen hatte, aber ein solches Urteil sahen sie durch ein späteres revidiert.

Die historische Argumentation der donatistischen Bischöfe auf der Konferenz von Karthago beruhte auf der Kombination von alten Traditionslinien mit

182 Vgl. o. Kap. 6.1.3.

183 Breuic. III 39; ep. 141.9; c. Don. 54. 
neu herangezogenen Dokumenten. Die Vorstellungen, dass Caecilianus und Felix vom Kaiser verurteilt worden seien, existierten bereits längere Zeit vor der Konferenz, vermutlich in unterschiedlichen Variationen. Es gab keine eigene donatistische Geschichtsschreibung, auf der die Donatisten 411 hätten aufbauen können. Erst aus der Notwendigkeit heraus entwickelten sie ein Konzept auf Grundlage der ihnen zur Verfügung stehenden schriftlichen Zeugnisse. Die zum Teil erheblichen Widersprüche dieser Quellen zu den Aussageabsichten der Donatisten zeigen jedoch, dass ihnen keine Dokumente zur Verfügung standen, die eine überzeugende historische Beweisführung ermöglichten.

Die älteren Überlieferungen der Donatisten waren nicht darauf ausgerichtet, eine kaiserliche Verurteilung Caecilians zu beweisen. Deutlich erkennt man in der Heranziehung neuer Zeugnisse, insbesondere bei der Verwendung des Reskriptes an Verinus, das Bemühen, dieses Defizit auszugleichen und sich den neuen Anforderungen zu stellen. Die älteren Überlieferungen betonten die Rolle der Donatisten als verfolgte Kirche der Märtyrer. Die Entscheidungen der Prozesse in Übersee waren für die Donatisten unerheblich, solange sie sich auf Grundlage ihres Selbstverständnisses als Kirche der Märtyrer verteidigen und behaupten konnten. Durch die Verfahrensweise der Konferenz von 411 wurden sie gezwungen juristisch und dem Kaiser loyal gegenüber zu argumentieren. Ein entsprechendes Argumentationsmodell, in dem Konstantin nicht mehr als Verfolger, sondern als anerkannter oberster Richter mit einer Entscheidung zugunsten der Donatisten auftrat, musste auf der Konferenz präsentiert werden. Die hastig vorgelegten Dokumente konnten jedoch nicht darüber hinwegtäuschen, dass die Donatisten einstmals bei Konstantin unterlegen waren.

\subsubsection{Geschichtsdeutungen bei Parmenianus}

Dass die donatistische Argumentation von 411 kein gefestigtes und vollständiges Bild donatistischer Traditionen abgibt, lässt sich durch eine von der Konferenz unabhängige Überlieferung zur causa Caeciliani bekräftigen, die in Augustins Schrift gegen Parmenianus erhalten ist. Augustinus zitiert dort Anschuldigungen Parmenians gegen den Bischof Ossius von Cordova, der zur Zeit Konstantins eine einflussreiche Persönlichkeit in der Kirchenpolitik war.

Parmenianus trat der katholischen Vorstellung entgegen, dass die Kirche über den ganzen Erdkreis verbreitet sein müsse. ${ }^{184} \mathrm{Er}$ begründete die donatistische Ablehnung der außerafrikanischen Kirchen mit dem Argument, dass diese von Sünden vergiftet worden seien, zum einen durch Verbrechen ihrer Bischöfe während der Verfolgungszeit ${ }^{185}$ zum anderen durch ihre Gemeinschaft

184 C. ep. Parm. I 1. - Augustinus analysiert und widerlegt mit den Schriften contra epistulam Parmeniani und de baptismo Parmenians Brief gegen Tyconius. Vgl. hierzu Congar, BA 28, 201-205, 718-720; Monceaux V, 231-237 und o. Kap. 2.2.2.

185 C. ep. Parm. I 4. 
mit den Traditoren Afrikas (societas criminum). ${ }^{186}$ In diesem Zusammenhang ging Parmenianus auch auf die causa Caeciliani ein und beurteilte das Prozedere der Entscheidungen aus seiner Sicht. Die vagen Formulierungen Augustins lassen jedoch nur schwer erkennen, welches Bild Parmenianus von den Ereignissen zeichnete. Offenbar berief er sich aber auf die Berichte seiner donatistischen Kollegen, die an den Verhandlungen von Rom, Arles und Mailand beteiligt waren, denn Augustinus weist mehrmals auf die mangelnde Beweiskraft solcher Aussagen hin. ${ }^{187}$ Parmenianus dagegen betonte, wie zuverlässig und wahrhaftig diese Bischöfe das Anliegen der Donatisten außerhalb Afrikas vertreten hätten.

Ohne dass die näheren Umstände erklärt werden, erwähnte Parmenianus die Gesandtschaft einiger Bischöfe in die europäischen Provinzen, die dort die Beschwerden der afrikanischen Donatisten klar und deutlich vorgebracht hätten. ${ }^{188}$ Vermutlich spielte er damit auf die Konzile von Rom und Arles an, auf denen die Anklagen gegen Caecilianus vorgetragen wurden. Dass Parmenianus die bischöflichen Urteile und die Verhandlungen vor dem Kaiser kannte und in seinem Brief erwähnte, ergibt sich aus den weiteren Ausführungen Augustins. Parmenianus sprach offensichtlich sehr positiv von einem beständigen Bemühen der donatistischen Vertreter, ihre Anliegen zu Gehör zu bringen. Letztlich ging er aber wohl von einer Niederlage und der Verurteilung der Donatisten in allen Instanzen aus, denn er versuchte nicht wie die Donatisten auf der Konferenz von 411, eine Verurteilung oder Verbannung Caecilians zu belegen. Im Gegenteil: Er versuchte die Urteile als Fehlentscheidungen darzustellen, indem er Anklagen gegen die Richter und die Prozesse erhob. Er unterstellte traditio, Korruption und einseitige Begünstigungen bei den Bischöfen und bei Konstantin, die ein gerechtes Urteil nicht zugelassen hätten. ${ }^{189}$

186 C. ep. Parm. I 2; vgl. I 6: frustra itaque dicit Parmenianus damnatos in Africa traditores in consortium sanctitatis acceptos a prouinciis transmarinis.

187 C. ep. Parm. I 2-3.

188 C. ep. Parm. I 2: dicit [Parmenianus] enim legatione functos quosdam, sicut ipse asserit, fidelissimos testes ad easdem uenisse prouincias [sc. Gallias, Hispanias, Italiam]; deinde geminato aduentu sanctissimorum, sicut ipse dicit, domini sacerdotum dilucide plenius ac uerius publicata esse quae obiciunt. - Congar (BA 28,721) verweist von dieser Stelle auf ep. 43.19 und Augustins Aussage, dass die Donatisten aus Furcht vor einer Anklage mit außerafrikanischen Kirchen in Kontakt kommen wollten. Allerdings ist dies eine Unterstellung Augustins. In der Aussage Parmenians wird deutlich, dass die Donatisten bei den europäischen Kirchen um eine Anerkennung ihres karthagischen Bischofs warben. Vgl. Monceaux IV, 21.

189 C. ep. Parm I 10-11: „Parmenianus gesteht auch ein, dass in der Stadt Arles bischöfliche Richter und die Parteien aus Afrika zusammengekommen sind, nämlich Caecilianus und die Donatisten. Er vertraute dabei vollkommen seinen Leuten, die als Besiegte nichts tun konnten, außer die Richter zu verleumden; und er leugnet auch nicht, dass sie wiederum zu Konstantin gekommen sind, und, weil sie auch dort durch ein endgültiges 
Eine gewichtige Rolle in den Prozessen gegen Caecilianus räumte Parmenianus dem Bischof Ossius von Cordova ein. ${ }^{190}$ Parmenianus erwähnte Ossius zunächst als Beispiel, um seine Anschuldigungen gegen die europäischen Kirchen zu untermauern. Er legte dar, dass Ossius von spanischen Bischöfen aufgrund irgendeines Vergehens rechtmäßig verurteilt worden, dieses Urteil jedoch später von gallischen Bischöfen aufgehoben worden sei. Ossius sei in die Kirche zurückgekehrt und die Spanier hätten sich diesem Urteil gebeugt. Sie hätten also einem falschen Urteil nachgegeben, anstatt standhaft zu bleiben. Dieses Beispiel diente Parmenianus als Parallele zum Fall Caecilianus: Anders als die spanischen Bischöfe hätten sich die Afrikaner, also die Donatisten, nicht dem Urteil gallischer Bischöfe (in Rom und Arles) untergeordnet, sondern seien im Bewusstsein der Wahrheit im Widerstand geblieben. ${ }^{191}$

Außer diesem Vergleich äußerte sich Parmenianus auch zu Tätigkeiten des Ossius von Cordova im Fall Caecilians. Dieser sei dafür verantwortlich gewesen, dass die Rückkehr wahrer Christen in die Kirchengemeinschaft Caecilians erzwungen worden sei. ${ }^{192}$ Auf den Rat des spanischen Bischofs hin, so meinte wohl Parmenianus, sei Konstantin gegen die Donatisten beeinflusst worden, was dazu geführt hätte, dass die Donatisten nach den bischöflichen Entscheidungen vom Kaiser verurteilt worden seien und Verfolgung erleiden mussten. ${ }^{193}$ Ossius war

Urteil besiegt worden sind, nun auch diesen beschuldigen, durch Gefälligkeit korrumpiert worden zu sein." (Fatetur etiam Parmenianus ad Arelatense oppidum et episcopos iudices et partes ex Africa conuenisse, Caecilianum scilicet atque Donatistas. ubi omnia suis credidit, qui nihil uicti potuerunt nisi de iudicibus conqueri, nec tamen negat rursus eos ad Constantinum uenisse et, quia ibi quoque ultimo iudicio superati sunt, etiam ipsum gratia corruptum esse criminatur). - Zu den Vorwürfen gegen die bischöflichen Richter vgl. o. Kap. 6.1.4.

190 Ossius von Cordova (ca. 256-357/58) gehörte zu den Ratgebern Konstantins, insbesondere im Arianischen Streit. Er war einer der einflussreichsten Bischöfe seiner Zeit und an den Entscheidungen der Synoden von Antiochia, Nicäa und Serdika maßgeblich beteiligt. Zur Person: V. C. de Clercq, Ossius of Cordova, A Contribution to the History of the Constantinian Period, Washington 1954; kritisch dazu: A. Lippold, Bischof Ossius von Cordova und Konstantin der Große, ZKG 92, 1981, 1-15; vgl. auch Girardet, Kaisergericht, passim; Congar, BA 28, 722 f.; Drake, Constantine and the Bishops, 217 224.

191 C. ep. Parm. I 7-8.

192 C. ep. Parm. I 10: cum enim diceret per Ossium Hispanum adiutorium praestitum Caeciliano, ut ad eorum communionem sanctorum et inlibatorum numerus cogeretur, et huic impietati fidem seruorum dei integram restitisse.

193 C. ep. Parm I 13: „Parmenianus wagt sogar sich darüber zu beklagen, dass Konstantin befohlen habe, sie [die Donatisten] auf das Schlachtfeld, das heißt einer Strafe zuzuführen. [Damit meint er] jene, die von den kirchlichen Richtern besiegt wurden, vor ihm [dem Kaiser] ihre Behauptungen nicht beweisen konnten und die durch gottlose Verblendung bis heute Spaltungen in die heilige Kirche gebracht haben. Und er beschuldigt [den Kaiser], er hätte diesen so grausamen Befehl aufgrund des Rates des Spaniers Ossius gegeben. Dies sind die üblichen Verdächtigungen, mit denen wie immer Men- 
in Parmenians Augen sowohl für die abschlägigen Urteile gegen die Donatisten als auch für die ersten Zwangsmaßnahmen zur Durchsetzung der Kircheneinheit verantwortlich. ${ }^{194}$ Parmenianus verleumdete Ossius folglich in zweifacher Weise: Er sah in ihm sowohl den von einem spanischen Konzil verurteilten, das heißt exkommunizierten Bischof, zum anderen den Kopf und die Triebfeder der antidonatistischen Politik am Kaiserhof.

Augustinus verteidigt in contra epistulam Parmeniani die Universalität der katholischen Kirche und weist die Ausführungen seines Gegners zurück. Die Vorwürfe gegen die Verfahren und die Richter in der causa Caeciliani lehnt er mit Verweis auf die vorliegenden Akten als unbegründet ab. Die katholischen Kirchen hätten sich rechtmäßigen Entscheidungen angeschlossen und könnten daher nicht pauschal abgeurteilt werden. ${ }^{195}$

Bei der Beurteilung von Ossius von Cordova hält sich Augustinus allerdings auffällig zurück. Offensichtlich wusste er nichts zu den Umständen der von Parmenianus angesprochenen Verurteilung des Ossius von spanischen Bischöfen. Er verteidigt zwar die Revisionsentscheidung der gallischen Bischöfe als Sieg der christlichen Milde gegenüber falschen Anklagen, aber dies formuliert er lediglich als Vermutung, um gleichzeitig das Sakrileg der Spaltung bei den Donatisten anzuprangern. Die Donatisten wollten nicht anerkennen, dass die europäischen Urteile im Fall Caecilianus gültig seien. Wenn Parmenianus noch lebte, folgert Augustinus, würde er ohnehin nicht mehr die spanischen Bischöfe für ihren Wankelmut verurteilen, da die Donatisten im Maximianistischen Schisma, bei Primianus wie bei Praetextatus und Felicianus, die Revisionsurteile ebenso anerkannt hätten. ${ }^{196}$ Hinsichtlich der Ratgebertätigkeit des Ossius bei Konstantin erwidert Augustinus lediglich, dass trotz eines so schweren Verbrechens, wie das der Kirchenspaltung, Ossius den Kaiser eher zu einem milderen Umgang mit den Donatisten aufgefordert hätte. Aber auch diese Aussage formuliert Augustinus als Vermutung und fügt eine scharfe Polemik gegen das

schen verurteilt werden, die nicht angehört worden sind." (Quin etiam conqueri audet Parmenianus, quod eos Constantinus ad campum id est ad supplicium duci iussit, qui uiciti aput ecclesiasticos iudices nec aput ipsum quae dicebant probare potuerunt et adhuc in sanctae ecclesiae praecisiones sacrilego furore ferebantur, et hoc eum tamquam immaniter iussisse Hispano Ossio suggerente criminatur, suspicionibus uidelicet suis, sicut semper, damnando inauditos).

194 Gegen Monceaux (V, 235 f.) sehe ich aus c. ep. Parm. I 10-11, 13 nicht, dass Ossius in der causa Felicis sowie bei den Konzilen in Rom und Arles in der causa Caeciliani direkten Einfluss genommen hätte. Die Aussagen lassen lediglich den Schluss zu, dass Ossius nach den wiederkehrenden Appellen der Donatisten dem Kaiser zu einer strengen Position geraten hatte.

195 C. ep. Parm. I 10-12. Augustinus verwendet hier die rhetorische Figur der Prosopopöie und lässt die Kirche von Philadelphia gegen die ungerechtfertigten Anklagen der Donatisten sprechen.

196 C. ep. Parm. I 8-9. 
falsche Martyriumsverständnis der Donatisten hinzu. ${ }^{197}$ Er weicht somit den direkten Anschuldigungen gegen Ossius aus und verteidigt die Maßnahmen gegen die Donatisten in allgemeiner Form.

Wann und in welcher Form Ossius von Cordova in den engeren Kreis um Konstantin gekommen war und welche Rolle er im Donatistenstreit spielte, lässt sich nicht mit Sicherheit sagen und wird in der Forschung kontrovers beurteilt. ${ }^{198}$ Fest steht lediglich, dass er wohl seit dem Jahr 324 in der Auseinandersetzung mit Anhängern des Arius im Vertrauen des Kaisers stand.

In Bezug auf den Donatismus kann außer den Aussagen Parmenians und Augustins nur eine weitere Stelle auf Ossius von Cordova bezogen werden: In einem bei Eusebius überlieferten Brief Konstantins an Bischof Caecilianus wird ein gewisser „Hosius“ (Ossius) in einer Funktion am Hofe des Kaisers erwähnt. ${ }^{199}$ Daraus geht hervor, dass dieser Hosius von Konstantin beauftragt worden sei, die Zuteilung der kaiserlichen Gelder für den Wiederaufbau der Kirchen zu verteilen und dafür eine Liste der Empfangsberechtigten angefertigt habe. Dieser Liste zufolge sollte auch Caecilianus von Karthago in Afrika Gelder empfangen und verteilen. Obwohl in der Forschung mehrheitlich angenommen wird, dass jener „Hosius“ mit Ossius von Cordova zu identifizieren ist, bleibt dies äußerst spekulativ. ${ }^{200}$ Es passt jedoch ins Bild donatistischer

197 C. ep. Parm. I 13.

198 De Clercq postuliert lediglich eine eingeschränkte Beratertätigkeit des Ossius. So sei die inkonsequente Haltung Konstantins gegenüber den Donatisten zu erklären. Weiterhin vermutet er, dass Ossius bei den europäischen Bischöfen gegen die Donatisten agitiert habe und auch der Vorschlag, Militiades als Richter zu bestimmen und das Konzil von Arles durchzuführen, auf Ossius zurückgehe. Lippold (ZKG 92, 1981, 1-15) beurteilt die Quellen zu Ossius wesentlich skeptischer und kritisiert, dass es de Clercq und anderen nur durch eine Kette an Hypothesen gelinge, etwas über Ossius' Rolle am Hof Konstantins vor dem Jahr 325 auszusagen. Die herangezogenen Zeugnisse (Eus. HE X 6.2-3, Zos. II 29.3; Eus. VC 32 sowie eine Vita Constantini aus dem 10. Jh. (Cod. Ang. gr. 22)) seien allesamt zu ungenau, um eindeutige Aussagen über Ossius zu treffen. Auf die von Parmenianus unterstellte Verurteilung in Spanien geht Lippold nur ganz am Rande ein (ebd., 8).

199 Brief Konstantins an Bischof Caecilianus bei Eus. HE X 6.2-3. - Zum Dokument: Maier I, Nr. 12, 140-142; von Soden Nr. 8; vgl. o. Kap. 7.2.

200 Vgl. die berechtigte Kritik an der communis opinio bei Lippold (ZKG 92, 1981, 5-7 und passim). Eine Identifizierung von jenem Hosius mit Ossius von Cordova liegt nahe, wenn man davon ausgeht, dass Ossius bereits zu diesem Zeitpunkt (im Jahre 312/313) am Hof Konstantins weilte und mit kirchenpolitischen Aufgaben betraut wurde, eine Hypothese, die sich, wie Lippold darlegt, kaum anhand der Quellen nachweisen lässt. Zur Interpretation von Zos. II 29.3 in Bezug auf Ossius vgl. auch Paschoud, Zosime, 57 und H.-U. Wiemer, Libanios und Zosimus über den Rombesuch Konstantins im Jahre 326, Historia 43, 1994, 469-494, hier 485 f. - Selbst unter der Annahme, es handele sich bei genanntem Hosius um Ossius von Cordova, bleiben jegliche Aussagen über die Haltung des Ossius zum Donatismus Spekulation. Es lässt sich aus den Quellen nicht 
Vorstellungen, wenn sie in Ossius einen der Hauptverantwortlichen für die Geldzuweisung an die Katholiken und an Caecilianus sahen und daran Interesse hatten, diesen Mann in Misskredit zu bringen. Denn die Donatisten klagten Caecilianus beim Kaiser an, gerade weil sie dessen Anerkennung durch den Kaiser und die europäischen Kirchen entgegentreten wollten. Die Anschuldigungen Parmenians lassen darauf schließen, dass die Rolle, die Ossius später in der Kirchenpolitik spielte, großes Misstrauen weckte. Es lag für die Donatisten nahe, dass Ossius, so wie er die Fäden im Arianischen Streit zog, auch gegen sie intrigierte. Der Brief Konstantins an Caecilianus war möglicherweise bekannt und konnte als Anlass derartiger Vermutungen herangezogen werden. Auch wenn keine weiteren Informationen oder schriftliche Zeugnisse über das Wirken des Ossius in diesen Jahren vorlagen, so genügten, wie bei den übrigen bekannten persönlichen Beschuldigungen, kleinste Hinweise und Gerüchte, um ein entsprechendes Feindbild aufzubauen.

Allerdings dürfte es falsch sein, Parmenians Darstellung als reine Erfindung zu werten. Es lässt sich aus der Erwähnung bei Augustinus durchaus schließen, dass Ossius bereits seit dem Jahr 313 bei Konstantin Einfluss besaß und die Interessen der katholischen Kirche vertrat. Mit zunehmender Schärfe des Konfliktes in Afrika drückte sich dieser Einfluss antidonatistisch aus. Möglicherweise verstand Augustinus Parmenians Anklagen in ähnlicher Weise, denn er leugnet nicht die Tätigkeit des Ossius, sondern legt sie nur zu Gunsten der katholischen Kirche aus: Ossius habe sich für die Kirche eingesetzt, indem er gegen das größere Übel, gegen das sacrilegium schismatis vorgegangen sei.

Im Gegensatz zur Darstellung der causa Caeciliani bei Cresconius und bei den donatistischen Bischöfen im Jahre 411 formulierte Parmenianus in seinem Brief eine ältere Tradition, die zweifellos den tatsächlichen Begebenheiten näher stand als die Bemühungen, Caecilians Verurteilung durch Konstantin nachzuweisen: Parmenianus ging von einem Freispruch Caecilians in Rom, Arles und im kaiserlichen Verfahren aus. Alle Entscheidungen, die kirchlichen und die kaiserlichen betrachtete er jedoch als Fehlentscheidungen, die durch Korruption und unrechtmäßiges Verfahren zustande gekommen seien. Im Falle des kaiserlichen Urteils gab er Ossius von Cordova die Schuld, den er auch für die beginnende Verfolgung der Donatisten verantwortlich machte. Parmenians Zeugnis verrät, dass Konstantin bei den Donatisten als Verfolger galt, der sich angestachelt durch falsche Ratgeber, wie etwa Ossius von Cordova, gegen die Donatisten entschieden hätte. ${ }^{201}$ Ausgehend von dieser donatistischen Überlie-

erschließen, dass Ossius eine klare antidonatistische Haltung eingenommen oder den Kaiser gegen die Donatisten beeinflusst hätte.

201 Möglicherweise griffen die donatistischen Bischöfe auf der Konferenz von Karthago auch auf die Überlieferung Parmenians und dessen Äußerungen über Ossius zurück, als sie andeuteten, dass ein „falsches Urteil“ Konstantin zu Ohren gekommen sei (Cap. Conl. Carth. III 519; vgl. breuic. III 37). 
ferung gingen Katholiken und Donatisten somit von den gleichen historischen Gegebenheiten aus. Was sie trennte, waren unterschiedliche Beurteilungen.

\subsection{Das Urteil Konstantins bei Augustinus}

Augustins Interpretation des iudicium Constantini ist bereits an verschiedenen Stellen angesprochen worden. ${ }^{202}$ Für seine Argumentation verwendete er die Informationen aus dem Brief an Eumalius. Dabei ist anzunehmen, dass er die wesentlichen Aussagen dieses Briefes weitergab. Dies bedeutet, seine Kenntnisse über den Ablauf nach dem Konzil von Arles waren wahrscheinlich geringer als unsere Kenntnisse heute, da ihm die anderen Briefe Konstantins aus diesem Zeitraum nicht bekannt waren. Diese Lücken konnten die Donatisten ausnützen und mit ihren Geschichtsinterpretationen ausfüllen, wie es unter anderem auf der Konferenz von 411 geschah. ${ }^{203}$

Bezeichnend ist die Unsicherheit Augustins hinsichtlich der Chronologie. Erst nach erneuten Recherchen nach der Konferenz von 411 stellte Augustinus fest, dass der Freispruch des Felix von Abthugni vor dem Urteil Konstantins gefällt worden war, eine für die gesamte Interpretation des Verlaufs sehr gewichtige Feststellung. ${ }^{204}$ Bei anderen Ereignissen sah sich Augustinus ebenso im Dunkeln wie die Historiker heute. So fehlten ihm bereits die Dokumente, die eine sichere Datierung des iudicium Constantini ermöglichten; wiederum erst nach der Konferenz konnte er durch die Datierung des Eumaliusbriefes eine annähernde Vorstellung der zeitlichen Abfolge gewinnen. Die bei Optatus überlieferte und von den Donatisten verwendete Brescia-Episode überforderte ebenfalls Augustins chronologische Kenntnisse. Er versuchte die Widerlegung der donatistischen Argumente, ohne eine Einordnung vornehmen zu können.

Augustins Beurteilung des iudicium Constantini orientiert sich an der Tatsache, dass Caecilianus freigesprochen wurde. Darüber hinaus betont er die Sorgfalt der kaiserlichen Untersuchung, die Umsichtigkeit des Urteils sowie die Autorität und die andauernde Gültigkeit dieser Entscheidung. Dagegen werden weder die politische Dimension des kaiserlichen Eingreifens noch die kirchenpolitischen Folgen deutlich. Gegenüber den Donatisten vermied Augustinus eine klare Stellungnahme, die über den Kontext der Ereignisse Aufschluss geben könnte. In seinen frühen Texten ist er darauf bedacht, das Urteil Konstantins im Vergleich zu den bischöflichen Urteilen abzuwerten. Die Argumentation von ep. 43 verdeutlicht diese Akzentuierung im Besonderen. ${ }^{205}$ In

202 Vgl. o. Kap. 3.4.2.2; 4.2.2; 5.3.2.

203 Vgl. o. Kap. 7.4.2.1.

204 C. Don 56; vgl. retr. II 27, 28. Zum Prozess gegen Felix von Abthugni s.o. Kap. 6.1.3.

205 Vgl. die ausführliche Analyse o. Kap. 4.2.1. 
den späteren Schriften verteidigt er zwar mit Hilfe des iudicium Constantini die Maßnahmen des Kaisers gegen die Donatisten, aber dies geschieht niemals ohne stereotype Schuldzuweisungen an sie. Auch unausgesprochen ist stets die Aussage hörbar: „Ohne eure Anklage beim Kaiser wäre es zu keinem Eingreifen Konstantins gekommen."

Wenngleich diese Aussagen aus der Argumentation erwachsen sind, so scheint Augustinus doch davon überzeugt gewesen $\mathrm{zu}$ sein, dass eine innerkirchliche Regelung des Schismas möglich gewesen wäre und so Eskalationen vermieden worden wären. Sein langes Zögern, kaiserliche Hilfe gegen die Donatisten zu erbitten, spricht für diese Einschätzung. Auf der anderen Seite konnte Augustinus ohne Schwierigkeiten das Urteil Konstantins als das eines christlichen Kaisers rechtfertigen. Hundert Jahre nach Konstantin entsprach es den Erfahrungen Augustins und seinem Bild des christlichen Römischen Reiches, dass der weltliche Herrscher auch Schützer der Kirche ist. ${ }^{206}$

206 Vgl. ciu. V 24-26; zum Konstantinbild bei Augustinus vgl. Szidat, REAug 36, 1990, 243-256. 